\title{
Presynaptic PTPo organizes neurotransmitter release machinery at excitatory synapses
}

Kyung Ah Han ${ }^{1}$, Hee-Yoon Lee ${ }^{2}$, Dongseok Lim ${ }^{1}$, Jungsu Shin ${ }^{1}$, Taek Han Yoon ${ }^{1}$, Chooungku

Lee ${ }^{3}$, Jeong-Seop Rhee ${ }^{3}$, Xinran Liu ${ }^{4}$, Ji Won Um ${ }^{1}$, Se-Young Choi ${ }^{2, \#}$ and Jaewon Ko ${ }^{1, \#}$

${ }^{1}$ Department of Brain and Cognitive Sciences, Daegu Gyeongbuk Institute of Science and Technology (DGIST), 333 Techno Jungangdae-Ro, Hyeonpoong-eup, Dalseong-gun, Daegu 42988, Korea; ${ }^{2}$ Department of Physiology and Neuroscience, Dental Research Institute, Seoul National University School of Dentistry, Seoul 03080, Korea; ${ }^{3}$ Department of Molecular Neurobiology, Max Planck Institute of Experimental Medicine, 37075, Göttingen, Germany; and ${ }^{4}$ Department of Cell Biology, Yale University School of Medicine, New Haven, CT 06510, USA

Running Title: PTP $\sigma$ as an excitatory synaptic organizer

${ }^{\#}$ Corresponding author: E-mail: sychoi@snu.ac.kr (S-.Y.C.) or jaewonko@ dgist.ac.kr (J.K.) 


\begin{abstract}
Leukocyte common antigen-related receptor tyrosine phosphatases (LAR-RPTPs) are

evolutionarily conserved presynaptic organizers. The synaptic role of vertebrate LAR-RPTPs in

vivo, however, remains unclear. This study systematically analyzed the effects of genetic

deletions of LAR-RPTP genes by generating single conditional knockout (cKO) mice targeting

PTP $\sigma$ and PTP $\delta$. Although the numbers of synapses were reduced in cultured neurons deficient

in individual PTPs, abnormalities in synaptic transmission, synaptic ultrastructures, and vesicle

localization were observed only in РТР $\sigma$-deficient neurons. Strikingly, loss of presynaptic РTPб

reduced neurotransmitter release prominently at excitatory synapses, concomitant with drastic

reductions in excitatory innervations onto postsynaptic target areas in vivo. However,

postsynaptic PTP $\sigma$ deletion had no effect on excitatory synaptic strength. Furthermore,

conditional deletion of PTP $\sigma$ in ventral CA1 specifically altered anxiety-like behaviors. Taken

together, these results demonstrate that PTP $\sigma$ is a bona fide presynaptic adhesion molecule that

controls neurotransmitter release and excitatory inputs.
\end{abstract}

Keywords: Excitatory synapse/PTP $\sigma /$ subiculum/synaptic adhesion/synaptic transmission

Subject Categories: Neuroscience 


\section{Introduction}

Distinct molecular assemblies at presynaptic nerve terminals and postsynaptic densities

are responsible for the fast and precise transmission of neural information (Südhof, 2018).

These structures act by coordinating the regulation of bidirectional signals across synaptic clefts, determining the properties of individual synapses, including the computation of neural information (Südhof, 2018). Several synaptic cell-adhesion molecules are thought to act not only as physical connectors across synaptic clefts, but also as trans-synaptic signaling hubs (Missler et al, 2012, Südhof, 2017, Südhof, 2018). Neurexins (Nrxns) are evolutionarily conserved receptors, with extensive splicing at six canonical sites (Aoto et al, 2015, Aoto et al, 2013, Dai et al, 2019). The splicings regulate the binding of Nrxns to distinct ligands, as well as glutamate receptor-mediated postsynaptic responses and long-term synaptic plasticity (Aoto et al, 2015, Aoto et al, 2013, Dai et al, 2019). Conditional knockout (cKO) mice with complete ablation of all Nrxn genes showed extreme phenotypes, depending on synapse types and analyzed brain areas (Chen et al, 2017). These findings suggested that Nrxns are contextspecific regulators of synapse properties, but are not essential for synapse initiation (Chen et al, 2017).

Similar to Nrxns, leukocyte common antigen-related receptor tyrosine phosphatases (LAR-RPTPs) are evolutionarily conserved key synaptic organizers expressed in presynaptic 
active zones (AZs) (Han et al, 2019, Südhof, 2012, Um \& Ko, 2013). Invertebrate LAR-RPTP orthologs (dLAR in Drosophila melanogaster and PTP-3 in Caenorhabditis elegans) were shown to be expressed in axons/growth cones, playing critical roles in axon guidance, dendritic growth, and synapse formation (Ackley et al, 2005, Chagnon et al, 2004, Han et al, 2019). In contrast, vertebrate LAR-RPTPs, consisting three members (LAR, PTP $\sigma$, and PTP $\delta$ ), are present in both dendritic spines and axons of cultured neurons (Han et al, 2018, Takahashi et al, 2012, Wyszynski et al, 2002). Analogous to Nrxns, LAR-RPTPs bind postsynaptic ligands, which do not overlap with Nrxn ligands, to induce presynaptic differentiation (Choi et al, 2016, Han et al, 2018, Li et al, 2015, Takahashi et al, 2011, Yim et al, 2013, Yoshida et al, 2011). Constitutive KO mice of individual or multiple LAR-RPTP exhibit pleiotropic abnormalities in both the peripheral and central nervous systems, and impairment in certain aspects of synapse development and function (Elchebly et al, 1999, Horn et al, 2012, McLean et al, 2002, Thompson et al, 2003, Uetani et al, 2006, Uetani et al, 2000, Wallace et al, 1999). In contrast, loss of PTP $\sigma$ and/or $\mathrm{PTP} \delta$, using short-hairpin-mediated knockdown (KD)-mediated manipulations, impairs structural and functional development, as well as the LAR-RPTP ligandinduced formation of artificial synapses (Yim et al, 2013; Han et al, 2018; Takahashi et al, 2012; Dunah et al, 2005). Intriguingly, PTP $\sigma$ and $\mathrm{PTP} \delta$ (but not LAR) serve as functional receptors for presynaptic assembly at specific synapse types (i.e., PTP $\sigma$ for excitatory synapses, 
such as Slitrks, TrkC, and SALMs, and PTP $\delta$ for inhibitory synapses, such as Slitrk3, and excitatory synapses, such as IL1RAPL1) (Choi et al, 2016, Han et al, 2018, Li et al, 2015, Takahashi et al, 2012, Valnegri et al, 2011, Yim et al, 2013, Yoshida et al, 2011). Although these findings clearly indicated that LAR-RPTPs may be central components in both pre- and postsynaptic neurons that organize various aspects of synapse development, a sophisticated approach using cKO deficient in LAR-RPTPs is required to precisely assess the synaptic role of vertebrate LAR-RPTPs in vivo.

The present study describes the generation of mutant mice carrying cKO alleles of PTP $\sigma$ or PTP $\delta$. We found that, in keeping with the KD effects (Han et al, 2018), conditional genetic deletions of PTP $\sigma$ and $\mathrm{PTP} \delta$ reduced the numbers of synapses at excitatory and inhibitory synapses, respectively, with $\mathrm{PTP} \sigma$-deficient synapses showing concomitant impairment in excitatory synaptic transmission. Moreover, deletion of $\mathrm{PTP} \sigma$ resulted in an abnormal increase in the length of presynaptic AZ and in postsynaptic density (PSD), and abnormal vesicular organization in presynaptic boutons. Furthermore, PTP $\sigma$ loss from layer II of medial prefrontal cortical (mPFC) neurons and hippocampal CA1 pyramidal neurons selectively impaired innervation and neurotransmitter release at excitatory, but not inhibitory, synapses formed on layer V of mPFCs and subicular pyramidal neurons. Strikingly, loss of PTP $\sigma$ did not alter postsynaptic AMPA receptor-mediated responses, suggesting that PTP $\sigma$ 
primarily serves as a presynaptic adhesion molecule that controls the innervation of presynaptic excitatory inputs and neurotransmitter release in vivo. Despite PTP $\sigma$ playing a similar presynaptic role at mPFCs and hippocampal circuits, РTP $\sigma$ deletions in ventral CA1 selectively influenced anxiety-like, but not social, behavior. These results suggested that PTP $\sigma$ is essential for the regulation of presynaptic functions in vivo, distinct from the roles of presynaptic Nrxns. 


\section{Results}

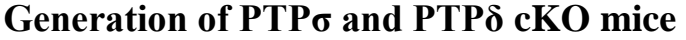

The goal of the present study was to determine the in vivo synaptic functions of

vertebrate LAR-RPTP isoforms by examining the phenotypes resulting from the deletion of individual LAR-RPTPs. Studies in constitutive KO mice have precluded investigations of the mechanisms of action of LAR-RPTPs because of the pleiotropic phenotypes that are unlikely unrelated to their synaptic roles (Um \& Ko, 2013). Transgenic mice with deletion of PTP $\sigma$ or $P T P \delta$ were generated by crossing $P T P \sigma^{\mathrm{f} / \mathrm{f}}$ mice, with exon 4 flanked by loxP sites, or $P T P \delta^{\mathrm{f} / \mathrm{f}}$ mice, with exon 12 flanked by loxP site, with a Cre recombinase driver line under control of the Nestin promoter (Nestin-Cre) (Fig EV1A and EV1B). $L A R^{\mathrm{f} / \mathrm{f}}$ mice were not generated because of the ubiquitous expression of this gene outside the brain (Kwon et al, 2010, Um \& Ko, 2013). RNAscope-based fluorescence in situ hybridization showed that the expression patterns of mRNAs encoding all three LAR-RPTP family members overlap in both the mPFC and the hippocampus (Appendix Fig 1A). Both PTP $\sigma$ and PTP $\delta$ mRNAs were detected in CaMKII $\alpha$ positive glutamatergic neurons and in Gadl-positive GABAergic neurons of adult mouse brains

(Appendix Fig 1B and 1C).

To evaluate the cellular effects of endogenous PTP $\sigma$ and PTP $\delta$ deletions, hippocampal 
neurons were cultured from $\mathrm{PTP} \sigma$ and $\mathrm{PTP} \delta \mathrm{cKO}$ mice. Neurons cultured for at $3-4$ days in

vitro (DIV) were infected with lentiviruses expressing EGFP-fused nuclear Cre-recombinase,

which results in a global loss of selective PTP isoforms in all neurons due to high infection

efficiency, or with a non-functional mutant version of Cre-recombinase $(\Delta \mathrm{Cre})$. Global

expression of Cre-recombinase caused a nearly complete and specific loss of expression of the

target PTP mRNAs in corresponding PTP cKO neurons when analyzed at DIV13-14 (Fig

EV1C), and specific loss of PTP protein in corresponding cKO brains (Fig EV1D). cKO mice

in which РТР $\sigma$ or РТР $\delta$ was deleted from the entire brain were viable and fertile, although a

modest reduction of body size and birth ratio was observed (Fig EV1E and EV1F). In addition,

PTP-cKO brains showed normal gross morphology, as revealed by staining for the neuron-

specific marker NeuN (Appendix Fig 2A and 2B) and for Nissl (Appendix Fig 2C and 2D).

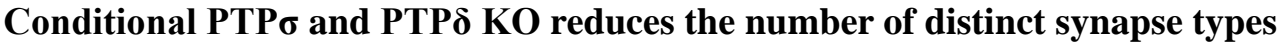

To assess the synaptic role of PTP $\sigma$ and $\mathrm{PTP} \delta$, cultured hippocampal PTP-cKO

neurons were infected with lentiviruses expressing either $\Delta$ Cre (Control) or wild-type Cre

recombinase at DIV3-4, and the neurons were stained with antibodies to various excitatory and

inhibitory synaptic markers at DIV14-16 (Fig 1A-1C). The density of excitatory, but not of

inhibitory, synaptic puncta was significantly reduced, as measured by staining of PTP $\sigma$-deficient 
neurons with antibodies to GluA1 (both surface and total), pan-Shank, and VGLUT1 ( 30-

40\%) (Fig 1A and 1C). Surprisingly, there were no marked changes in the density of excitatory and inhibitory synaptic puncta, except for that of GAD67 ( 50\%), on PTP $\delta$ KO neurons (Fig 1B and 1C). Moreover, measurements of the apparent sizes of synaptic puncta, reflecting a combination of antigen concentration and true synapse size, showed a small but significant reductions in the sizes of pan-Shank ${ }^{+}$puncta on PTP $\sigma$-deficient neurons and GAD67-positive puncta on PTP $\delta$-deficient neurons (Fig 1A, 1B and Appendix Fig 2E). Intriguingly, PTP $\sigma$ KO, but not PTP $\delta$ KO, neurons exhibited marginally smaller cell body sizes (Appendix Fig 2F, 2G, 2I and 2J), but similar dendritic branching as quantified by Sholl analysis, compared with control neurons (Appendix Fig $\mathbf{2 H}$ and $\mathbf{2 K}$ ). These results are consistent with the previously reported PTP KD effect (Han et al, 2018).

\section{Conditional PTPб KO impairs excitatory synaptic transmission}

To examine whether the reduced number of synapses in PTP-deficient neurons were accompanied by corresponding effects on the transmission of respective synapse types, hippocampal dissociated cultured neurons were assessed electrophysiologically (Fig 1D-1K). Lentivirus-mediated global loss of PTP $\sigma$ specifically reduced the frequency and decay time, but not the amplitude, of excitatory synaptic transmission, as shown by measurement of miniature 
excitatory postsynaptic currents (mEPSCs) and miniature inhibitory postsynaptic currents (mIPSCs) (Fig 1D-1G). These results are consistent with the PTP $\sigma$ KD effect on excitatory synaptic transmission (Dunah et al, 2005, Han et al, 2018, Ko et al, 2015). Moreover, lentivirusmediated global loss of PTP $\delta$ had little effect on baseline synaptic transmission at both excitatory and inhibitory synapses (Fig $\mathbf{1 H}-\mathbf{1 K})$. These results are different from the previous KD results showing specific reductions in excitatory (for PTP $\sigma \mathrm{KD}$ ) and inhibitory (for PTP $\delta$ KD) synaptic transmission (Han et al, 2018), similar to the effects of gene manipulations on neuroligins (Chanda et al, 2017).

\section{Conditional PTPo, but not PTPס, KO alters synaptic vesicle tethering and active zone}

\section{architectures}

To further understand whether PTPб-cKO affects synaptic structures, we performed transmission electron microscopy (TEM) with cultured cells. Presynaptic terminals and postsynaptic densities were examined and imaged from chemically fixed hippocampal neurons, as described (Acuna et al, 2016) (Fig 2). TEM analyses of cultured neurons showed that PTP $\sigma-$ deficient and control presynaptic terminals contained similar numbers of total vesicles, but that the distribution of vesicles in the PTP $\sigma$-deficient terminals was significantly skewed (Fig $2 \mathrm{~A}$, 2D, 2E and 2F). Specifically, the number of membrane-proximal vesicles, defined as vesicles < 
$100 \mathrm{~nm}$ from the presynaptic AZ membrane, was significantly increased in $\mathrm{PTP} \sigma$-deficient presynaptic terminals (Fig 2E). In contrast, the number of tethered vesicles, defined as vesicular structures docked at presynaptic AZ membranes, was only marginally increased, an increase that was not statistically significant (Fig 2F). Surprisingly, the AZ length was increased by $\sim 30 \%$ (Fig 2A and 2B), similar to the doubled AZ size in Caenorhabditis elegans mutants lacking ptp3A, an orthologue of the type IIa RPTP gene (Ackley et al, 2005, Han et al, 2019). Consistent with this, a corresponding increase ( 15\%) in PSD length was observed (Fig 2A and 2C). This phenotype was not observed in PTP $\delta$-deficient presynaptic terminals, nor were there any alterations in other anatomical parameters (Fig 2H-2M). Quantitative immunoblot analysis of PTP $\sigma$ - and PTP $\delta$-deficient neurons showed comparable expression of presynaptic AZ and PSD proteins, although the level of RIM1/2 was significantly lower in PTP $\delta$-deficient neurons (Fig 2G, 2N, Appendix Fig 3A and 3B). These results suggest that PTP $\sigma$ and PTP $\delta$ are not functionally redundant, and that $\mathrm{PTP} \sigma$, but not $\mathrm{PTP} \delta$, is crucial in controlling the structural organization of both presynaptic AZs and PSDs.

\title{
Conditional KO of PTPo reduces synaptic localization of excitatory synaptic vesicles in
}

\author{
presynaptic boutons
}


Altered localization of synaptic vesicles in PTP $\sigma$-deficient nerve terminals may align

with the possibility that PTP $\sigma$ directly regulates the number of readily releasable vesicles (RRPs) (Zucker \& Regehr, 2002). We thus examined whether the number of RRPs was changed at excitatory synapses by stimulating release of the entire RRP using a well-established hypertonic sucrose solution (500 mOsm) and quantifying RRP size by integrating the total charge transfer during the first 2 seconds of the release (Rosenmund \& Stevens, 1996). Strikingly, the number of RRPs was significantly reduced in PTP $\sigma$-cKO neurons, as indicated by reductions of $\sim 14.7 \%$ in charge transfer and $\sim 31.2 \%$ in peak amplitude (Fig 3A-3C). This provides a hypothetical explanation for the positive regulation of neurotransmitter release by PTP $\sigma$ at excitatory synapses, despite the increased anatomic proximity of synaptic vesicles to the active zone.

To better understand the role of PTPs in organizing presynaptic functions at the excitatory synapse (see Fig 1), we infected cultured hippocampal РTPб- or PTP $\delta$-cKO neurons with $\triangle$ Cre-EGFP or Cre-EGFP-expressing lentiviruses, transfected the neurons with venusfused VGLUT1 (an excitatory synapse-specific vesicle marker) 5 days after the infections, and stained neurons with antibodies to Bassoon (a presynaptic active zone marker) 2 days after the transfections (Fig 3). We found that expression of VGLUT1-Venus in PTP $\sigma-c K O$ neurons resulted in a more diffuse pattern of Venus-fused vesicular markers compared with control 
neurons infected with $\triangle$ Cre-EGFP, indicating that ablation of PTP $\sigma$ inhibits the synaptic localization of synaptic vesicles at excitatory presynaptic boutons (Fig 3D and 3E). No changes in Bassoon localization at presynaptic boutons were observed in $\mathrm{PTP} \sigma-\mathrm{cKO}$ neurons (Fig 3D and 3F). To further dissect the mechanism by which РТP $\sigma$ regulates vesicle localization at excitatory synapses, we designed three lentiviruses expressing PTP $\sigma$ variants, based on validated HA epitope-tagged PTP $\sigma$ variants that were previously used in cultured neurons (Han et al, 2018). These lentiviruses expressed PTP $\sigma$ wild-type (WT), a PTP $\sigma$ deletion mutant lacking the D2 domain $(\Delta \mathrm{D} 2)$, or a PTP $\sigma$ point mutant defective in tyrosine phosphatase activity (C1157S). Lentiviral expression of PTP $\sigma \mathrm{WT}$, but not other PTP $\sigma$ variants, completely reversed the diffuse distribution pattern of VGLUT1-Venus fluorescence in PTP $\sigma$-cKO neurons, producing a punctate pattern (Fig 3D and $\mathbf{3 E}$ ). In addition, synaptic localization of vesicles was not rescued by expression of РTP $\sigma$ intracellular mutants, suggesting that PTP $\sigma$ requires D2 domain-mediated molecular interactions and tyrosine phosphatase activity to appropriately direct excitatory synaptic vesicles into presynaptic boutons. Collectively, these results suggest that PTP $\sigma$ is specifically involved in presynaptic assembly by organizing vesicle localization at excitatory synapses using intracellular mechanisms.

\section{Conditional PTPo KO in mPFC and CA1 neurons reduces excitatory presynaptic}




\section{innervation onto postsynaptic target neurons and excitatory neurotransmitter release}

Although the synaptic roles of invertebrate orthologues of type IIa RPTPs have been

primarily studied from the perspective of their presynaptic structure and function (Chagnon et

al, 2004, Um \& Ko, 2013), mammalian PTP $\sigma$ and PTP $\delta$ appear to be expressed in both

presynaptic and postsynaptic neurons (Dunah et al, 2005, Han et al, 2018) (Appendix Fig 3C).

Because the functional locus of a specific synaptic protein cannot be precisely determined in

cultured neurons, a Cre driver line under the control of a Wolfram syndrome 1 homolog (Wfs1)

promoter was utilized (Kitamura et al, 2014, Madisen et al, 2010). The presence of Wfs1-

positive neurons, including in the dorsal CA1 and layer II/III of the mPFC, were confirmed by

robust tdTomato expression in the Ai9 reporter mouse line (Luuk et al, 2008, Madisen et al,

2010) (Appendix Fig 4A). Immunohistochemical analysis of Wfs1 expression in the $\mathrm{mPFC}$ and

hippocampal CA1 showed strong Wfs1-immunoreactive signals in Tbr1-positive excitatory

neurons but not GAD67-positive GABAergic neurons (Appendix Fig 4B). Because presynaptic

organization was abnormally altered in $\mathrm{PTP} \sigma$-deficient cultured neurons (Fig 2), the pre- and

postsynaptic effects of PTP $\sigma$ deletions were analyzed by focusing on presynaptic CA1 neurons

of the hippocampus at synapses formed onto postsynaptic pyramidal neurons in the subiculum

and on those in presynaptic layer II/III neurons at synapses formed onto postsynaptic layer $\mathrm{V}$

neurons of the mPFC (Figs 4 and 5). $P T P \sigma^{\mathrm{f} / \mathrm{f}}$ mice were crossed with a Wfs1-Cre driver line to 
yield Wfs1-PTP $\sigma$ mice, which were viable and fertile and comparable in size to control mice

(Appendix Fig 4C). Moreover, NeuN and Nissl staining of Wfs1-PTP $\sigma$ brains showed normal gross morphology (Appendix Fig 4D and 4E). Anatomical changes at synapses formed by presynaptic CA1 region neurons on postsynaptic subicular neurons and presynaptic layer II/III layer neurons on postsynaptic layer V neurons were evaluated by quantitative immunofluorescence analyses (Fig 4A), which showed that the density and integrated intensity of VGLUT1 puncta were significantly reduced in subicular, but not mPFC layer V, neurons (Fig 4B-4F). However, the density and intensity of GAD67 puncta in the corresponding brain regions were comparable in Wfs1-PTP $\sigma$ and control mice (Fig 4G-4K). Adeno-associated viruses (AAVs) expressing Cre-recombinase (AAV-Cre) or inactive Cre-recombinase (AAV$\Delta$ Cre) were stereotactically injected into ventral hippocampal CA1 (vCA1) of $P T P \sigma^{\mathrm{t} / \mathrm{f}}$ and $P T P \delta^{\mathrm{f} / \mathrm{f}}$ mice. Subsequent quantitative immunohistochemical analyses showed decreased excitatory (but not GABAergic) innervations onto subicular neurons from $P T P \sigma^{\mathrm{f} / \mathrm{f}}$ mice infected with AAV-Cre, and decreased GABAergic (but not excitatory) innervation onto subicular neurons from $P T P \delta^{\mathrm{f} / \mathrm{f}}$ mice infected with AAV-Cre (Fig EV2).

To further corroborate these anatomical observations and identify any possible presynaptic changes, PPRs in subicular and mPFC layer V neurons were measured (Fig 5A). Although EPSC-PPRs were significantly increased in both synapses (Fig 5B, 5C, 5F and 5G), 
IPSC-PPRs were not changed in mPFC layer V neurons from Wfs1-PTP $\sigma$ mice (Fig 5D and

5E). Taken together, these results suggest that PTP $\sigma$ is a critical modulator of presynaptic innervations and neurotransmitter release at excitatory synapses.

\section{Conditional PTPo deletions exert no postsynaptic effect}

Next, the effect of presynaptic deletion of PTP $\sigma$ on basal synaptic transmission was analyzed in Wfs1-PTP $\sigma$ mice. Surprisingly, there was a marginal reduction in frequency, but not amplitude, of spontaneous EPSCs (sEPSCs) in mPFC layer V (but not subicular pyramidal) neurons (Fig EV3A-EV3C and EV3G-EV3I), but no detectable effect on the frequency or amplitude of mIPSCs in mPFC layer V pyramidal neurons (Fig EV3D-EV3F). The ratio of NMDA- to AMPA-receptor mediated EPSCs (i.e. NMDA/AMPA ratio) was assessed by stimulating Schaffer collateral axons of hippocampal CA3 neurons or axons of hippocampal CA1 neurons, and measuring postsynaptic responses in hippocampal CA1 neurons and subicular neurons, respectively (Fig 6D, 6E and Appendix Fig 5). In agreement with findings showing no prominent phenotype affecting basal excitatory synaptic transmission in neurons lacking РТP $\sigma$, there were no changes in the density of excitatory and inhibitory synapses, in NMDA/AMPA ratio, and in the frequency and amplitude of excitatory synaptic transmission in РТР $\sigma$-deficient CA1 pyramidal neurons (Fig 6 and EV3J-EV3L). These results suggest that 
PTP $\sigma$ primarily functions presynaptically and does not trans-synaptically regulate postsynaptic responses in vivo.

\section{PTPo controls formation of excitatory inputs via intracellular mechanisms}

To interrogate whether interactions of PTP $\sigma$ with intracellular scaffolds and/or

substrates are responsible for presynaptic innervation at excitatory synapses, we designed AAVs expressing PTP $\sigma$ WT and its intracellular variants $(\Delta \mathrm{D} 2$ and C1157S) (Fig EV4A). PTP $\sigma$ expression was driven by the neuron-specific synapsin promoter, and immunohistochemically with anti-HA antibody (Fig EV4). These PTP $\sigma$ AAVs, along with AAV-Cre, were stereotactically injected into the vCA1 of adult male Wfs1-PTP $\sigma$ mice, with quantitative immunofluorescence analyses performed after 3 weeks after stereotactic surgery. Expression of WT PTP $\sigma$, but not the other PTP $\sigma$ variants, significantly increased the density of VGLUT1 puncta in proximal subiculum regions of Wfs1-PTP $\sigma$ mice (Fig EV4). The density of VGLUT1 puncta in distal subiculum regions was not influenced, in line with the specific connectivity between the vCA1 and proximal subiculum (O’Mara, 2005). Expression of PTP $\sigma$ intracellular mutants failed to completely reverse the deficits in innervation of excitatory synaptic inputs (Fig EV4). These results suggest that PTP $\sigma$ requires intracellular mechanisms (D2-mediated interactions and tyrosine phosphorylation) to organize innervation of excitatory inputs onto 
postsynaptic targets in vivo.

\section{PTPo deletion in ventral CA1 induces abnormal anxiety-like behavior}

To assess the behavioral consequences of the PTP $\sigma$ deletion in mice, adult (9-11-week

old) male Wfs1-PTP $\sigma$ mice and their control littermates were screened using a behavioral panel

designed to assess locomotion, anxiety, sociability, and learning (Fig 7 and EV5). In the

Laboras test, in which mouse movements were recorded continuously for 48 hours, both control

and Wfs1-PTP $\sigma$ mice exhibited overall similar home cage-like activities, although Wfs1-PTP $\sigma$

mice showed a marginal reduction in the amount of food eaten (Fig EV5A and EV5B). Wfs1-

PTP $\sigma$ mice did not show anxiety-like behavior in open-field tests, spending an amount of time

in the center region of the open-field arena (Fig EV5C and EV5D), and in light-dark transition

tests, as measured by time spent in the light box and number of total entries in the light-dark

apparatus (Fig EV5E and EV5F). However, these mice were less anxious in the elevated plus-

maze (EPM) test, spending more time in open arms (Fig 7A-7C), suggesting that deletion of

PTP $\sigma$ from discrete brain regions manifests as anxiolytic-like behaviors under specific

conditions. In tests for various forms of memory, Wfs 1-PTP $\sigma$ mice exhibited no abnormalities in

Y-maze tests, which assess working memory (Fig EV5G and EV5H), and novel object-

recognition tests, which assess recognition memory (Fig EV5I and EV5J). Meanwhile, Wfs1- 
$P T P \sigma$ mice exhibited low freezing time in contextual fear conditioning tests, which assess fear memory (Fig EV5K and EV5L). Intriguingly, analysis of two different facets of social behaviors in three-chamber tests revealed that Wfs1-PTP $\sigma$ mice exhibit mildly impaired sociability, spending less time in the chamber containing the stranger mouse than in either of the empty chambers (Fig 7D-7F). However, when the inanimate object was replaced by another stranger mouse, both control and Wfs1-PTP $\sigma$ mice showed comparable preference for exploring the new stranger mouse (Fig 7D-7F). These results suggest that Wfs1-PTP $\sigma$ mice are impaired in social interactions (sociability), whereas social novelty recognition and social anxiety remained intact.

To identify the specific brain regions responsible for two prominent behavioral phenotypes, anxiety-like behavior and sociability, one of the brain regions (vCA1), in which Wfs1 promoter activity was positive, was selected (Appendix Fig 4A). The vCA1 neurons of adult male $P T P \sigma^{\mathrm{f} / \mathrm{f}}$ mice were stereotactically injected with AAV-EGFP/ $\triangle \mathrm{Cre}(\Delta \mathrm{Cre})$ or AAVEGFP/Cre (Cre) separately (Fig 7G and 7H), and the mice were subjected to the EPM and three-chamber tests (Fig 7I-7N). Surprisingly, we found that Cre expression in the vCA1 region replicated the impairment in anxiety-like behavior of Wfs1-PTP $\sigma$ mice in the EPM test, but had no effect on the three-chamber test $(\mathbf{F i g} \mathbf{7 I}-\mathbf{7 N})$. These results suggest that PTP $\sigma$ presynaptically regulates the operation of a specific neural circuit that mediates distinct mouse 
bioRxiv preprint doi: https://doi.org/10.1101/2020.01.10.901546; this version posted January 10, 2020. The copyright holder for this preprint (which was not certified by peer review) is the author/funder. All rights reserved. No reuse allowed without permission.

behavior. 


\section{Discussion}

Although many studies have unequivocally shown that Nrxns are crucial at synapses,

few studies have evaluated the in vivo roles of vertebrate LAR-RPTPs. Investigations using

constitutive KO mice lacking one or two LAR-RPTPs, or shRNA-mediated KD approaches,

showed that LAR-RPTPs are significant regulators of various aspects of nervous system

development (Chagnon et al, 2004, Han et al, 2016, Han et al, 2019, Takahashi \& Craig, 2013,

Um \& Ko, 2013). These studies showed that LAR-RPTPs affect the development and/or

maturation of synapses as well as having potential compensatory adaptations and possibly

unintentional off-target phenomena during development. Therefore, the present study involved

the generation of PTPб and PTP $\delta$ floxed mice, with these conditional KO mice analyzed to

determine the synaptic roles of PTP $\sigma$ and $\mathrm{PTP} \delta$. To this end, we employed a variety of

experimental approaches including high-density cultured neurons generated using Cre-

expressing lentiviruses in vitro, acute slices and tissues obtained from mice crossed with Cre

driver lines, and slices and tissues obtained from 3 mice stereotactically injected in vivo with

Cre-expressing AAVs into specific brain areas (i.e. vCA1).

Our in vitro data demonstrated that PTP $\sigma \mathrm{KO}$, but not $\mathrm{PTP} \delta \mathrm{KO}$, specifically reduced

the numbers of excitatory synapses and basal excitatory synaptic transmission, in agreement

with previous KD studies (Han et al, 2018, Ko et al, 2015) (Fig 1). Moreover, PTPб KO altered 
vesicle tethering and ultrastructural features (Fig 2), decreased RRP size and synaptic

localization of excitatory synaptic vesicles (Fig 3). Our in vivo results further suggest that PTP $\sigma$ presynaptically functions at two different types of synapses involving layer II-V connections in mPFC and CA1-subiculum connection in the hippocampus by modulating glutamate release

(Figs 4-6), and that this regulation guides a specific behavior (Fig 7). Compared with the pervasive loss-of-function consequences of Nrxns in various cell-types across diverse brain areas and neural circuits (Südhof, 2017), the effects of conditional deletion of PTPб were relatively marginal, whereas the effects of conditional deletion of PTP $\delta$ were surprisingly subtle or unnoticeable. These findings were unexpected, as members of the LAR-RPTP family bind to various synapse organizers crucial for discrete aspects of synapse development (Südhof, 2017, Um \& Ko, 2013). Nevertheless, the current study revealed that vertebrate LAR-RPTPs perform unexpected distinct functions, which may help shape specific synaptic properties across many overlapping neural circuits.

\section{Dissection of PTPo in vivo functions using sophisticated approaches.}

A rich body of previous studies have shown that invertebrate LAR-RPTPs have presynaptic roles in controlling AZ assembly and proper vesicle localization (Han et al, 2019).

A few studies of vertebrate LAR-RPTP function have revealed their critical roles in postsynaptic 
neurons, including their regulation of spine morphogenesis development and their stabilization of surface AMPA-type glutamate receptors (Dunah et al, 2005, Wyszynski et al, 2002). Because several LAR-RPTP ligands have been identified as putative postsynaptic organizers in rodent neurons, LAR-RPTPs were thought to act in presynaptic neurons in a manner similar to Nrxns (Südhof, 2012). Consistent with previous findings (reviewed in Han et al, 2019), the results in the current study showed the loss-of-function phenotype of PTP $\sigma$, demonstrating that conditional KO of PTP $\sigma$ in cultured hippocampal neurons specifically impairs excitatory, but not inhibitory, synaptic transmission (Fig 1). In contrast, conditional KO of PTP $\delta$ did not significantly affect most synaptic parameters (Figs 1and 2). These results were quite surprising and unexpected, as PTP $\delta$ is strongly expressed in brains and constitutive PTP $\delta$ KO was found to impair learning, alter long-term synaptic plasticity, and cause abnormal dendritic arborization (Nakamura et al, 2017, Uetani et al, 2000). Moreover, PTP $\delta$ KD produced pleiotropic effects on both presynaptic and postsynaptic processes (Dunah et al, 2005, Han et al, 2018, Li et al, 2015, Yim et al, 2013). Some discrepancies between the results of our and previous studies may be due to differences in developmental changes caused by constitutive $\mathrm{KO}$ and the welldocumented off-target effects of RNA interference. Secondary effects triggered by KD may also have contributed to previously observed severe phenotypes; for example, PTP $\delta$ KD induced PTPб upregulation in neurons, and vice versa, whereas PTP $\delta$ KO did not (Han et al, 2018) (Fig 
2N and Appendix Fig 3B). Nevertheless, PTP $\sigma$ KO and PTP $\sigma$ KD had similar overall effects on synapse density and transmission in vitro, indicating the importance of confirmatory analyses using a sophisticated system and approaches in elucidating РTP $\sigma$ function in vivo. It is possible, however, that the approaches employed in this study were not sufficiently sensitive to detect subtle changes in synapse properties. Moreover, the selection of experimental preparations may preclude detection of synaptic roles of $\mathrm{PTP} \delta$ at in vivo synapses. In addition, $\mathrm{PTP} \sigma$ may functionally compensate for PTP $\delta$ loss, but not vice versa, whereas PTP $\delta$ may have peripheral roles in the operation of specific neural circuits in which, РTP $\sigma$ is expressed. The use of cKO models to study the canonical and non-canonical roles of PTP $\sigma$ and PTP $\delta$ in vivo at various stages of synapse development in other classes of neurons is warranted and may provide a more sophisticated understanding of how LAR-RPTPs act as a multivalent signaling platform in presynaptic neurons.

\section{Function of PTPб as a presynaptic adhesion molecule in regulating excitatory synapse}

properties at mammalian excitatory synapses.

We found that loss of PTP $\sigma$ resulted in increased length of the presynaptic AZ and PSD membranes, and increased numbers of membrane-proximal vesicles (Fig 2). Some of these phenotypes were similar to those of $\mathrm{KO}$ mice lacking a subset of $\mathrm{AZ}$ proteins involved in 
vesicle tethering and recruitment of VGCCs to AZ membranes, and were also similar to loss-offunction phenotypes of Syd-2 mutations in C. elegans (an orthologue of liprin- $\alpha$ ) (Acuna et al, 2016, Dai et al, 2006, Grauel et al, 2016, Kaeser et al, 2011, Wang et al, 2016, Zhen \& Jin, 1999). Although a subset of these phenotypes may reflect adaptive changes as a homeostatic mechanism, PTP $\sigma$ likely contributes to the normal distribution of SVs and the organization of trans-synaptic nanomolecular complexes for efficient glutamate release (Fig 2). Importantly, investigation of common/redundant functions of LAR-RPTPs using conditional triple KOs of PTP $\sigma$, PTP $\delta$, and LAR is required to provide further insights into the major observations of the current study.

Impaired glutamate release efficiency observed in PTP $\sigma$ cKO mice has been observed in several prior studies reporting loss-of-function of $\operatorname{Nrxn} 1 \alpha$ (Etherton et al, 2009), liprin- $\alpha 2$ (Spangler et al, 2013), and RIM1 (Kaeser et al, 2008). Strikingly, PTP $\sigma$ KO induces abnormal vesicle positioning close to AZ membranes (Fig 2), but drastically suppressed RRP size in cultured neurons (Fig 3) that is controlled by positional priming (Neher \& Sakaba, 2008). These results suggest that $\mathrm{PTP} \sigma \mathrm{KO}$ may disorganize $\mathrm{AZ}$ structure and function by decoupling key nanomolecular machinery in AZs.

Our genetic manipulations using the Wfs1-Cre driver line allowed determination of the presynaptic and postsynaptic role of PTP $\sigma$ in excitatory neurons (Figs 4-7). PTPo deletion in 
mPFC layer II or hippocampal CA1 reduced structural innervation of excitatory inputs and increased EPSC-PPRs in mPFC layer V or subicular neurons, along with a marginal reduction in frequency, but not amplitude, of sEPSCs (Fig 4, 5 and EV3). Intriguingly, PTPo deletion in hippocampal CA1 failed to elicit any changes in Schaffer collateral evoked excitatory synaptic transmission or basal synaptic transmission (Fig 6), indicating that postsynaptic strength is not trans-synaptically regulated by РTP $\sigma$ in vivo. These results suggest that $\mathrm{PTP} \sigma$ primarily functions as a presynaptic adhesion molecule to regulate the amount and/or pattern of excitatory inputs, resulting in the modulation of neurotransmitter release.

\section{PTPб requires various molecular mechanisms to regulate excitatory neurotransmitter}

release.

PTP $\sigma$ employs various extracellular and intracellular mechanisms in mediating excitatory presynaptic assembly (Han et al, 2018). Utilization of in vivo replacement strategies in $\mathrm{PTP} \sigma \mathrm{cKO}$ mice revealed that multiple molecular mechanisms contribute to the regulation of innervation of excitatory synaptic inputs of CA1 neurons onto subiculum neurons (Fig EV4). These findings suggest that the ability of PTP $\sigma$ to regulate different presynaptic properties is due to the concerted actions of various mechanisms - including the availability of release-ready SVs, the integrity of $\mathrm{AZ}$ organization, and the magnitude of $\mathrm{Ca}^{2+}$ influx-by coordinating 
extracellular signals with intracellular machineries responsible for AP-gated glutamate release of SVs. The most parsimonious mechanism by which PTP $\sigma$ likely regulates glutamate release is through the direct interaction of PTP $\sigma$ with liprin- $\alpha$ via its intracellular D2 domain. Liprin- $\alpha 3$ functions as an upstream AZ scaffolding factor in AZ assembly, further interacting with RIMs and other presynaptic proteins, including ELKS, mDiaphanous, CASK, and GIT1 (Han et al, 2019, Südhof, 2012, Wong et al, 2018). Because PTPб requires intracellular complexes for presynaptic assembly (Han et al, 2018), PTPo may mediate various presynaptic functions by coordinating the interactions of liprin- $\alpha$ with other presynaptic proteins. Alternatively, a subset of РТР $\sigma$ substrates may be involved in РТР $\sigma$-mediated glutamate release. Several validated PTP $\sigma$ substrates have been associated with the regulation of actin cytoskeleton remodeling processes (Han et al, 2018, Um \& Ko, 2013). Systematic analyses using cKO mice lacking PTP $\sigma$ substrates, combined with a high-resolution approach to identify putative substrates, are crucial to fully understand how a network of actin filaments associated with SVs is coordinated with neurotransmitter release (Doussau \& Augustine, 2000, Nelson et al, 2013). The ability of PTP $\sigma$, along with specific Cav2 complexes, to directly regulate $\mathrm{Ca}^{2+}$ currents should also be rigorously examined. Extracellular interactions of PTP $\sigma$ with postsynaptic ligands could control the function of VGCCs (Muller et al, 2010). This hypothesis was supported by a study showing that KD of Slitrk1, a postsynaptic ligand for $\mathrm{PTP} \sigma$, increased the number of docked SVs, 
mimicking some of the loss-of-function phenotype of PTP $\sigma \mathrm{cKO}$ (Schroeder et al, 2018) (Fig 3).

\section{Role of PTPб function in neural circuits: canonical or context-specific function.}

One prominent mechanism of altered neurotransmitter release in regulating specific properties of neural circuits is STP. STP has been implicated in many cognitive functions involving $\mathrm{mPFC}$ and the hippocampus, including short-term working memory, information processing, and decision-making processes (Abbott \& Regehr, 2004, Mongillo et al, 2008). Because this form of plasticity was thought to reflect a presynaptic change in $\mathrm{Ca}^{2+}$-dependent neurotransmitter release, РTP $\sigma$ loss may lead to abnormal cognitive or emotional behavioral states, owing to a dysfunction in excitatory neural circuit properties.

The presynaptic release phenotype we observed at two different synapse types is in agreement with findings indicating that LAR-RPTPs are key hubs for presynaptic functions (Takahashi \& Craig, 2013, Um \& Ko, 2013). Thus, an investigation of the roles of PTP $\sigma$ is required to determine the mechanisms by which the complex interaction network of PTP $\sigma$ organizes the properties of specific neural circuits. Our results strongly suggest that this activity has significant implications for the dynamics of specific neural circuits (Fig 7). Strikingly, specific deletion of PTP $\sigma$ in CA1 neurons impaired anxiety-like behavior without altering sociability in mice, suggesting that presynaptic PTP $\sigma$ mediates specific behaviors in mice. 
Despite our results clearly linking presynaptic PTP $\sigma$ functions in specific brain regions with specific behaviors, the causal relationships between presynaptic phenotypes and deficits in specific behaviors caused by presynaptic $\mathrm{PTP} \sigma$ deletion remain to be directly and fully determined (Fig 7). Anatomical effects of PTP $\sigma$ KO are similarly in distal and proximal subicular neurons, which are molecularly heterogeneous links to parallel streams for disparate cognitive processing (Cembrowski et al, 2018). Thus, in-depth investigations are needed to determine details of the molecular mechanisms of PTP $\sigma$ (e.g. alternative splicing-mediated specific synaptic adhesion pathways) and to concomitantly identify input/output-defined circuit elements responsible for behavioral deficits of presynaptic РТPб KO observed in this study. These investigations may improve the understanding of the molecular logics of the responsible neural circuit dynamics and behavior. Anatomical and electrophysiological analyses of PTP $\sigma$ cKO presented in the current study should be extended to better understand the synapseorganizing role of PTP $\sigma$ as a fundamental building block of all types of synapses. In summary, our study demonstrated that PTP $\sigma$ is a key factor in tuning presynaptic properties responsible for coordinating excitation-to-inhibition balance in neural circuits and certain behaviors, likely by organizing neurotransmitter release machinery at excitatory synapses. 


\section{Materials and Methods}

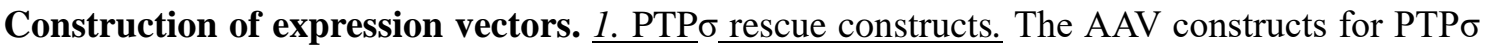
protein rescue were generated using previously described L-313 lentiviral constructs as templates (Han et al, 2018). AAVs encoding human PTP $\sigma$ WT and all PTP $\sigma$ mutants $(\Delta \mathrm{D} 2$ and C1157S) were amplified by PCR and subsequently subcloned into the XbaI and BamHI sites of the vector, a gift from Dr. Hailan Hu (Li et al, 2013). 2. Others. The plasmids pAAV-hSyn$\Delta$ Cre-GFP and pAAV-hSyn-Cre-GFP were from Dr. Thomas C. Südhof (Stanford University, Palo Alto, CA, USA); FSW- $\Delta$ Cre and FSW-Cre were from Dr. Pascal S. Kaeser (Harvard University, Cambridge, MA, USA); and pCAGG-VGLUT1-Venus was from Dr. Frank Polluex (Columbia University, New York, NY, USA).

Antibodies. PTP $\delta$-specific antibodies were generated in our laboratory by immunizing rabbits with keyhole limpet hemocyanin (KLH)-conjugated synthesized peptides specific

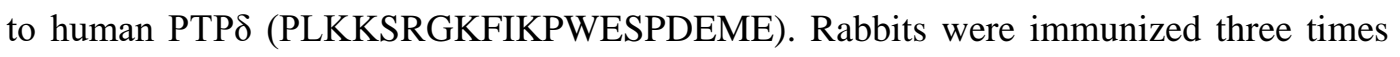
with the KLH-conjugated peptides, and their sera were collected. PTP $\delta$-specific antibodies (JK179, 1 mg/ml; RRID: AB_2810232) were affinity-purified using Sulfolink columns (Pierce) on which the same peptides had been immobilized. Commercially 
obtained antibodies included: mouse monoclonal anti-GAD67 (clone 1G10.2; Millipore; RRID: AB_2278725), guinea pig polyclonal anti-VGLUT1 (Millipore; RRID: AB_2301751), rabbit polyclonal anti-VGLUT1 (Synaptic Systems; RRID: AB_887880), rabbit polyclonal anti-GABA $A_{A}$ R2 (Synaptic Systems; RRID: AB_2263066), mouse monoclonal anti-PSD-95 (clone K28/43; Neuromab; RRID: AB_2292909), mouse monoclonal anti-PTP $\sigma$ (clone 17G7.2; MediMabs; RRID: AB_1808357), mouse monoclonal anti-CASK (clone K56A/50; NeuroMab; RRID: AB_2068730), mouse monoclonal anti-HA (clone 16B12; BioLegend; RRID: AB_2565006); mouse monoclonal anti-Bassoon (clone SAP7F407; Stressgen; RRID: AB_2313990); rabbit polyclonal antiMunc13-1 (Synaptic Systems; RRID: AB_887733), rabbit polyclonal anti-RIM-BP2 (Synaptic Systems; RRID: AB_2619739), rabbit polyclonal anti-RIM1/2 (Synaptic Systems; RRID: AB_887775), mouse monoclonal anti-ELKS (Sigma-Aldrich; RRID: AB_2100013), mouse monoclonal anti-Synaptophysin (clone SVP-38; Sigma-Aldrich; RRID: AB_477523), mouse monoclonal anti-MAP2 (clone AP-20; Sigma-Aldrich; RRID: AB_477171), rabbit polyclonal anti-MAP2 (Abcam; RRID: AB_776174), mouse monoclonal anti- $\beta$-actin (clone C4; Santa Cruz Biotechnology; RRID: AB_626632), mouse monoclonal GluN1 (clone 54.1; Millipore; RRID: AB_94946), rabbit polyclonal Cav2.1 (Synaptic Systems; RRID: AB_2619841), and mouse monoclonal anti-gephyrin 
(clone 3B11; Synaptic Systems; RRID: AB_887717). Rabbit polyclonal anti-liprin $\alpha 2$ (RRID:AB_2810258) and rabbit polyclonal anti-liprin-a3 (RRID:AB_2810259) antibodies were gifts of Dr. Susanne Schoch-McGovern (Bonn, Germany); rat polyclonal anti-PTP $\delta$ antibody (RRID:AB_2810260) was the gift of Dr. Fumio Nakamura (Yokohama, Japan); rabbit polyclonal anti-pan-Shank (1172; RRID:AB_2810261), and rabbit polyclonal anti-Homer1 antibodies (1133; RRID: AB_2810985) were the gifts of Dr. Eunjoon Kim (KAIST, Korea).

Chemicals. 6-Cyano-7-nitroquinoxaline-2,3-dione (CNQX) was obtained from SigmaAldrich (Cat No. C127). Tetrodotoxin (TTX; Cat No. 1069); picrotoxin (Cat No. 1128), QX-314 (Cat No. 1014); and D-2-amino-5-phosphonovalerate (D-AP5; Cat No. 0106) were purchased from Tocris.

Neuron culture, transfections, imaging, and quantitation. Hippocampal and cortical mouse neuron cultures were prepared from embryonic day 17 (E1) mouse embryos, as described previously (Ko et al, 2011). Mouse cultured neurons were seeded onto coverslips coated with poly-D-lysine (Sigma-Aldrich), and grown in Neurobasal medium supplemented with B-27 (Thermo Fisher), 0.5\% FBS (WELGENE), $0.5 \mathrm{mM}$ GlutaMAX (Thermo Fisher), and sodium 
pyruvate (Thermo Fisher). Cultured neurons were infected with lentiviruses at DIV3-4. For immunocytochemistry, cultured neurons were fixed with $4 \%$ paraformaldehyde/4\% sucrose in PBS for $10-30 \mathrm{~min}$ at $4{ }^{\circ} \mathrm{C}$, and permeabilized with $0.2 \%$ Triton X-100 in PBS for $10-30 \mathrm{~min}$ at $4^{\circ} \mathrm{C}$. Neurons were blocked with $3 \%$ horse serum $/ 0.1 \%$ BSA in PBS for $15 \mathrm{~min}$ at room temperature and incubated with primary and secondary antibodies in blocking solution for $70 \mathrm{~min}$ at room temperature. The primary antibodies were used in these experiments included anti-VGLUT1 (Synaptic Systems; 1:700), anti-GAD67 (Millipore; 1:100), anti-GABA ${ }_{\mathrm{A}} \mathrm{R} 2$ (Synaptic Systems; 1:500), anti-GluA1 (1193; 1:200), anti-Gephyrin (Synaptic Systems; 1:100), and anti-pan-Shank (1172; 1:200). Images of randomly selected neurons were acquired using a confocal microscope (LSM800, Carl Zeiss) with a $63 \times$ objective lens; all image settings were kept constant during image acquisition. Z-stack images obtained by confocal microscopy were converted to maximal projections, and puncta size and the density of the indicated presynaptic marker proteins were analyzed in a blinded manner using MetaMorph software (Molecular Devices Corp.).

Production of lentiviruses. Lentiviruses were produced by transfecting HEK293FT cells with three plasmids-lentivirus vectors, psPAX2 (or pCMVdeltaR8.2), and pMD2.G-at a 2:2:1 ratio. After $72 \mathrm{~h}$, lentiviruses were harvested by collecting the media as previously described 
(Han et al, 2018, Hsia et al, 2014).

Production of adeno-associated viruses. HEK293T cells were co-transfected with the indicated AAV vectors, pHelper and AAV1.0 (serotype 2/9) capsids vectors. After 72 hours, the transfected HEK293T cells were collected, and resuspended in PBS, and lysed by subjecting them to four freeze-thaw cycles in an ethanol/dry ice bath $\left(7\right.$ minutes each) and a $37^{\circ} \mathrm{C}$ water bath $(5 \mathrm{~min})$. The lysates were centrifuged and the supernatants were mixed with $40 \%$ polyethylene glycol and $2.5 \mathrm{M} \mathrm{NaCl}$ and centrifuged at $2000 \times \mathrm{g}$ for $30 \mathrm{~min}$. The cell pellets were resuspended in HEPES buffer (20 mM HEPES, $115 \mathrm{mM} \mathrm{NaCl}, 1.2 \mathrm{mM} \mathrm{CaCl} 2,1.2 \mathrm{mM}$

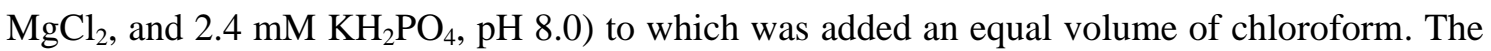
mixture was centrifuged at $400 \times \mathrm{g}$ for $5 \mathrm{~min}$ and concentrated three times with a Centriprep centrifugal filter (Cat. 4310, Millipore) at $1,220 \times \mathrm{g}(20 \mathrm{~min}$ each) and an Amicon Ultra centrifugal filter (Cat. UFC500396, Millipore) at 16,000 $\times \mathrm{g}$ for $30 \mathrm{~min}$. AAVs were titered by treating $1 \mu \mathrm{l}$ of concentrated, filter-sterilized AAVs with $1 \mu \mathrm{l}$ of DNase I (AMPD1; Sigma) for 30 min at $37{ }^{\circ} \mathrm{C}$ to eliminate any contaminating plasmid DNA. After treatment with $1 \mu 1$ of stop solution (50 mM ethylenediaminetetraacetic acid) for $10 \mathrm{~min}$ at $65^{\circ} \mathrm{C}, 10 \mu \mathrm{g}$ of protease $\mathrm{K}$ (Cat. P2308; Sigma) was added and the sample was incubated for $1 \mathrm{~h}$ at $50^{\circ} \mathrm{C}$. Reactions were stopped by heat inactivation at $95{ }^{\circ} \mathrm{C}$ for $20 \mathrm{~min}$. The final virus titer was quantified by qRT- 
PCR. Empty AAV vector was used to generate a standard curve for qRT-PCRs targeting GFP sequences.

qRT-PCRs. Cultured rat cortical neurons were infected with recombinant lentiviruses at DIV4 and harvested at DIV11 for qRT-PCR using SYBR green qPCR master mix (TaKaRa). Total RNA was extracted from mouse cortical neurons using TRIzol reagent (Invitrogen) according to the manufacturer's protocol. Briefly, cells in each well of a 12-well plate of cultured neurons were harvested and incubated with $500 \mu \mathrm{T}$ TRIzol reagent at room temperature for 5 minutes. After phenol-chloroform extraction, RNA in the upper aqueous phase was precipitated. cDNA was synthesized from $500 \mathrm{ng}$ of RNA by reverse transcription using a ReverTra Ace- $\alpha$ kit (Toyobo). Quantitative PCR was performed on a CFX96 Touch Real-Time PCR system BioRad) using $0.5 \mu 1$ of cDNA. The ubiquitously expressed $\beta$-actin was used as an endogenous control. The sequences of the primer pairs used were: mouse Ptprs, 5'ATCAGAGAGCCCAAGGATCA-3' (forward) and 5'-GCCACACACTCGTACACGTT-3' (reverse); mouse Ptprd, 5'-CTCCTTGATCCCCATCTCTG-3' (forward) and 5'-CAG GGCAGCCACTAAACTTC-3' (reverse); and mouse Ptprf, 5'CCCGATGGCTGAGTACAACA-3' (forward) and 5'-CATCCCGGGCGTCTGTGA-3' (reverse). 
Quantification of cell body size and Sholl analysis. Cultured mouse neurons were infected with lentivirus expressing EGFP- $\Delta$ Cre or EGFP-Cre at DIV4, and the neurons were transfected with L-317 vector expressing mCherry protein at DIV8. Fluorescent images were acquired at DIV 11 using by confocal microscopy (LSM800; Carl Zeiss). The sizes of green fluorescence positive neurons were measured using MetaMorph software (Molecular Devices), and branch intersections were measured using Sholl analysis function of Fiji/ImageJ software (National Institute of Health, USA).

Electron microscopy. E17 embryonic hippocampi of PTP $\sigma$ and PTP $\delta$ mice were seeded onto $35 \mathrm{~mm}$ coverslips at densities of 450,000 cells/well. The neurons were infected with lentiviral vectors expressing $\Delta$ Cre or Cre at DIV4. At DIV14, cultured neurons were fixed in $2 \%$ glutaraldehyde, $0.1 \mathrm{M}$ Na-cacodylate buffer, $\mathrm{pH} \mathrm{7.4,} \mathrm{for} 1 \mathrm{~h}$ at room temperature and overnight at $4{ }^{\circ} \mathrm{C}$. The cells were post-fixed in $0.5 \% \mathrm{OsO}_{4}$ (osmium tetroxide), $0.8 \% \mathrm{~K}$ ferricyanide at room temperature for $60 \mathrm{~min}$. All specimens were stained en bloc with $2 \%$ aqueous uranyl acetate for $30 \mathrm{~min}$, dehydrated in a graded ethanol series up to $100 \%$, embedded in Embed 812 resin (Electron Microscopy Science, PA), and polymerized overnight in a $60{ }^{\circ} \mathrm{C}$ oven. Thin sections $(50-60 \mathrm{~nm})$ were cut with a Leica ultramicrotome and post-stained with uranyl acetate 
and lead citrate. Sample grids were examined using a FEI Tecnai BioTWIN transmission electron microscope running at accelerating voltage of $80 \mathrm{kV}$. Images were recorded with a Morada CCD camera and iTEM (Olympus) software. This protocol allowed the unambiguous staining of membranes of synaptic vesicles as well as of pre- and post-synaptic compartments, resulting in accurate measurements of the nanoscale organization of the synaptic vesicles within nerve endings. To analyze synapse ultrastructure, the lengths of active zone and PSD, tethered vesicles, the membrane proximal vesicles, and total vesicle numbers were quantified using MetaMorph software (Molecular Devices). The numbers of total vesicles and docked vesicles were counted manually, and the distances from the active zone and the PSD to the vesicle center were measured. Vesicles located below $200 \mathrm{~nm}$ were considered membrane-proximal vesicles.

Animals. PTP $\sigma$ conditional knockout mice were purchased from The KOMP Repository Collection (UC Davis, USA). PTP $\delta$ conditional knockout mice were generated at Biocytogen Co., Ltd (Beijing, China). Ai9 reporter mice were purchased from Jackson Research Laboratories (007909). Nestin-Cre (003771, Jackson Research Laboratories) mice were the gift of Dr. Albert Chen (DUKE-NUS, Singapore). Wfs1-Cre mice (009103, Jackson Research Laboratories) were the gift of Dr. Susumu Tonegawa (Massachusetts Institute of Technology, USA). All mice were maintained and handled in accordance with protocols (DGIST-IACUC- 
17122104-001) approved by the Institutional Animal Care and Use Committee of DGIST. Mice

were maintained under standard, temperature-controlled laboratory conditions on a 12:12

light/dark cycle (lights on at 9:00 am and off at 9:00 pm), and with water and food supplied $a d$

libitum. All animal experiments were performed according to approved animal protocols at

DGIST Laboratory Animal Resource Center.

RNAscope analyses. RNAscope analyses of mouse brains were performed using

RNAscope ${ }^{\circledR}$ Fluorescent Multiplex Assay kits (Advanced Cell Diagnostics) according to

the manufacturer's direction. Briefly, within 5 min of dissection, mouse brains were

immersed in cryo-embedding medium and frozen on dry ice. Brain tissue was sliced into

$20 \mu \mathrm{m}$-thick coronal sections using a cryotome (Model CM-3050-S; Leica Biosystems),

mounted, and dried at $-20^{\circ} \mathrm{C}$ for $10 \mathrm{~min}$. Tissue samples were fixed with $4 \%$

formaldehyde for 15 minutes at $4^{\circ} \mathrm{C}$ and dehydrated by incubation at room temperatures

(RT) in $50 \% \mathrm{EtOH}$ for $5 \mathrm{~min}$, in $70 \% \mathrm{EtOH}$ for $5 \mathrm{~min}$, and twice $100 \% \mathrm{EtOH}$ for $5 \mathrm{~min}$.

The fixed samples were treated with protease IV for $30 \mathrm{~min}$ at RT and washed twice with

1X PBS. To detect RNA, the sections were incubated in different amplifier solutions in a

HybEZ hybridization oven (Advanced Cell Diagnostics) at $40^{\circ} \mathrm{C}$. Three synthetic

oligonucleotides complementary to nucleotide residues 1051-1947 of Mm-Ptprs-C1, 
1329-2486 of Mm-Ptprd-C1 and Mm-Ptprd-C2, and 4001-5386 of Mm-Ptprf-C3

(Advanced Cell Diagnostics) were labeled by conjugation to Alexa Fluor 488, Altto 550 and Altto 647, and the labeled probe mixtures were hybridized by tissue samples by incubating them with slide-mounted sections for 2 hours at $40^{\circ} \mathrm{C}$. Nonspecifically hybridized probes were removed by washing the sections three times for 2 minutes each with $1 \mathrm{X}$ wash buffer at RT, followed by incubations at $40^{\circ} \mathrm{C}$ with Amplifier 1-FL for 30 minutes, Amplifier 2-FL for 15 minutes, Amplifier 3-FL for 30 minutes, and Amplifier 4 Alt B-FL for 15 minutes. Each amplifier was removed by washing twice in $1 \mathrm{X}$ wash buffer at RT. The fluorescence images were acquired using a LSM 800 microscope (Carl Zeiss).

Stereotaxic surgery and virus injections. For behavioral and electrophysiology experiments, 4-5-week-old mice were anesthetized by intraperitoneal injection of 2\% 2,2,2-tribromoethanol (Sigma), dissolved in saline, and secured in a stereotaxic apparatus. For immunohistochemistry (IHC), 6 to 7-week-old mice were used. Viral solutions were injected using a Nanoliter 2010 Injector (World Precision Instruments), including a NanoFil syringe and 33 gauge needle, at a flow rate of $50 \mathrm{nl} / \mathrm{min}$ (injected volume, $500 \mathrm{nl}$ ). The coordinates used for stereotaxic injections targeting the ventral hippocampal CA1 were, relative to the bregma, anteroposterior (AP) -3.1 
$\mathrm{mm}$; medial-lateral (ML), $\pm 3.2 \mathrm{~mm}$; and dorsal-ventral (DV), $-2.5 \mathrm{~mm}$. The coordinates for targeting the mPFC were, relative to the bregma, AP, $+1.7 \mathrm{~mm}$; ML, $\pm 0.4 \mathrm{~mm}$; and DV, -2.2 mm. Behavioral tests were performed 5 weeks after each injected mouse was returned to its home cage, and immunohistochemical and electrophysiological analyses were performed 3 weeks later.

Immunohistochemistry. Male mice aged 8-10-weeks were anesthetized and immediately perfused, first with PBS for 5 minutes and then with $4 \%$ paraformaldehyde for 5 minutes. Their brains were removed, fixed overnight in $4 \%$ paraformaldehyde, incubated overnight in $30 \%$ sucrose (in PBS), and sliced into 35- $\mu \mathrm{m}$-thick coronal sections using a cryotome (Model CM3050-S; Leica Biosystems). The sections were permeabilized in PBS containing 0.5\% Triton X100 for $1 \mathrm{~h}$ and blocked in PBS containing 5\% bovine serum albumen and 5\% horse serum for 1 minutes. The brain sections were incubated overnight with primary antibodies for overnight at $4{ }^{\circ} \mathrm{C}$. The following primary antibodies were used: anti-VGLUT1 (1:200), anti-GAD67 (1:100). The brain sections were washed three times with PBS and incubated with the appropriate Cy3conjugated secondary antibodies (Jackson ImmunoResearch) for 2 hours at RT. After three washes with PBS, the sections were counterstained with DAPI (4',6-diamidino-2phenylinodole) and mounted onto glass slides (Superfrost Plus; Fisher Scientific) with 
Vectashield mounting medium (H-1200; Vector Laboratories).

In vitro and ex vivo electrophysiology. 1 . Electrophysiology of primary cultured neurons.

Hippocampal neurons obtained from PTP $\sigma$ and PTP $\delta$ cKO mice were infected on DIV4 with lentiviruses encoding Cre-EGFP or dCre-EGFP, followed by analysis at DIV13-16. Pipettes were pulled from borosilicate glass (o.d. 1.5mm, i.d. 0.86mm; Sutter Instrument), using a Model P-97 pipette puller (Sutter Instrument). The resistance of pipettes filled with internal solution varied between 3-6 M . The internal solution contained $145 \mathrm{mM}$ Cs-methanesulfonate, $5 \mathrm{mM} \mathrm{NaCl}, 5 \mathrm{mM}$ TEA-Cl, $10 \mathrm{mM}$ HEPES, $5 \mathrm{mM}$ EGTA, 0.3 mM Na-GTP, 4 mM Mg-ATP, 10 mM disodium phosphocreatine and $1 \mathrm{mM}$ QX-314 with $\mathrm{pH}$ adjusted to $7.2-7.4$ with $\mathrm{KOH}$, and an osmolarity of $290-295 \mathrm{mOsmol} / \mathrm{L}$. The external solution consisted of $130 \mathrm{mM} \mathrm{NaCl}, 4 \mathrm{mM} \mathrm{KCl}, 2 \mathrm{mM} \mathrm{CaCl}_{2}, 1 \mathrm{MgCl}_{2}, 10 \mathrm{mM}$ HEPES, and $10 \mathrm{mM}$ D-glucose with $\mathrm{pH}$ adjusted to $7.2-7.4$ with $\mathrm{NaOH}$, and an osmolarity of 300-305 mOsmol/L. Whole-cell configuration was generated at RT using MPC-200 manipulators (Sutter Instrument) and a Multiclamp 700B amplifier (Molecular Devices). mEPSCs, mIPSCs, and sucrose EPSCs were recorded at a holding potential of $-70 \mathrm{mV}$. For sucrose puffing, $500 \mathrm{mM}$ sucrose was applied directly on the dendritic field of the patched neurons at a puff pressure of 6-8 psi using a PV-820 Pneumatic Picopump system 
(World Precision Instruments). Receptor-mediated synaptic responses were pharmacologically isolated by applying drug combinations of $50 \mu \mathrm{M}$ picrotoxin, $10 \mu \mathrm{M}$ CNQX, $50 \mu \mathrm{M}$ D-APV and/or $1 \mu \mathrm{M}$ tetrodotoxin. Synaptic currents were analyzed offline using Clampfit 10.5 (Molecular Devices) software. 2. Acute slice electrophysiology. Transverse hippocampal formation and coronal mPFC $(300 \mu \mathrm{m})$ were prepared from 10 12-week-old male mice, as described (Noh et al, 2019). The mice were anesthetized with isoflurane and decapitated, and their brains were rapidly removed and placed in ice-cold, oxygenated $\left(95 \% \mathrm{O}_{2} / 5 \% \mathrm{CO}_{2}\right)$, low- $\mathrm{Ca}^{2+} /$ high- $\mathrm{Mg}^{2+}$ dissection buffer containing $5 \mathrm{mM}$

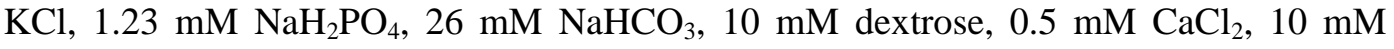
$\mathrm{MgCl}_{2}$, and $212.7 \mathrm{mM}$ sucrose. Slices were transferred to a holding chamber in an incubator containing oxygenated $\left(95 \% \mathrm{O}_{2} / 5 \% \mathrm{CO}_{2}\right)$ artificial cerebrospinal fluid (ACSF) containing $124 \mathrm{mM} \mathrm{NaCl}, 5 \mathrm{mM} \mathrm{KCl}, 1.23 \mathrm{mM} \mathrm{NaH}_{2} \mathrm{PO}_{4}, 2.5 \mathrm{mM} \mathrm{CaCl}_{2}, 1.5 \mathrm{mM} \mathrm{MgCl}_{2}$, $26 \mathrm{mM} \mathrm{NaHCO} 3$, and $10 \mathrm{mM}$ dextrose at $28-30^{\circ} \mathrm{C}$ for at least $1 \mathrm{~h}$ before recording. After $>1 \mathrm{~h}$ incubation in ACSF, slices were transferred to a recording chamber with continuous perfusion $(2 \mathrm{ml} / \mathrm{min})$ by ACSF oxygenated with $95 \% \quad \mathrm{O}_{2} / 5 \% \quad \mathrm{CO}_{2}$ at $23-25^{\circ} \mathrm{C}$. All recordings were performed on pyramidal neurons in the subiculum, mPFC layer $\mathrm{V}$, or hippocampal CA1 area identified by their size and morphology. Virus-infected neurons were identified by GFP fluorescence. Patch pipettes (4-6 M $\Omega$ ) were filled with a solution 
containing $130 \mathrm{mM} \mathrm{Cs-MeSO}$, $0.5 \mathrm{mM}$ EGTA, $5 \mathrm{mM}$ TEA-Cl, $8 \mathrm{mM} \mathrm{NaCl}, 10 \mathrm{mM}$ HEPES, 1 mM QX-314, 4 mM ATP-Hg, 0.4 mM GTP-Na, 10 mM phosphocreatine- $\mathrm{Na}_{2}$, $0.1 \mathrm{mM}$ spermine (for measuring mEPSCs, EPSC-PPRs and IPSC-PPRs); $130 \mathrm{mM} \mathrm{CsCl}$, 1.1 mM EGTA, $2 \mathrm{mM} \mathrm{MgCl}$, $0.1 \mathrm{mM} \mathrm{CaCl}_{2}, 10 \mathrm{mM} \mathrm{NaCl}, 10 \mathrm{mM}$ HEPES, $2 \mathrm{mM}$ ATP$\mathrm{Na}, \mathrm{pH} 7.4$ with an osmolarity of $280-290 \mathrm{mOsmol} / \mathrm{L}$ (for measuring mIPSCs). The extracellular recording solution consisted of ACSF supplemented with picrotoxin (100 $\mu \mathrm{M})$, TTX $(1 \mu \mathrm{M})$, and DL-AP5 $(50 \mu \mathrm{M})$ for measuring mEPSCs; picrotoxin $(100 \mu \mathrm{M})$ for measuring EPSC-PPRs; TTX $(1 \mu \mathrm{M})$, CNQX $(20 \mu \mathrm{M})$ and DL-AP5 $(50 \mu \mathrm{M})$ for measuring mIPSCs; and CNQX (20 $\mu \mathrm{M})$ and DL-AP5 (50 $\mu \mathrm{M})$ for measuring IPSC-PPRs. Evoked synaptic responses were elicited by stimulation $(0.2 \mathrm{~ms}$ current pulses $)$ using a concentric bipolar electrode (for CA1-subiculum synapses) or theta glass capillaries filled with ACSF (for mPFC layer II-V synapses) placed 200-300 mm in front of postsynaptic pyramidal neurons at intensities that produced $40-50 \%$ of the maximal E/IPSC amplitude. Recordings were obtained using a Multiclamp 700B amplifier (Molecular Devices) under visual control with differential interference contrast illumination on an upright microscope (BX51WI; Olympus). Only cells with an access resistance $<20 \mathrm{M} \Omega$ and an input resistance $>100 \mathrm{M} \Omega$ were studied. The cells were discarded if the input or the access resistance changed more than 20\%. Data were acquired and analyzed using pClamp 10.7 
(Molecular Devices). Signals were filtered at $3 \mathrm{kHz}$ and digitized at $10 \mathrm{kHz}$ with DigiData

1550 (Molecular Devices).

Mouse behavioral tests. Male PTP ${ }^{\mathrm{f} / \mathrm{f}}:: \mathrm{Wfs} 1-\mathrm{Cre}\left(W f_{S} 1-\mathrm{PTP} \sigma\right), \mathrm{PTP}^{\mathrm{f} / \mathrm{f}}(\mathrm{Ctrl} ; 7-10$ weeks old), and $\mathrm{PTP \sigma}^{\mathrm{f} / \mathrm{f}}$ (9-11 weeks old) mice injected with AAV- $\triangle \mathrm{Cre} / \mathrm{EGFP}$ (Control) or AAVCre/EGFP (РTP $\sigma-\mathrm{cKO})$ into their CA1 regions were used for behavioral tests. The order of testing was Laboras, Y-maze, open-field, novel object-recognition, elevated-plus maze, lightdark transition (LDT), contextual fear conditioning (CFC) and three-chamber tests. Mice were excluded from quantitative analyses if one or both of the injections were off-target, as demonstrated by post hoc immunostaining after behavioral analyses.

Behavioral analyses. 1 . Y-maze test. Mice were introduced into the center of a Y-shaped white acrylic maze with three $40-\mathrm{cm}-$ long arms at $120^{\circ}$ angles from each other and allowed to explore freely for 8 minutes. Entry into an arm was defined as the entry of all four limbs of a mouse. Mouse movement was recorded using a top-view infrared camera, and analyzed using EthoVision XT 10 software (Noldus). 2. Open-field test. Mice were placed into a white acrylic open-field box $(40 \times 40 \times 35 \mathrm{~cm})$, and allowed to freely explore the environment for 30 minutes in the dark (0 lux). The distance moved and time spent in the center zone were recorded with a 
top-view infrared camera, and analyzed using EthoVision XT 10 software (Noldus). $\underline{\text { 3. Novel }}$ object-recognition test. Mice were habituated to an open field chamber for 10 minutes. During training sessions, two identical objects were placed in the center of the chamber at regular intervals, and mice were allowed to explore the objects for 10 minutes. The mice were subsequently returned to their home cages for 24 hours. For novel object-recognition tests, one of the two objects was replaced by a new object placed in the same position of the chamber. Mice were returned to the chamber and allowed to explore freely for 10 minutes. The movement of mice was recorded by an infrared camera, and the number and duration of contacts were analyzed using EthoVision XT 10 (Noldus). 4. Elevated plus-maze test. The elevated plus-maze is a plus-shaped $(+)$ white acrylic maze with two open arms $(30 \times 5 \times 0.5 \mathrm{~cm})$ and two closed arms $(30 \times 5 \times 30 \mathrm{~cm})$ positioned at a height of $45 \mathrm{~cm}$ from the floor. Light conditions around open and closed arms were $\sim 300$ and $\sim 30$ lux, respectively. For the test, mice were introduced into the center zone of the elevated plus-maze and allowed to move freely for 5 minutes. All behaviors were recorded with a top-view infrared camera, and the time spent in each arm and the number of arm entries were measured and analyzed using EthoVision XT 10 software (Noldus). 5. Light-dark transition test. The light-dark transition test maze consists of equally sized light and dark chambers, measuring $20 \times 10 \times 35 \mathrm{~cm}$ each. The light conditions for the light and dark chambers were 500 600 and 0 lux, respectively. A mouse was introduced into the 
center of the light chamber and allowed to explore freely for $10 \mathrm{~min}$. All behaviors were recorded by a top-view infrared camera, and the time spent and number of entries into the light chamber were measured and analyzed using EthoVision XT 10 software (Noldus). $\underline{\text { 6. Three- }}$ chamber test. Mice were placed into a white acrylic box divided into three chambers, measuring $20 \times 40 \times 22 \mathrm{~cm}$ each, and allowed to freely explore the environment for 10 minutes in the dark (0 lux). After a habituation time, an age-matched social target mouse (S1) and an object target (O) were placed in wire cups on each side of the chamber, and the mouse nose point approaches to the mouse and object were measured for $10 \mathrm{~min}$. The object target was replaced by a new social target mouse (S2) and social novelty was again measured for $10 \mathrm{~min}$. The approach time was calculated as the times spent sniffing $\mathrm{S} 1$ and $\mathrm{O}$, or S2 and S. $\underline{7 \text {. Contextual fear }}$ conditioning test. Contextual fear conditioning tests were performed using circadian cabinets (Actimetrics). On training day, mice were placed in a fear conditioning chamber and allowed to habituate for $120 \mathrm{sec}$. Subsequently a tone $(85 \mathrm{~dB}, 20 \mathrm{sec})$ paired with a footshock $(0.55 \mathrm{~mA}, 2$ sec) separated by 1 min intervals was delivered three times. The mice were returned to their home cages for $24 \mathrm{~h}$ and transferred to the same conditioning chamber. Freezing times were measured for $180 \mathrm{sec}$ after habituation for $120 \mathrm{sec}$. Altered context tests were performed $24 \mathrm{~h}$ later. During these tests, the conditioning chamber was modified with a white circular plastic cylinder on a white background. Freezing times were measured for $180 \mathrm{sec}$ after habituation for 
$120 \mathrm{sec}$. After $3 \mathrm{~h}$, freezing times were measured under a conditioning noise background for 180 sec after habituation for $120 \mathrm{sec}$. All freezing times were analyzed by FreezeFrame Ver1

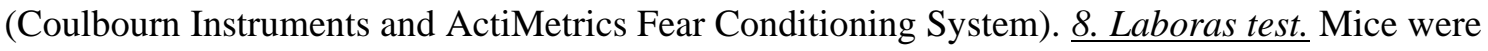
placed in a Laboratory Animal Behavior Observation Registration and Analysis System (Laboras System), and home cage activity (locomotion, climbing, rearing, grooming, eating and drinking) was monitored continuously for $48 \mathrm{~h}$ with a 12/12 light (9:00 am to 9:00 pm)/dark (9:00 pm to 9:00 am) cycle and ad libitum feeding. 


\section{References}

Abbott LF, Regehr WG (2004) Synaptic computation. Nature 431: 796-803

Ackley BD, Harrington RJ, Hudson ML, Williams L, Kenyon CJ, Chisholm AD, Jin Y

(2005) The two isoforms of the Caenorhabditis elegans leukocyte-common antigen relate

d receptor tyrosine phosphatase PTP-3 function independently in axon guidance and syna

pse formation. J Neurosci 25: 7517-7528

Acuna C, Liu X, Südhof TC (2016) How to Make an Active Zone: Unexpected Univers

al Functional Redundancy between RIMs and RIM-BPs. Neuron 91: 792-807

Aoto J, Foldy C, Ilcus SM, Tabuchi K, Südhof TC (2015) Distinct circuit-dependent fun

ctions of presynaptic neurexin-3 at GABAergic and glutamatergic synapses. Nat Neurosci

18: $997-1007$

Aoto J, Martinelli DC, Malenka RC, Tabuchi K, Südhof TC (2013) Presynaptic neurexin

-3 alternative splicing trans-synaptically controls postsynaptic AMPA receptor trafficking.

Cell 154: $75-88$

Cembrowski MS, Phillips MG, DiLisio SF, Shields BC, Winnubst J, Chandrashekar J, B

as E, Spruston N (2018) Dissociable Structural and Functional Hippocampal Outputs via

Distinct Subiculum Cell Classes. Cell 173: 1280-1292

Chagnon MJ, Uetani N, Tremblay ML (2004) Functional significance of the LAR recept 
or protein tyrosine phosphatase family in development and diseases. Biochem Cell Biol 8

2: $664-675$

Chanda S, Hale WD, Zhang B, Wernig M, Südhof TC (2017) Unique versus Redundant Functions of Neuroligin Genes in Shaping Excitatory and Inhibitory Synapse Properties. J Neurosci 37: 6816-6836

Chen LY, Jiang M, Zhang B, Gokce O, Südhof TC (2017) Conditional Deletion of All Neurexins Defines Diversity of Essential Synaptic Organizer Functions for Neurexins. Ne uron 94: $611-625$

Choi Y, Nam J, Whitcomb DJ, Song YS, Kim D, Jeon S, Um JW, Lee SG, Woo J, K won SK, Li Y, Mah W, Kim HM, Ko J, Cho K, Kim E (2016) SALM5 trans-synaptica lly interacts with LAR-RPTPs in a splicing-dependent manner to regulate synapse develo pment. Sci Rep 6: 26676

Dai J, Aoto J, Südhof TC (2019) Alternative Splicing of Presynaptic Neurexins Different ially Controls Postsynaptic NMDA and AMPA Receptor Responses. Neuron 102: 993-100 8

Dai Y, Taru H, Deken SL, Grill B, Ackley B, Nonet ML, Jin Y (2006) SYD-2 Liprin-a lpha organizes presynaptic active zone formation through ELKS. Nat Neurosci 9: 1479-1 487 
Doussau F, Augustine GJ (2000) The actin cytoskeleton and neurotransmitter release: an overview. Biochimie 82: 353-363

Dunah AW, Hueske E, Wyszynski M, Hoogenraad CC, Jaworski J, Pak DT, Simonetta A, Liu G, Sheng M (2005) LAR receptor protein tyrosine phosphatases in the developm ent and maintenance of excitatory synapses. Nat Neurosci 8: 458-467

Elchebly M, Wagner J, Kennedy TE, Lanctot C, Michaliszyn E, Itie A, Drouin J, Trem blay ML (1999) Neuroendocrine dysplasia in mice lacking protein tyrosine phosphatase $\mathrm{s}$ igma. Nat Genet 21: 330-333

Etherton MR, Blaiss CA, Powell CM, Südhof TC (2009) Mouse neurexin-1alpha deletio n causes correlated electrophysiological and behavioral changes consistent with cognitive impairments. Proc Natl Acad Sci U S A 106: 17998-18003

Grauel MK, Maglione M, Reddy-Alla S, Willmes CG, Brockmann MM, Trimbuch T, Ro senmund T, Pangalos M, Vardar G, Stumpf A, Walter AM, Rost BR, Eickholt BJ, Hauc ke V, Schmitz D, Sigrist SJ, Rosenmund C (2016) RIM-binding protein 2 regulates relea se probability by fine-tuning calcium channel localization at murine hippocampal synapse s. Proc Natl Acad Sci U S A 113: 11615-11620

Han KA, Jeon S, Um JW, Ko J (2016) Emergent Synapse Organizers: LAR-RPTPs and Their Companions. Int Rev Cell Mol Biol 324: 39-65 
Han KA, Ko JS, Pramanik G, Kim JY, Tabuchi K, Um JW, Ko J (2018) PTPsigma Dri ves Excitatory Presynaptic Assembly via Various Extracellular and Intracellular Mechanis ms. J Neurosci 38: 6700-6721

Han KA, Um JW, Ko J (2019) Intracellular protein complexes involved in synapse asse mbly in presynaptic neurons. Adv Protein Chem Struct Biol 116: 347-373

Horn KE, Xu B, Gobert D, Hamam BN, Thompson KM, Wu CL, Bouchard JF, Uetani N, Racine RJ, Tremblay ML, Ruthazer ES, Chapman CA, Kennedy TE (2012) Receptor protein tyrosine phosphatase sigma regulates synapse structure, function and plasticity. $J$ Neurochem 122: 147-161

Hsia HE, Kumar R, Luca R, Takeda M, Courchet J, Nakashima J, Wu S, Goebbels S, An W, Eickholt BJ, Polleux F, Rotin D, Wu H, Rossner MJ, Bagni C, Rhee JS, Brose N, Kawabe H (2014) Ubiquitin E3 ligase Nedd4-1 acts as a downstream target of PI3K/ PTEN-mTORC1 signaling to promote neurite growth. Proc Natl Acad Sci U S A 111: 1 $3205-3210$

Kaeser PS, Deng L, Wang Y, Dulubova I, Liu X, Rizo J, Südhof TC (2011) RIM prote ins tether $\mathrm{Ca}^{2+}$ channels to presynaptic active zones via a direct PDZ-domain interaction. Cell 144: 282-295

Kaeser PS, Kwon HB, Chiu CQ, Deng L, Castillo PE, Südhof TC (2008) RIM1alpha a 
nd RIM1beta are synthesized from distinct promoters of the RIM1 gene to mediate diffe rential but overlapping synaptic functions. J Neurosci 28: 13435-13447

Kitamura T, Pignatelli M, Suh J, Kohara K, Yoshiki A, Abe K, Tonegawa S (2014) Isla nd cells control temporal association memory. Science 343: 896-901

Ko J, Soler-Llavina GJ, Fuccillo MV, Malenka RC, Südhof TC (2011) Neuroligins/LRRT Ms prevent activity- and $\mathrm{Ca}^{2+} /$ calmodulin-dependent synapse elimination in cultured neuro ns. J Cell Biol 194: 323-334

Ko JS, Pramanik G, Um JW, Shim JS, Lee D, Kim KH, Chung GY, Condomitti G, Ki m HM, Kim H, de Wit J, Park KS, Tabuchi K, Ko J (2015) PTPsigma functions as a presynaptic receptor for the glypican-4/LRRTM4 complex and is essential for excitatory synaptic transmission. Proc Natl Acad Sci U S A 112: 1874-1879

Kwon SK, Woo J, Kim SY, Kim H, Kim E (2010) Trans-synaptic adhesions between ne trin-G ligand-3 (NGL-3) and receptor tyrosine phosphatases LAR, protein-tyrosine phosph atase delta (PTPdelta), and PTPsigma via specific domains regulate excitatory synapse fo rmation. J Biol Chem 285: 13966-13978

Li K, Zhou T, Liao L, Yang Z, Wong C, Henn F, Malinow R, Yates JR, 3rd, Hu H (2 013) betaCaMKII in lateral habenula mediates core symptoms of depression. Science 341 : 1016-1020 
Li Y, Zhang P, Choi TY, Park SK, Park H, Lee EJ, Lee D, Roh JD, Mah W, Kim R,

Kim Y, Kwon H, Bae YC, Choi SY, Craig AM, Kim E (2015) Splicing-Dependent Tran s-synaptic SALM3-LAR-RPTP Interactions Regulate Excitatory Synapse Development and Locomotion. Cell Rep 12: 1618-1630

Luuk H, Koks S, Plaas M, Hannibal J, Rehfeld JF, Vasar E (2008) Distribution of Wfs 1 protein in the central nervous system of the mouse and its relation to clinical sympto ms of the Wolfram syndrome. J Comp Neurol 509: 642-660

Madisen L, Zwingman TA, Sunkin SM, Oh SW, Zariwala HA, Gu H, Ng LL, Palmiter RD, Hawrylycz MJ, Jones AR, Lein ES, Zeng H (2010) A robust and high-throughput Cre reporting and characterization system for the whole mouse brain. Nat Neurosci 13: $133-140$

McLean J, Batt J, Doering LC, Rotin D, Bain JR (2002) Enhanced rate of nerve regene ration and directional errors after sciatic nerve injury in receptor protein tyrosine phosph atase sigma knock-out mice. J Neurosci 22: 5481-5491

Missler M, Südhof TC, Biederer T (2012) Synaptic cell adhesion. Cold Spring Harb Pe rspect Biol 4: a005694

Mongillo G, Barak O, Tsodyks M (2008) Synaptic theory of working memory. Science 3 19: $1543-1546$ 
Muller CS, Haupt A, Bildl W, Schindler J, Knaus HG, Meissner M, Rammner B, Striess nig J, Flockerzi V, Fakler B, Schulte U (2010) Quantitative proteomics of the Cav2 cha nnel nano-environments in the mammalian brain. Proc Natl Acad Sci U S A 107: 14950 $-14957$

Nakamura F, Okada T, Shishikura M, Uetani N, Taniguchi M, Yagi T, Iwakura Y, Ohshi ma T, Goshima Y, Strittmatter SM (2017) Protein Tyrosine Phosphatase delta Mediates t he Sema3A-Induced Cortical Basal Dendritic Arborization through the Activation of Fyn Tyrosine Kinase. J Neurosci 37: 7125-7139

Neher E, Sakaba T (2008) Multiple roles of calcium ions in the regulation of neurotrans mitter release. Neuron 59: 861-872

Nelson JC, Stavoe AK, Colon-Ramos DA (2013) The actin cytoskeleton in presynaptic a ssembly. Cell Adh Migr 7: 379-387

Noh K, Lee H, Choi TY, Joo Y, Kim SJ, Kim H, Kim JY, Jahng JW, Lee S, Choi SY, Lee SJ (2019) Negr1 controls adult hippocampal neurogenesis and affective behaviors.

Mol Psychiatry 24: 1189-1205

O'mara S (2005) The subiculum: what it does, what it might do, and what neuroanatomy has yet to tell us. J Anat 207: 271-282

Rosenmund C, Stevens CF (1996) Definition of the readily releasable pool of vesicles at 
hippocampal synapses. Neuron 16: 1197-1207

Schroeder A, Vanderlinden J, Vints K, Ribeiro LF, Vennekens KM, Gounko NV, Wierda KD, de Wit J (2018) A Modular Organization of LRR Protein-Mediated Synaptic Adhe sion Defines Synapse Identity. Neuron 99: 329-344

Spangler SA, Schmitz SK, Kevenaar JT, de Graaff E, de Wit H, Demmers J, Toonen R F, Hoogenraad CC (2013) Liprin-alpha2 promotes the presynaptic recruitment and turnov er of RIM1/CASK to facilitate synaptic transmission. J Cell Biol 201: 915-28

Südhof TC (2012) The presynaptic active zone. Neuron 75: 11-25

Südhof TC (2017) Synaptic Neurexin Complexes: A Molecular Code for the Logic of N eural Circuits. Cell 171: 745-769

Südhof TC (2018) Towards an Understanding of Synapse Formation. Neuron 100: 276-2 93

Takahashi H, Arstikaitis P, Prasad T, Bartlett TE, Wang YT, Murphy TH, Craig AM (20 11) Postsynaptic TrkC and presynaptic PTPsigma function as a bidirectional excitatory sy naptic organizing complex. Neuron 69: 287-303

Takahashi H, Craig AM (2013) Protein tyrosine phosphatases PTPdelta, PTPsigma, and LAR: presynaptic hubs for synapse organization. Trends Neurosci 36: 522-534

Takahashi H, Katayama K, Sohya K, Miyamoto H, Prasad T, Matsumoto Y, Ota M, Yas 
uda H, Tsumoto T, Aruga J, Craig AM (2012) Selective control of inhibitory synapse d evelopment by Slitrk3-PTPdelta trans-synaptic interaction. Nat Neurosci 15: 389-98

Thompson KM, Uetani N, Manitt C, Elchebly M, Tremblay ML, Kennedy TE (2003) R eceptor protein tyrosine phosphatase sigma inhibits axonal regeneration and the rate of a xon extension. Mol Cell Neurosci 23: 681-92

Uetani N, Chagnon MJ, Kennedy TE, Iwakura Y, Tremblay ML (2006) Mammalian mot oneuron axon targeting requires receptor protein tyrosine phosphatases sigma and delta. $J$ Neurosci 26: 5872-80

Uetani N, Kato K, Ogura H, Mizuno K, Kawano K, Mikoshiba K, Yakura H, Asano M , Iwakura Y (2000) Impaired learning with enhanced hippocampal long-term potentiation in PTPdelta-deficient mice. EMBO J 19: 2775-85

Um JW, Ko J (2013) LAR-RPTPs: synaptic adhesion molecules that shape synapse deve lopment. Trends Cell Biol 23: 465-75

Valnegri P, Montrasio C, Brambilla D, Ko J, Passafaro M, Sala C (2011) The X-linked intellectual disability protein IL1RAPL1 regulates excitatory synapse formation by bindin g PTPdelta and RhoGAP2. Hum Mol Genet 20: 4797-809

Wallace MJ, Batt J, Fladd CA, Henderson JT, Skarnes W, Rotin D (1999) Neuronal def ects and posterior pituitary hypoplasia in mice lacking the receptor tyrosine phosphatase 
PTPsigma. Nat Genet 21: 334-8

Wang SSH, Held RG, Wong MY, Liu C, Karakhanyan A, Kaeser PS (2016) Fusion Co mpetent Synaptic Vesicles Persist upon Active Zone Disruption and Loss of Vesicle Doc king. Neuron 91: 777-791

Wong MY, Liu C, Wang SSH, Roquas ACF, Fowler SC, Kaeser PS (2018) Liprin-alpha 3 controls vesicle docking and exocytosis at the active zone of hippocampal synapses. $P$ roc Natl Acad Sci U S A 115: 2234-2239

Wyszynski M, Kim E, Dunah AW, Passafaro M, Valtschanoff JG, Serra-Pages C, Streuli M, Weinberg RJ, Sheng M (2002) Interaction between GRIP and liprin-alpha/SYD2 is $r$ equired for AMPA receptor targeting. Neuron 34: 39-52

Yim YS, Kwon Y, Nam J, Yoon HI, Lee K, Kim DG, Kim E, Kim CH, Ko J (2013) Slitrks control excitatory and inhibitory synapse formation with LAR receptor protein tyr osine phosphatases. Proc Natl Acad Sci U S A 110: 4057-4062

Yoshida T, Yasumura M, Uemura T, Lee SJ, Ra M, Taguchi R, Iwakura Y, Mishina M (2011) IL-1 receptor accessory protein-like 1 associated with mental retardation and autis $\mathrm{m}$ mediates synapse formation by trans-synaptic interaction with protein tyrosine phospha tase delta. J Neurosci 31: 13485-99

Zhen M, Jin Y (1999) The liprin protein SYD-2 regulates the differentiation of presynap 
tic termini in C. elegans. Nature 401: 371-5

Zucker RS, Regehr WG (2002) Short-term synaptic plasticity. Annu Rev Physiol 64: 355 


\section{Acknowledgements}

We thank Drs. Susumu Tonegawa (MIT, USA) and Albert Chen (DUKE-NUS, Singapore) for the gift of Wfs1-Cre and Nestin-Cre driver lines, respectively. This study was supported by the Korea Healthcare Technology R \& D Project, funded by the Ministry for Health and Welfare Affairs, Republic of Korea (Grant HI17C0080 to J.K.).

\section{Author contributions}

S.Y.C. and J.K. conceived the project; K.A.H, H.Y.L., D.L., J.S., T.H.Y., C.L. and X.L. performed the experiments; K.A.H., H.Y.L., D.L., J.S., T.H.Y., C.L., J.S.R., J.W.U., S.Y.C. and J.K. analyzed the data; S.Y.C. and J.K. wrote the manuscript with input from the other authors.

\section{Conflict of interest}

The authors declare that they have no conflict of interest 


\section{Figure Legends}

Figure 1. Conditional KO of PTPб impairs excitatory synapse development and

\section{transmission in cultured hippocampal neurons}

A, B PTP $\sigma \mathrm{cKO}(\mathbf{A})$ but not PTP $\delta$ cKO (B) in cultured hippocampal neurons specifically reduces excitatory synapse density. Double immunofluorescence analysis of MAP2 (blue) and the indicated synaptic markers (red) in mature cultured neurons (DIV14) derived from $P T P \sigma^{\text {fff }}$ or $P T P \delta^{f f f}$ mice infected with lentiviruses expressing $\Delta$ Cre or Cre at DIV3. Synaptic markers assayed included surface GluA1 (sGluA1), total GluA1, Shank, and VGLUT1 as excitatory synaptic markers, and surface $\mathrm{GABA}_{\mathrm{A}} \gamma 2$ (sGA 2 2), total $\mathrm{GABA}_{\mathrm{A}} \gamma 2$, gephyrin $(\mathrm{Gphn})$, and GAD67 as inhibitory synaptic markers. Scale bar: $10 \mu \mathrm{m}$.

C Quantification of images in (A and $\mathbf{B}$ ), measuring the density of the indicated synaptic markers. Data are means \pm SEMs (n denotes number of analyzed neurons; $\triangle \mathrm{Cre} / \mathrm{PTP} \sigma$ cKO/sGluA1, n = 16; Cre/PTP $\sigma$ cKO /sGluA1, n = 17; $\Delta$ Cre/PTP $\sigma$ cKO/GluA1, n = 16; Cre /PTP $\sigma \mathrm{cKO} / \mathrm{GluA} 1, \mathrm{n}=15 ; \Delta \mathrm{Cre} / \mathrm{PTP} \sigma \mathrm{cKO} /$ Shank, $\mathrm{n}=16$; Cre/PTP $\sigma \mathrm{cKO} /$ Shank, $\mathrm{n}=16$; $\Delta \mathrm{Cre} / \mathrm{PTP} \sigma \mathrm{cKO} / \mathrm{VGLUT} 1, \mathrm{n}=15 ; \mathrm{Cre} / \mathrm{PTP} \sigma \mathrm{cKO} / \mathrm{VGLUT1}, \mathrm{n}=16 ; \Delta \mathrm{Cre} / \mathrm{PTP} \sigma$ $\mathrm{cKO} / \mathrm{sGABA}_{\mathrm{A}} \mathrm{R} \gamma 2, \mathrm{n}=15 ; \mathrm{Cre} / \mathrm{PTP} \sigma \mathrm{cKO} / \mathrm{sGABA}{ }_{\mathrm{A}} \mathrm{R} \gamma 2, \mathrm{n}=15 ; \Delta \mathrm{Cre} / \mathrm{PTP} \sigma \mathrm{cKO} / \mathrm{GABA}_{\mathrm{A}} \mathrm{R} \gamma 2$, $\mathrm{n}=16 ; \mathrm{Cre} / \mathrm{PTP} \sigma \mathrm{cKO} / \mathrm{GABA}_{\mathrm{A}} \mathrm{R} \gamma 2, \mathrm{n}=16 ; \Delta \mathrm{Cre} / \mathrm{PTP} \sigma \mathrm{cKO} / \mathrm{Gephyrin,} \mathrm{n}=16 ; \mathrm{Cre} / \mathrm{PTP} \sigma$ 
cKO/Gephyrin , $\mathrm{n}=15 ; \Delta \mathrm{Cre} / \mathrm{PTP} \sigma \mathrm{cKO} / \mathrm{GAD} 67, \mathrm{n}=16 ; \mathrm{Cre} / \mathrm{PTP} \sigma \mathrm{cKO} / \mathrm{GAD} 67, \mathrm{n}=16$;

$\Delta \mathrm{Cre} / \mathrm{PTP} \delta \mathrm{cKO} / \mathrm{sGluA} 1, \mathrm{n}=14 ; \mathrm{Cre} / \mathrm{PTP} \delta \mathrm{cKO} / \mathrm{sGluA} 1, \mathrm{n}=14 ; \Delta \mathrm{Cre} / \mathrm{PTP} \delta \mathrm{cKO} / \mathrm{GluA} 1, \mathrm{n}=$ 14; $\mathrm{Cre} / \mathrm{PTP} \delta \mathrm{cKO} / \mathrm{GluA} 1, \mathrm{n}=15 ; \Delta \mathrm{Cre} / \mathrm{PTP} \delta \mathrm{cKO} / \mathrm{Shank}, \mathrm{n}=21$; Cre/PTP $\delta \mathrm{cKO} / \mathrm{Shank}, \mathrm{n}=$ 21; $\Delta \mathrm{Cre} / \mathrm{PTP} \delta \mathrm{cKO} / \mathrm{VGLUT} 1, \mathrm{n}=15 ; \mathrm{Cre} / \mathrm{PTP} \delta \mathrm{cKO} / \mathrm{VGLUT} 1, \mathrm{n}=16 ; \Delta \mathrm{Cre} / \mathrm{PTP} \delta$

$\mathrm{cKO} / \mathrm{sGABA}_{\mathrm{A}} \mathrm{R} \gamma 2, \mathrm{n}=16 ; \mathrm{Cre} / \mathrm{PTP} \delta \mathrm{cKO} / \mathrm{sGABA}_{\mathrm{A}} \mathrm{R} \gamma 2, \mathrm{n}=17 ; \Delta \mathrm{Cre} / \mathrm{PTP} \delta \mathrm{cKO} / \mathrm{GABA}_{\mathrm{A}} \mathrm{R} \gamma 2$, $\mathrm{n}=10 ; \mathrm{Cre} / \mathrm{PTP} \delta \mathrm{cKO} / \mathrm{GABA}_{\mathrm{A}} \mathrm{R} \gamma 2, \mathrm{n}=10 ; \Delta \mathrm{Cre} / \mathrm{PTP} \delta \mathrm{cKO} / \mathrm{Gephyrin,} \mathrm{n}=16 ; \mathrm{Cre} / \mathrm{PTP} \delta$ cKO/Gephyrin , $\mathrm{n}=16 ; \Delta \mathrm{Cre} / \mathrm{PTP} \delta \mathrm{cKO} / \mathrm{GAD} 67, \mathrm{n}=16$; and Cre/PTP $\delta \mathrm{cKO} / \mathrm{GAD} 67, \mathrm{n}=16$. Mann-Whitney U test; $\left.{ }^{*} p<0.05 ;{ }^{* *} p<0.01 ;{ }^{* * *} p<0.001 ;{ }^{* * * *} p<0.0001\right)$.

D, E Representative mEPSC traces (D) and quantification of frequencies, amplitudes and kinetics $(\mathbf{E})$ of mEPSCs recorded from hippocampal cultured neurons derived from $P T P \sigma^{f f f}$ mice infected with lentiviruses expressing inactive $(\Delta \mathrm{Cre})$ or active $(\mathrm{Cre})$ cre-recombinase. Data are means \pm SEMs (n denotes number of analyzed neurons; $\triangle \mathrm{Cre}, 20$ and $\mathrm{Cre}, 15$; Unpaired $\mathrm{t}-$ test; $\left.{ }^{*} p<0.05\right)$

F, G Representative mIPSC traces $(\mathbf{F})$ and quantification of frequencies, amplitudes and kinetics (G) of mIPSCs recorded from hippocampal cultured neurons derived from $P T P \sigma^{f / f}$ mice infected with lentiviruses expressing $\Delta$ Cre or Cre. Data are means \pm SEMs (n denotes number of analyzed neurons; $\Delta \mathrm{Cre}, 18$ and Cre, 17 ; Unpaired t-test)

H, I Representative mEPSC traces $(\mathbf{H})$ and quantification of frequencies, amplitudes and 
kinetics (I) of mEPSCs recorded from hippocampal cultured neurons derived from $P T P \delta^{f f f}$ mice infected with lentiviruses expressing $\Delta$ Cre or Cre. Data are means \pm SEMs (n denotes number of analyzed neurons; $\Delta \mathrm{Cre}, 19$ and $\mathrm{Cre}, 13$; Unpaired t-test)

$\mathbf{J}, \mathbf{K}$ Representative mIPSC traces ( $\mathbf{J})$ and quantification of frequencies, amplitudes and kinetics (K) of mIPSCs recorded from hippocampal cultured neurons derived from $P T P \delta^{f f}$ mice infected with lentiviruses expressing $\Delta$ Cre or Cre. Data are means \pm SEMs ( $\mathrm{n}$ denotes number of analyzed neurons; $\Delta \mathrm{Cre}, 18$ and Cre, 16; Unpaired t-test).

\section{Figure 2. PTPб deletion induces abnormal organization of synapse structures}

A Representative electron micrographs of hippocampal neurons cultured from $P T P \sigma^{f / f}$ mice infected with lentiviruses expressing $\Delta \mathrm{Cre}$ (control) or Cre.

B, C PTP $\sigma$ deletion increases length of synaptic membranes. Cumulative distribution of the lengths of AZ $(\mathbf{B})$ and PSD $(\mathbf{C})$ for the indicated genotypes. Data are means \pm SEMs (n denotes the number of analyzed neurons; $\Delta \mathrm{Cre}, 100$ and Cre, $88 ;{ }^{*} p<0.05 ;{ }^{* * *} p<0.001$; Mann Whitney U-test).

D-F Total numbers of vesicles per bouton (D), membrane-proximal vesicles (E), and membrane-tethered vesicles $(\mathbf{F})$ of control and PTP $\sigma$-deficient synapses. Data are means \pm SEMs (n denotes the number of analyzed neurons; $\Delta$ Cre, 100 and Cre, $88 ;{ }^{*} p<0.05$; Mann 
Whitney U-test).

G Quantitative immunoblot analysis of PTPs, AZ proteins, and PSD proteins from control and

Nestin-PTP $\sigma$ mice. Data are means \pm SEMs $\left(\mathrm{n}=4\right.$ mice per group $\left.;{ }^{*} p<0.05\right)$.

H Representative electron micrographs of hippocampal neurons cultured from $P T P \delta^{f / f}$ mice

infected with lentiviruses expressing $\Delta$ Cre (control) or Cre.

I, J PTP $\delta$ deletion has no effect on the length of synaptic membranes. Cumulative distribution of the lengths of AZ (I) and PSD (J) for the indicated genotypes. Data are means \pm SEMs (n denotes the number of analyzed neurons; $\Delta \mathrm{Cre}, 88$ and $\mathrm{Cre}, 105)$.

K-M Total number of vesicles per bouton $(\mathbf{K})$, membrane-proximal vesicles $(\mathbf{L})$, and membrane-tethered vesicles $(\mathbf{M})$ of control and PTP $\delta$-deficient synapses. Data are means \pm SEMs (n denotes the number of analyzed neurons; $\Delta \mathrm{Cre}, 88$ and $\mathrm{Cre}, 105$ ).

N Quantitative immunoblot analysis of PTPs, AZ proteins, and PSD proteins from control and Nestin-PTP $\delta$ mice. Levels of RIM1 and RIM2 expression were significantly lower in PTP $\delta$ deficient than in control mice. Data are means \pm SEMs $\left(n=4\right.$ mice per group; ${ }^{*} p<0.05$; Mann Whitney U-test).

Figure 3. PTPo deletion reduces vesicle localization in excitatory presynaptic boutons

A Representative traces of AMPAR-EPSCs evoked by single $2 \mathrm{sec}$ pulse of $0.5 \mathrm{M}$ sucrose 
delivered at a 1-min interval, recorded from hippocampal cultured neurons derived from $P T P \sigma^{f / f}$ mice infected with lentiviruses expressing inactive $(\triangle \mathrm{Cre})$ or active (Cre) crerecombinase.

B, C Bar graphs showing charge transfer $(\mathbf{B})$ and peak amplitudes $(\mathbf{C})$ of sucrose-evoked EPSCs, estimated as the synaptic charge transfer integrated over $30 \mathrm{sec}$. Recordings were performed in the presence of $1 \mu \mathrm{M}$ tetrodoxin and $50 \mu \mathrm{M}$ picrotoxin. Data are means \pm SEMs (n denotes number of analyzed neurons; $\Delta \mathrm{Cre}, 26$ and Cre, $\left.29 ;{ }^{*} p<0.05 ;{ }^{* * *} p<0.001\right)$.

D Representative images of cultured neurons (DIV10) derived from $P T P \sigma^{f f f}$ mice infected with lentiviruses expressing $\Delta$ Cre or Cre at DIV3 and transfected with VGLUT1-Venus (green) at DIV8. Anti-Bassoon (red) was used to mark the presynaptic active zone. Scale bar: $10 \mu \mathrm{m}$.

E Quantification of synaptic vesicle diffusion from images in (D), determined by measuring the average length of the major axis of VGLUT1-Venus fluorescence in transfected axons. Data are means \pm SEMs ( $n$ denotes the number of analyzed neurons; $\Delta$ Cre, $n=19 ;$ Cre, $n=18$; $\mathrm{Cre}+/ \mathrm{PTP} \sigma \mathrm{WT}, \mathrm{n}=15 ; \mathrm{Cre}+/ \mathrm{PTP} \sigma \mathrm{C} 1157 \mathrm{~S}, \mathrm{n}=15 ;$ and $\mathrm{Cre}+/ \mathrm{PTP} \sigma \Delta \mathrm{D} 2, \mathrm{n}=17 ;{ }^{* * * *} p<$ 0.0001; ANOVA with a non-parametric Kruskal-Wallis test).

F Quantification of VGLUT1-Venus fluorescence enrichment at presynaptic active zone for the images in (D). Data are means \pm SEMs ( $\mathrm{n}$ denotes the number of analyzed neurons; $\Delta \mathrm{Cre}, \mathrm{n}=$ 
19; Cre, $\mathrm{n}=18 ; \mathrm{Cre}+/ \mathrm{PTP} \sigma \mathrm{WT}, \mathrm{n}=15 ; \mathrm{Cre}+\mathrm{PTP} \sigma \mathrm{C} 1157 \mathrm{~S}, \mathrm{n}=15 ;$ and $\mathrm{Cre}+/ \mathrm{PTP} \sigma \Delta \mathrm{D} 2, \mathrm{n}=$

17; ANOVA with a non-parametric Kruskal-Wallis test).

Figure 4. Wfs1-PTP $\sigma$ KO mice exhibit decreased excitatory synaptic innervation in

\section{postsynaptic target neurons}

A Schematic depiction of anatomical analyses in the subiculum (SuB; left) and the medial prefrontal cortex (mPFC; right). Each subiculum was divided into the proximal and distal subiculum.

B, G Representative immunofluorescence images of the proximal and distal SuB of $\mathrm{Ctrl}$ and

Wfs1-PTP $\sigma$ mice using VGLUT1 (B) or GAD67 (G). Scale bar: $20 \mu \mathrm{m}$.

$\mathbf{C , ~ H}$ Quantification of the density, size and integrated intensity of VGLUT1-positive (C) and

GAD67-positive $(\mathbf{H})$ synaptic puncta in the proximal SuB. Data are means \pm SEMs (n denotes the number of analyzed brain mice; 8 mice per each group; ${ }^{* *} p<0.01$ and ${ }^{* * *} p<0.001$; Mann Whitney U-test).

D, I Quantification of the density, size and integrated intensity of VGLUT1-positive (D) and GAD67-positive (I) synaptic puncta in the distal SuB. Data are means \pm SEMs (n denotes the number of analyzed mice; 8 mice per each group; ${ }^{* *} p<0.01,{ }^{* * *} p<0.001$; Mann Whitney Utest). 
E, J Representative immunofluorescence images of the mPFC layer V of Ctrl and Wfs1-PTP $\sigma$ mice using VGLUT1 (E) or GAD67 (J). Scale bar: $20 \mu \mathrm{m}$.

F, K Quantification of the density, size and integrated intensity of VGLUT1-positive (F) and GAD67-positive $(\mathbf{K})$ synaptic puncta in the mPFC layer V. Data are means \pm SEMs (n denotes the number of analyzed brain mice; 8 mice per each group; Mann Whitney U-test).

Figure 5. Presynaptic deletion of PTP at excitatory synapses of postsynaptic target neurons

A Experimental strategies for electrophysiological recordings in mPFC and hippocampal SuB neurons of Wfs $1-P T P \sigma$ mice.

B, D Representative traces of paired pulse ratios (PPRs) of EPSCs (B) and IPSCs (D) in synapses of mPFC layer II to layer V at two different interstimulus intervals (20 and $50 \mathrm{~ms}$ for EPSC-PPRs and 20 and $50 \mathrm{~ms}$ for IPSC-PPRs).

C, E EPSC-PPRs (C) and IPSC-PPRs (E) in synapses of mPFC layers II-V as a function of the indicated interstimulus intervals. Data are means $\pm \operatorname{SEMs~}\left({ }^{* *} p<0.01,{ }^{* * * *} p<0.001\right.$; two-tailed Student's t-test).

F Representative traces of paired pulse ratios (PPRs) of EPSCs in hippocampal CA1-SuB synapses at two different interstimulus intervals (20 and $50 \mathrm{~ms}$ ). 
G EPSC-PPRs in hippocampal CA1-SuB synapses as a function of the indicated interstimulus intervals. Data are means $\pm \operatorname{SEMs}\left({ }^{* *} p<0.01\right.$; two-tailed student's t-test).

Figure 6. Postsynaptic deletion of PTPб exerts no effects on excitatory synapse

\section{organization in hippocampal CA1 region}

A, F Representative immunofluorescence images of the stratum radiatum (SR) and stratum oriens (SO) layer of control and Wfs1-PTP $\sigma$ mice using VGLUT1 (A) or GAD67 (F). Scale bar: $20 \mu \mathrm{m}$.

B, C Quantification of the density, size and integrated intensity of VGLUT1-positive synaptic puncta in the SO $(\mathbf{B})$ and SR $(\mathbf{C})$ layers of the hippocampal CA1 region. Data are means \pm SEMs ( $\mathrm{n}=8$ mice per each group; Mann Whitney U-test).

D, E Representative traces (D) of evoked EPSCs at holding potentials of $-70 \mathrm{mV}$ and $+40 \mathrm{mV}$ in control and Wfs1-PTP $\sigma$ mice. (E) AMPAR/NMDAR ratios, calculated by dividing the EPSC peak amplitude at $10 \mathrm{~ms}(-70 \mathrm{mV})$ by the EPSC amplitude at $130 \mathrm{~ms}(+40 \mathrm{mV})$. Data are means \pm SEMs $(\mathrm{n}=14$ cells from 4-5 mice; two-tailed student's t-test).

G-I Quantification of the density, size and integrated intensity of GAD67-positive synaptic puncta in the SO $(\mathbf{G})$, SR $(\mathbf{H})$ and SP (I) layers of the hippocampal CA1 region. Data are means \pm SEM ( $\mathrm{n}=8$ mice per each group; Mann Whitney U-test). 
Figure 7. Presynaptic deletion of PTPo in ventral hippocampal CA1 selectively induces

\section{abnormal anxiety-like behavior}

A-C Analysis of control and Wfs1-PTP $\sigma$ mice in the elevated-plus maze (EPM) tests.

Representative heat map (A) and graphs showing time spent in open arms (B) and number of entries $(\mathbf{C})$. Data are means \pm SEMs (control, $\mathrm{n}=24$; Wfs1-PTP $\sigma, \mathrm{n}=23 ;{ }^{*} p<0.05$; Mann Whitney U-test).

D-F Analysis of control and Wfs1-PTP $\sigma$ mice in three-chamber tests. Representative heat map (D) and quantification of sociability (E) and social novelty (F). Sniffing time was defined as the time spent sniffing the novel mouse and the novel object. Abbreviations: E, empty cup; S1: stranger mouse 1; S2: stranger mouse 2. Data are means \pm SEMs (control, $n=21$; and Wfs1$P T P \sigma, \mathrm{n}=24 ;{ }^{*} p<0.05,{ }^{* *} p<0.01,{ }^{* * * *} p<0.0001 ;$ Mann Whitney U-test).

G Schematic diagram of mouse behavior. AAV- $\Delta$ Cre or AAV-Cre was bilaterally injected into the ventral CA1 (vCA1) region of the hippocampus of $\sim 6$ week-old $\mathrm{PTP}^{\mathrm{f} / \mathrm{f}}$ mice. Four weeks later, these mice were subjected to the EPM and three-chamber tests in the indicated order. Abbreviation: EPM, elevated plus-maze test.

H Representative coronal section showing EGFP expression after AAV injection the vCA1. Scale bar, $1 \mathrm{~mm}$. 
I-K Analysis of $\Delta$ Cre- and Cre-injected PTP $^{\mathrm{f} / \mathrm{f}}$ mice in the elevated-plus maze (EPM) tests.

Representative heat map (I) and graphs showing time spent in open arms (J) and number of entries $(\mathbf{K})$. Data are means \pm SEMs $\left(\mathrm{PTP}^{f / f}+\Delta \mathrm{Cre}, \mathrm{n}=11\right.$; and $\mathrm{PTP}^{f f f}+\mathrm{Cre}, \mathrm{n}=11 ;{ }^{* * *} p<$ $0.001,{ }^{* * * * *} p<0.0001 ;$ Mann Whitney U-test).

$\mathbf{L}-\mathbf{N}$ Analysis of $\Delta$ Cre- and Cre-injected $\mathrm{PTP}^{\mathrm{f} / \mathrm{f}}$ mice in three-chamber tests. Representative heat map (L) and quantification of sociability (M) and social novelty (N). Sniffing time was defined as time spent sniffing the novel mouse and the novel object. Abbreviations: E, empty cup; S1: stranger mouse 1; S2: stranger mouse 2. Data are means $\pm \mathrm{SEMs}\left(\mathrm{PTP \sigma}^{f / f}+\Delta \mathrm{Cre}, \mathrm{n}=\right.$ 11; and $\mathrm{PTP} \sigma^{\text {fff }}+\mathrm{Cre}, \mathrm{n}=11$ mice; ${ }^{*} p<0.05$; Mann Whitney U-test). 


\section{Expanded View Figure Legends}

\section{Expanded View Figure 1. Generation of PTP cKO mice}

A, B Conditional KO (cKO) strategy for PTP $\sigma(\mathbf{A})$ and PTP $\delta(\mathbf{B})$ mouse lines. Exon 4 of the PTP $\sigma$ gene and exon 12 of the PTP $\delta$ gene were targeted (left). Primer locations for the WT and post Flp alleles are indicated with arrows (middle). PCR genotyping of WT and PTP floxed mice (right).

C Quantitative RT-PCR analysis of neuron RNA. Relative levels of PTP $\sigma$, PTP $\delta$, and LAR mRNAs were measured in cultured cortical neurons infected with lentiviruses expressing Crerecombinase. Data are means \pm SEMs ( $n=4$ independent experiments).

D Representative immunoblot analysis of level of PTP $\sigma$ and PTP $\delta$ proteins in brain homogenates from 8-week old control and PTP cKO mice. Levels of PTP $\sigma$ and PTP $\delta$ proteins were measured in the indicated PTP floxed mice crossed with Nestin-Cre mice (Nestin-PTP $\sigma$ or Nestin- $P T P \delta$ ) or respective PTP floxed mice (Ctrl). Arrows indicate band(s) immunoreactive with $\mathrm{PTP} \sigma$-specific and $\mathrm{PTP} \delta$-specific (JK179) antibodies.

E Images illustrating the body size of littermate control (Ctrl), Nestin-PTP $\sigma$ and Nestin-PTP $\delta$ mice at 2 months of age. Nestin- $P T P \sigma$ and Nestin- $P T P \delta$ mice were significantly smaller than age- and sex-matched Ctrl mice. 
F Birth rates of genotyped pups from breeding of $\mathrm{PTP}^{\mathrm{f} / \mathrm{f}}$ or $\mathrm{PTP}{ }^{\mathrm{f} / \mathrm{f}}$ mice with the corresponding

Nestin-PTP $\sigma^{f /+}$ or Nestin-PTP $\delta^{f /+}$ mice. Data are means \pm SEMs $(n=79$ for PTP $\sigma$ and 81 for PTP $\delta$ mice).

Expanded View Figure 2. Deletion of PTPo and PTPס from hippocampal CA1 specifically decreases innervation of excitatory and inhibitory synaptic inputs on subicular neurons, respectively

A, D Representative VGLUT1 (A) and GAD67 (D) positive immunofluorescence images of proximal and distal SuB of $P T P \sigma^{\text {fff }}$ mice injected with AAV- $\triangle$ Cre or AAV-Cre. Scale bar: $20 \mu \mathrm{m}$.

B, E Quantification of the density, size and integrated intensity of VGLUT1-positive (B) and GAD67-positive (E) synaptic puncta in proximal SuB. Data are means \pm SEMs (n denotes the number of analyzed brain slices; $18-19$ brain slices from 4 mice; ${ }^{* *} p<0.01$; Mann Whitney Utest).

C, F Quantification of the density, size and integrated intensity of VGLUT1-positive (C) and GAD67-positive (F) synaptic puncta in distal SuB. Data are means \pm SEMs (n denotes the number of analyzed brain slices; 18-19 brain slices from 4 mice; Mann Whitney U-test).

G, J Representative VGLUT1 (G) and GAD67 (J) positive immunofluorescence images of proximal and distal SuB of $P T P \delta^{f f f}$ mice injected with AAV- $\triangle$ Cre or AAV-Cre. Scale bar: $20 \mu \mathrm{m}$. 
$\mathbf{H}, \mathbf{K}$ Quantification of the density, size and integrated intensity of VGLUT1-positive (H) and GAD67-positive (K) synaptic puncta in proximal SuB. Data are means \pm SEMs (n denotes the number of analyzed brain slices; $13-14$ brain slices from 3 mice; ${ }^{*} p<0.05 ;{ }^{* *} p<0.01$; Mann Whitney U-test).

I, L Quantification of the density, size and integrated intensity of VGLUT1-positive (I) and GAD67-positive (L) synaptic puncta in distal SuB. Data are means \pm SEMs (n denotes the number of analyzed brain slices; 13-14 brain slices from 3 mice; Mann Whitney U-test).

Expanded View Figure 3. Marginal effect of presynaptic deletion of PTPo on excitatory and inhibitory synaptic transmission in pyramidal neurons of mPFC layer $\mathrm{V}$ and

\section{hippocampal subiculum}

A-C Representative sEPSC traces (A) recorded from mPFC layer V pyramidal neurons in acute mPFC slices from littermate control and Wfs1-PTP $\sigma$ mice, and cumulative distribution of sEPSC frequencies $(\mathbf{B})$ and amplitudes $(\mathbf{C})$. Insets show average sEPSC frequencies $(\mathbf{B})$ and amplitudes $(\mathbf{C})$. Data are means \pm SEMs (n denotes the number of analyzed neurons; Control, 13; and Wfs1-PTP $\sigma, 15$; two-tailed Student's t-tests).

D-F Representative mIPSC traces (D) recorded from mPFC layer V pyramidal neurons in acute mPFC slices from littermate control and Wfs1-PTP $\sigma$ mice, and cumulative distribution plots of 
mIPSC frequencies $(\mathbf{E})$ and amplitudes $(\mathbf{F})$. Insets show average mIPSC frequencies $(\mathbf{E})$ and amplitudes $(\mathbf{F})$. Data are means \pm SEMs (n denotes the number of analyzed neurons; Control, 14; and Wfs1-PTP $\sigma, 12$; two-tailed Student's t-tests).

G-I Representative sEPSC traces $(\mathbf{G})$ recorded from SuB pyramidal neurons in acute SuB slices from littermate control and Wfs1-PTP $\sigma$ mice, and cumulative distribution of sEPSC frequencies (H) and amplitudes (I). Insets show average sEPSC frequencies (H) and amplitudes (I). Data are means \pm SEMs (n denotes the number of analyzed neurons; Control, 12; and Wfs1-PTP $\sigma$, 21; two-tailed Student's t-tests).

$\mathbf{J}-\mathbf{L}$ Representative mEPSC traces $(\mathbf{J})$ recorded from CA1 pyramidal neurons in acute CA1 slices from littermate control and Wfs1-PTP $\sigma$ mice, and cumulative distribution plots of mEPSC frequencies $(\mathbf{K})$ and amplitudes $(\mathbf{L})$. Insets show average mEPSC frequencies $(\mathbf{K})$ and amplitudes $(\mathbf{L})$. Data are means \pm SEMs (n denotes the number of analyzed neurons; Control, 11 ; and Wfs1-PTP $\sigma, 13$; two-tailed Student's t-tests).

Expanded View Figure 4. Analysis of PTPo extracellular and intracellular mechanisms involved in controlling innervation of excitatory inputs in subiculum

A Schematic diagram of AAV constructs expressing PTP $\sigma$ WT and the indicated PTP $\sigma$ variants and experimental strategy (see Han et al, 2018). 
B Representative images of subiculum 3 weeks after stereotactic infection of Wfs1-PTP $\sigma$ mice with the indicated AAVs, followed by immunostaining for EGFP (green) to detect infected neurons and HA to detect the expression of AAV-rescue viruses (red). Scale bar, $20 \mu \mathrm{m}$.

C Representative immunofluorescence images of the proximal and distal subiculum of Wfs1-

$P T P \sigma$ mice 3 weeks after stereotactic injection of the indicated AAVs. Brain sections were

immunostained for VGLUT1 and HA to show neurons infected with the indicated AAVs. Scale bar: $20 \mu \mathrm{m}$.

D, E Quantification of the density, size and integrated intensity of VGLUT1-positive synaptic puncta in proximal (D) and distal (E) subicular neurons. Data are means \pm SEMs (n denotes the number of analyzed brain slices; $\mathrm{n}=14-18$ slices from 3 mice; ${ }^{*} p<0.05$, ANOVA with a nonparametric Kruskal-Wallis test).

Expanded View Figure 5. Wfs1-PTP $\sigma$ mice exhibit no altered behaviors, including changes in locomotion, light-induced anxiety-like behavior, spatial working memory, learning and memory

A, B Activities of control and Wfs1-PTP $\sigma$ mice in Laboras cages, where movements of mice were monitored for 48 hours. Data are means \pm SEMs (Control, $\mathrm{n}=16$; Wfs1-PTP $\sigma, \mathrm{n}=16$; Mann-Whitney U Test). 
C, D Analysis of the locomotor activity of Wfs1-PTP $\sigma$ mice by open field tests. Representative heat map (C) and graphs (D) showing comparable locomotor activity of control and Wfs1-PTP $\sigma$ mice, as recorded by distance moved, time spent in the center region of the open field arena, and frequency of entry into this region. Data are means \pm SEMs (Control, $\mathrm{n}=19$; Wfs $1-P T P \sigma, \mathrm{n}=$ 15; Mann-Whitney U test).

E, F Analysis of the light-induced anxiety-like behavior by light-dark transition tests in Wfs1$P T P \sigma$ mice. Representative heat map (E) and graphs (F) showing comparable light-induced anxiety-like behavior of control and Wfs1-PTP $\sigma$ mice, as measured by time spent in light box and number of total entries into the light chamber. Data are means \pm SEMs (Control, $n=18$; Wfs1-PTP $\sigma, \mathrm{n}=18$; Mann-Whitney U test).

G, H Analysis of the spatial working memory by Y-maze tests in Wfs1-PTP $\sigma$ mice. Representative heat map (E) and graphs (F) showing comparable spatial working memory of control and Wfs1-PTP $\sigma$ mice, as measured by spontaneous alternation performance ratio and total number of arm entries. Data are means \pm SEMs (Control, $\mathrm{n}=11$; Wfs1-PTP $\sigma, \mathrm{n}=11$; Mann-Whitney U test).

I, $\mathbf{J}$ Analysis of object recognition memory by novel object recognition tests in Wfs1-PTP $\sigma$ mice. Representative heat map (I) and graphs (J) showing comparable object recognition memory of control and Wfs1-PTP $\sigma$ mice, as measured by exploration times during the training 
and testing phases. Data are means \pm SEMs (Control, $\mathrm{n}=11$; Wfs $1-P T P \sigma, \mathrm{n}=11 ;{ }^{* *} p<0.01$;

Mann-Whitney U test).

$\mathbf{K}$, L Analysis of contextual fear memory by contextual fear conditioning tests in Wfs1-PTP $\sigma$

mice. Design of the contextual fear conditioning test $(\mathbf{K})$ and graphs $(\mathbf{L})$ showing comparable contextual memory of control and Wfs1-PTP $\sigma$ mice. Data are means \pm SEMs (Control, $\mathrm{n}=16$;

Wfs1-PTP $\sigma, \mathrm{n}=16,{ }^{* *} p<0.01$; Mann-Whitney U test). 
A Anatomical analyses in the subiculum

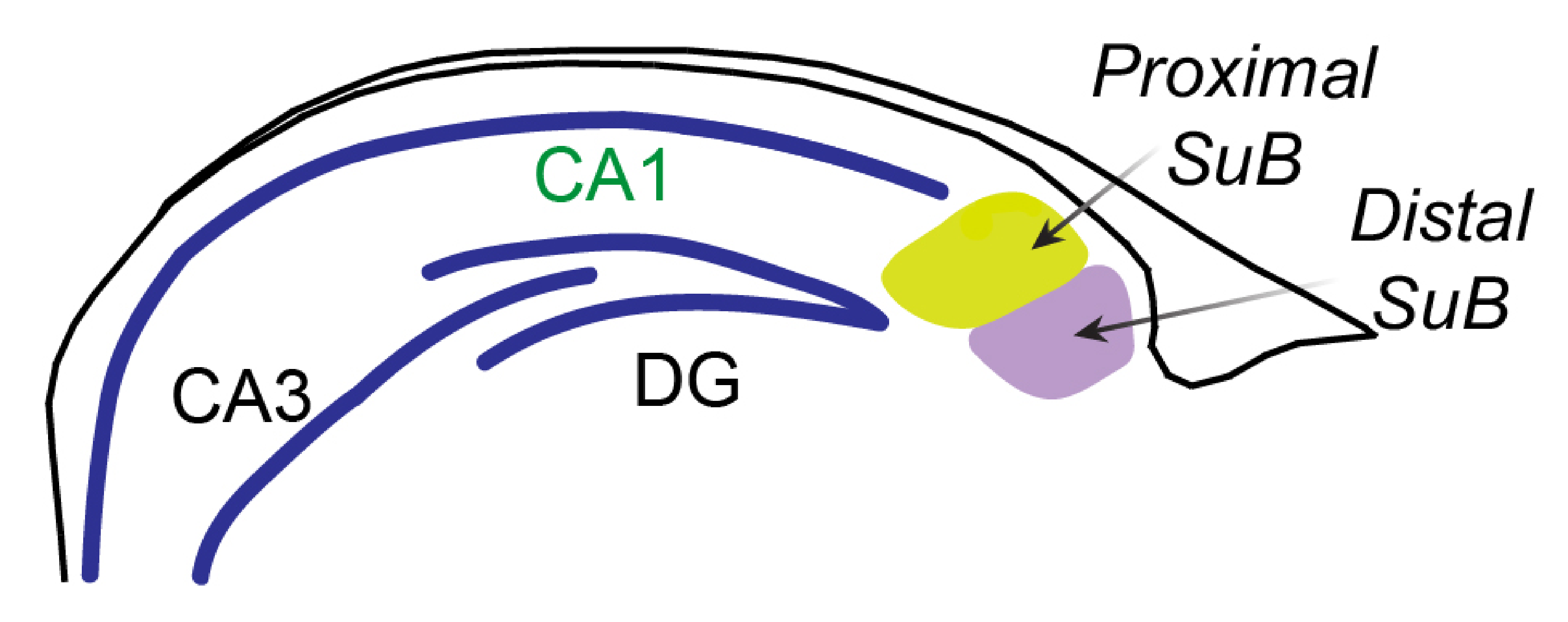

Anatomical analyses in the MPFC layer $V$

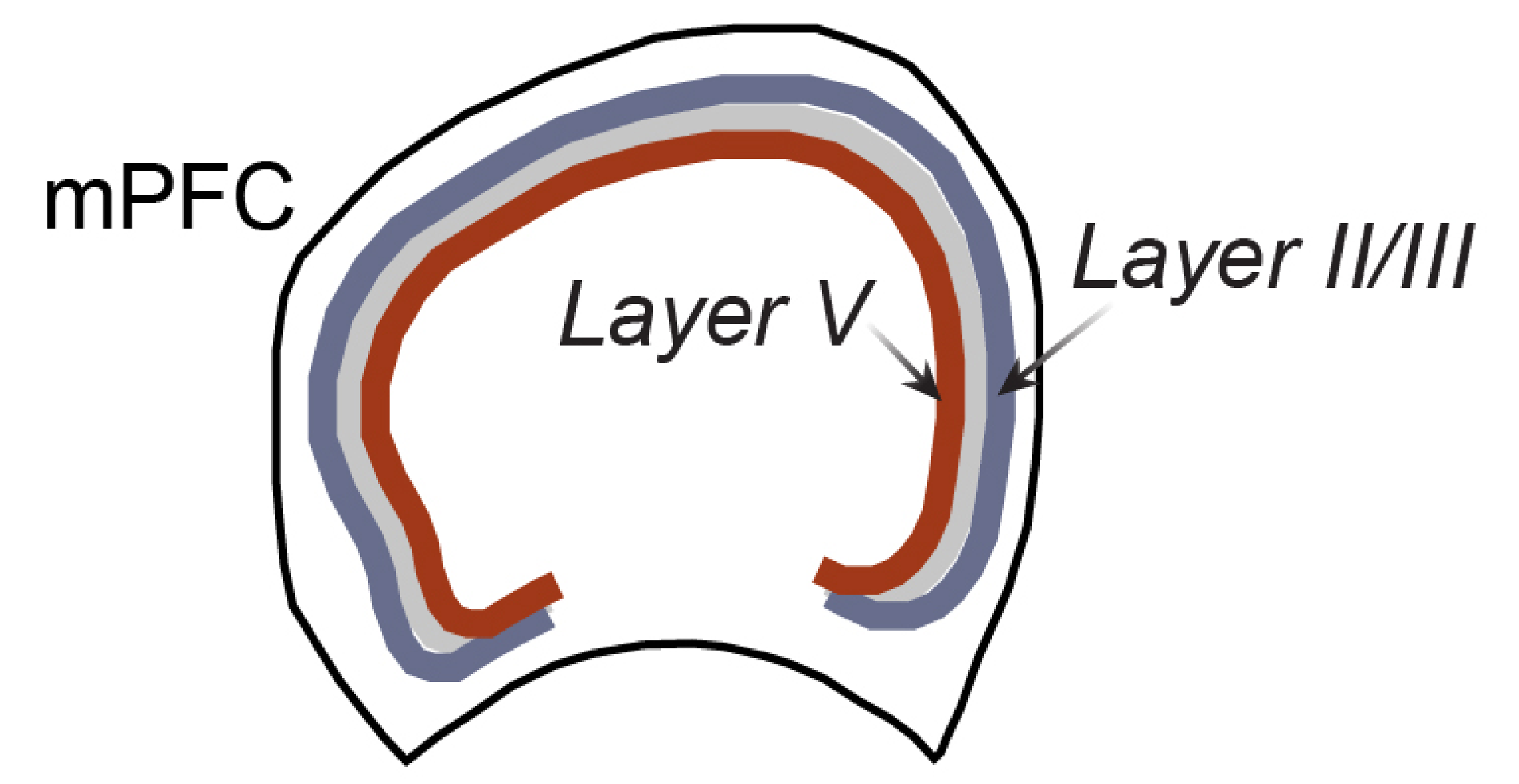

\section{Quantification of synaptic puncta in proximal \& distal SuB}

$B$
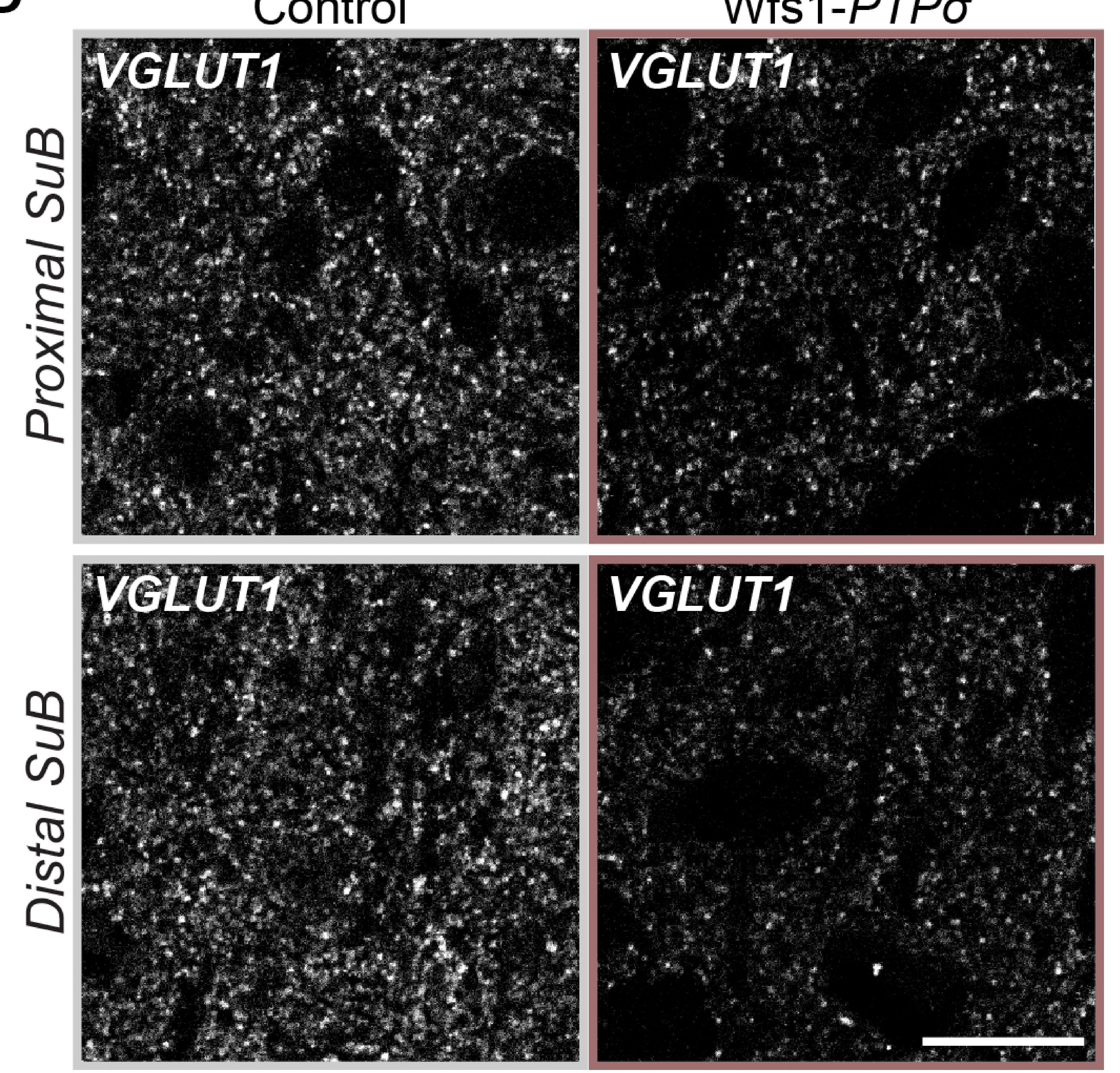

C

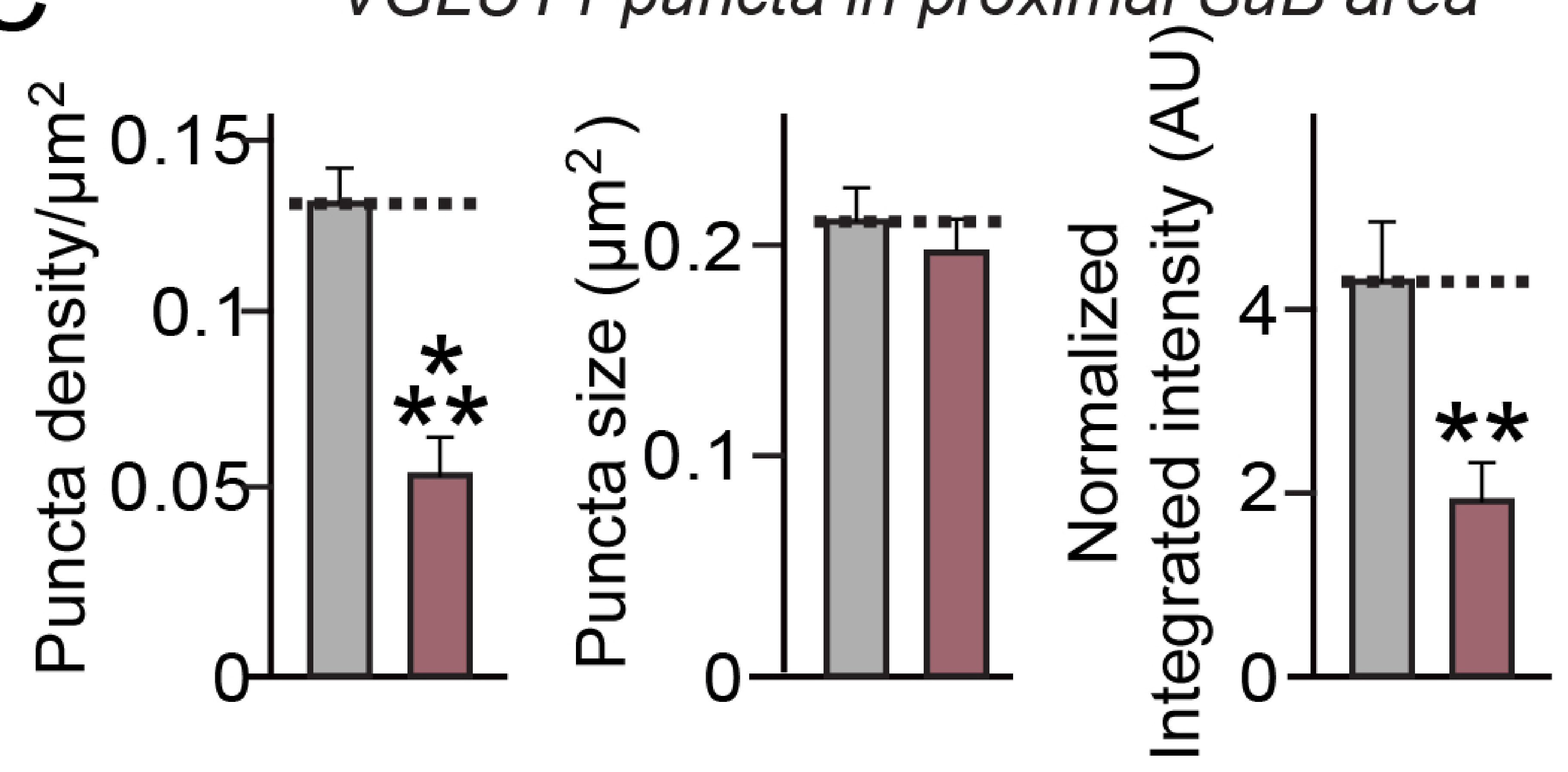

$\mathrm{D}$

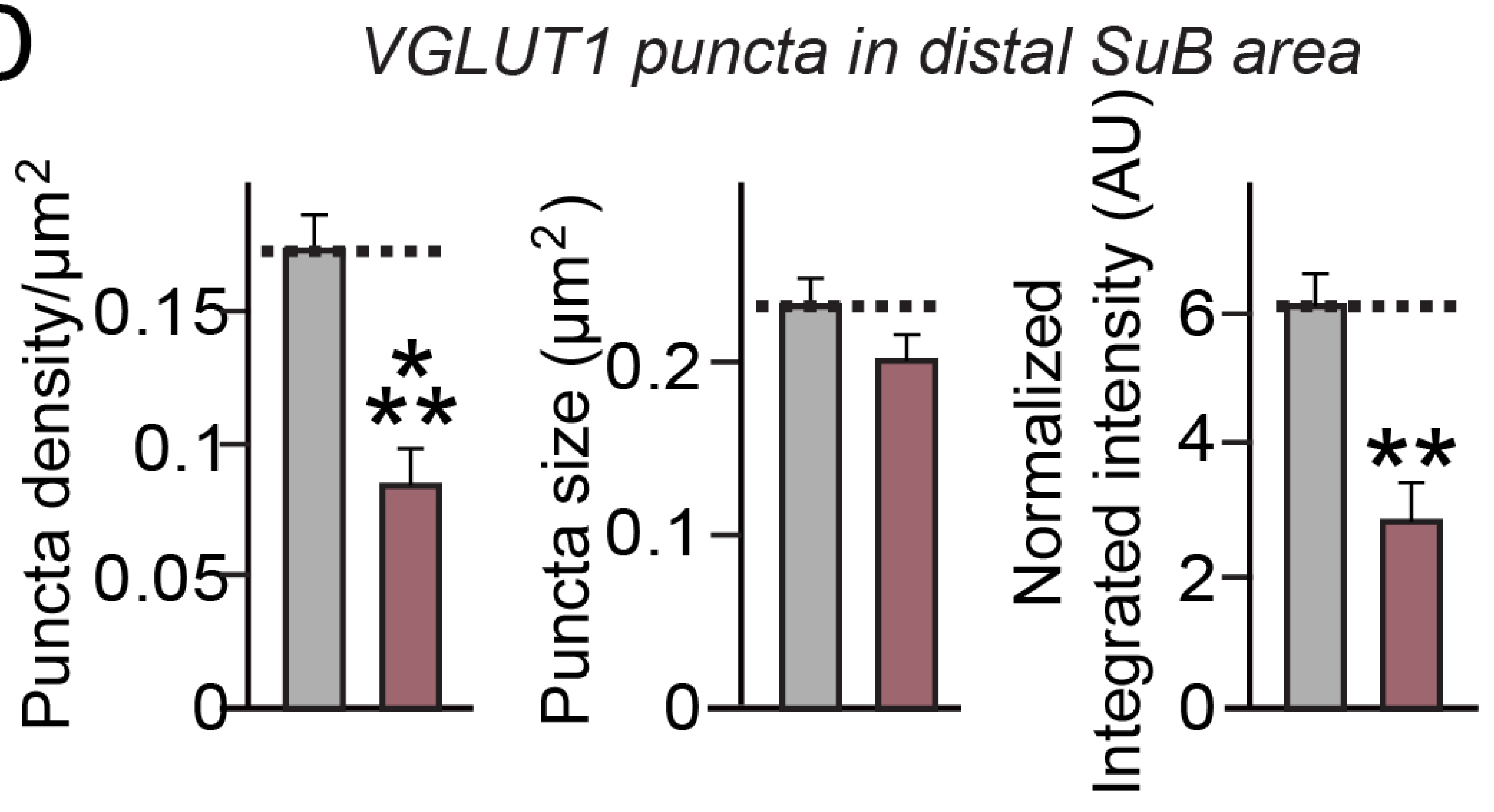

口Control aWfs1-PTPO
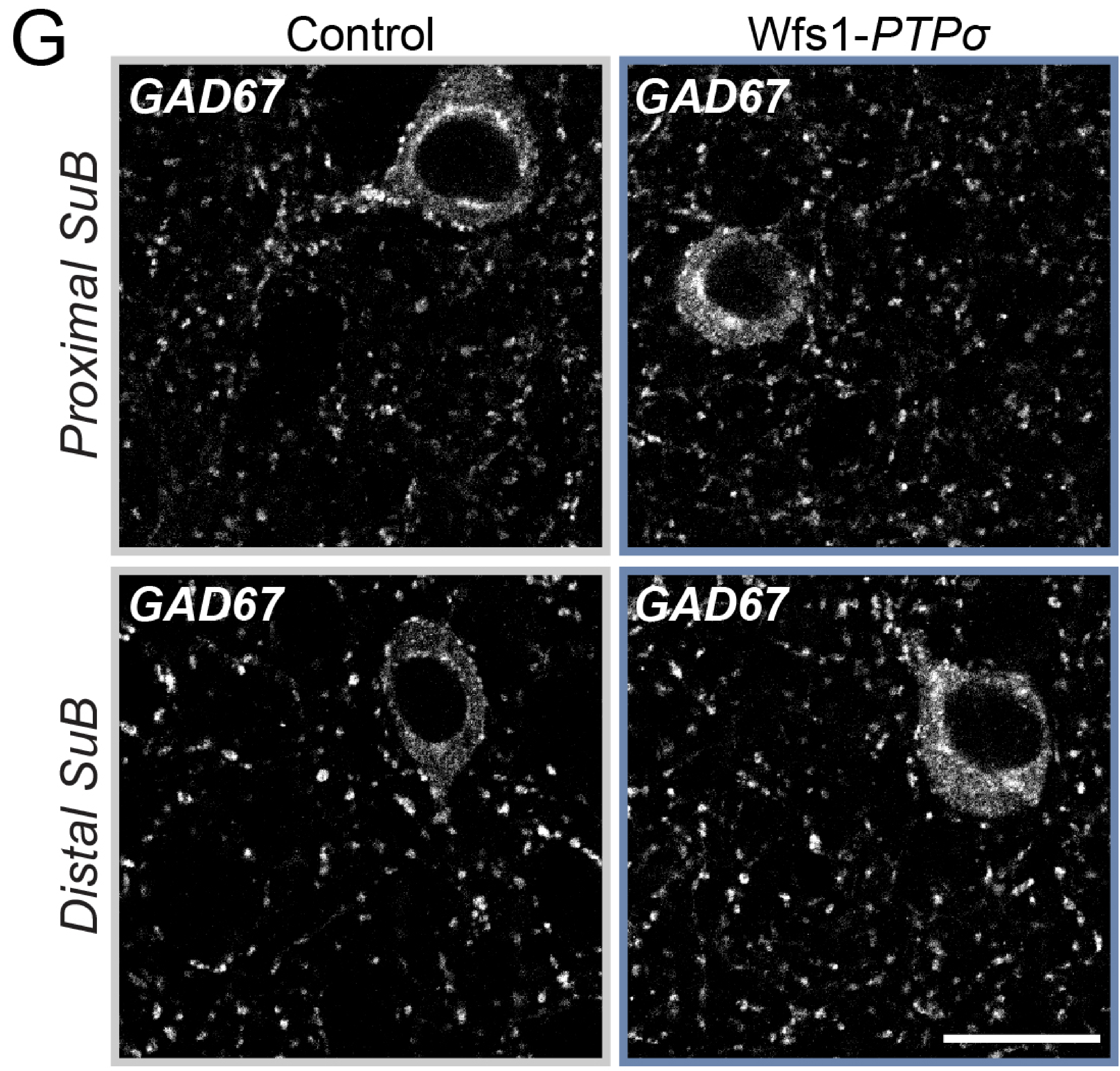

$\mathrm{H}$

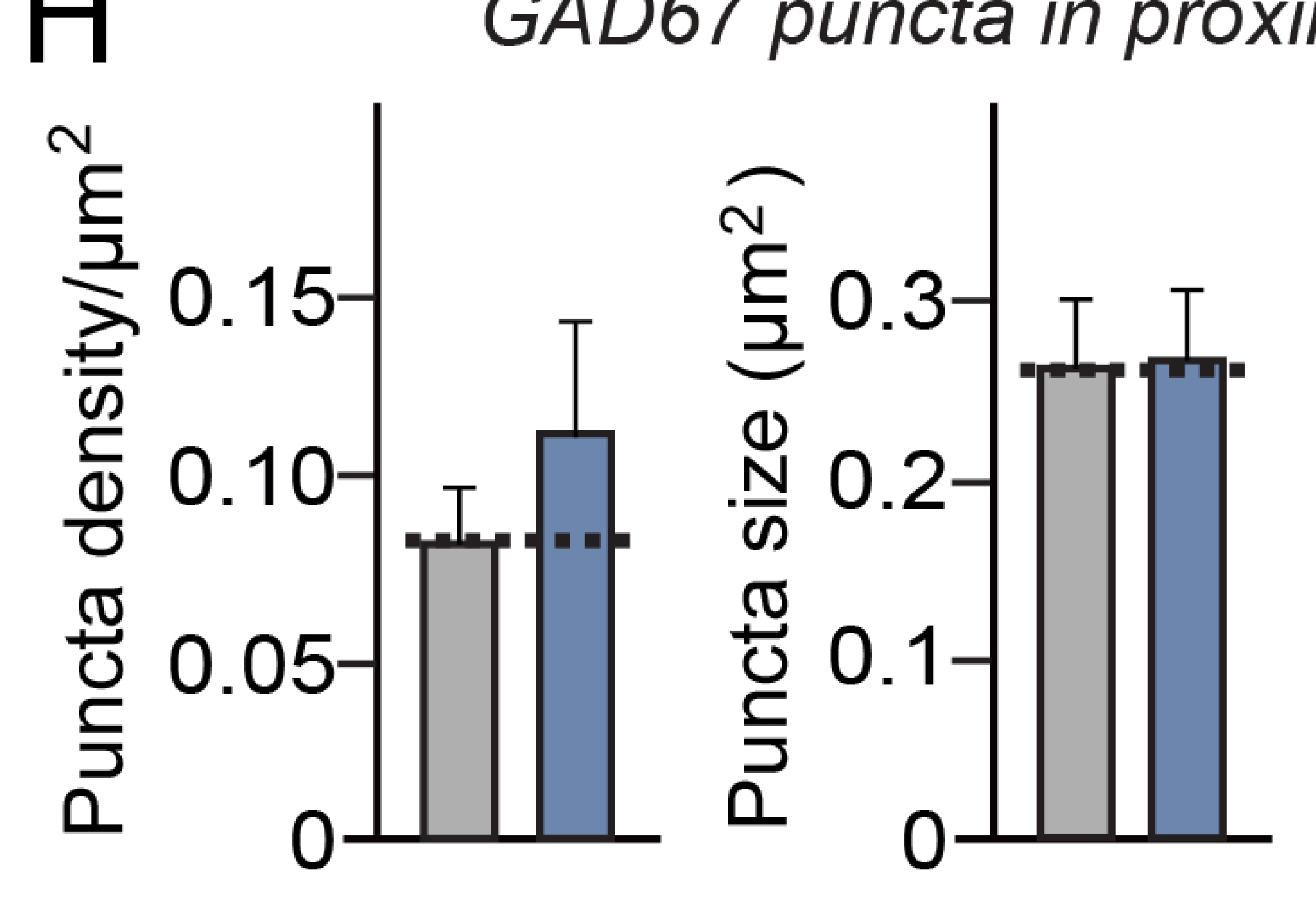

Wfs1-PTPo

imal SuB area

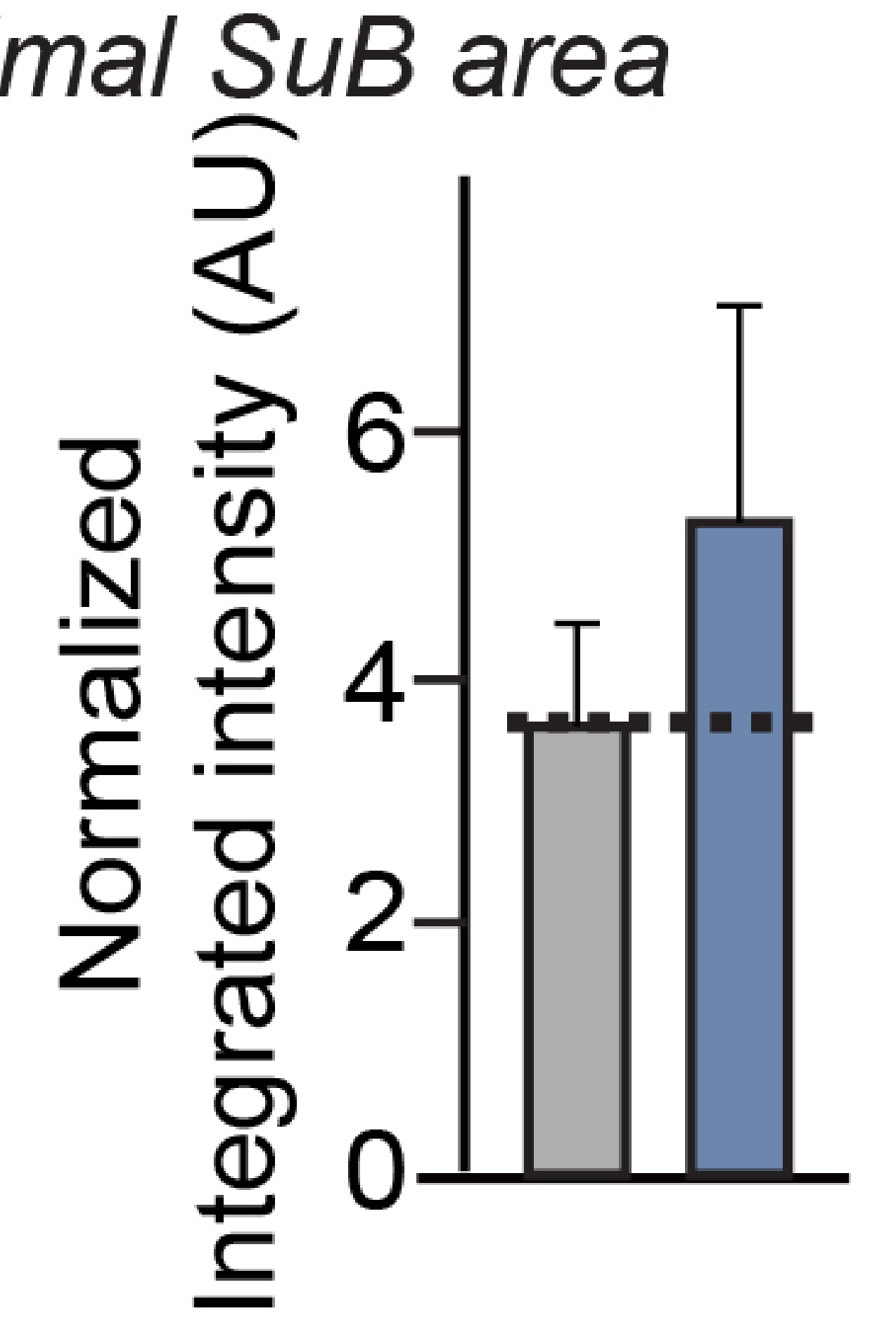

GAD67 puncta in distal SuB area

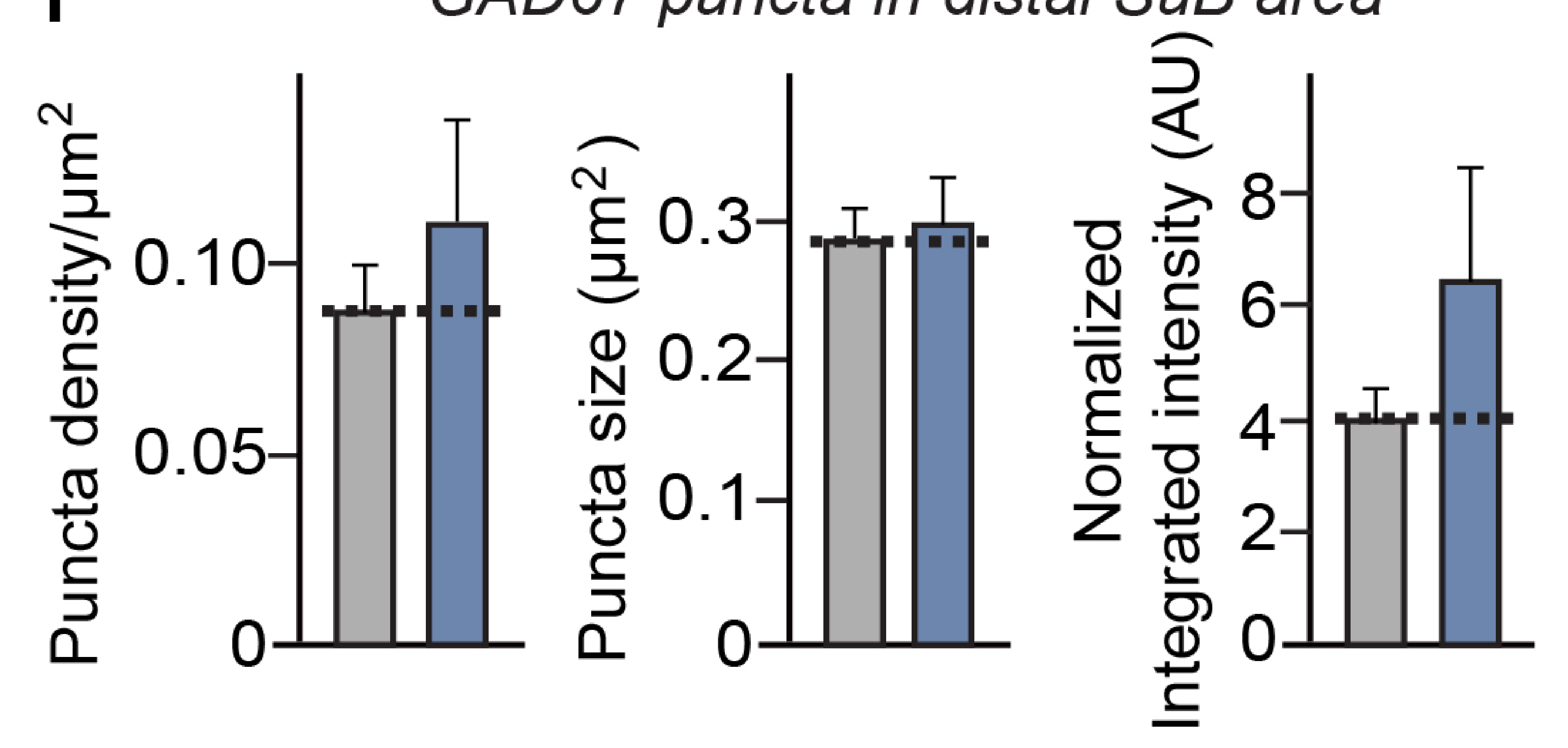

口Control $\square$ Wfs1-PTPo

Quantification of synaptic puncta in MPFC V layers

$E$
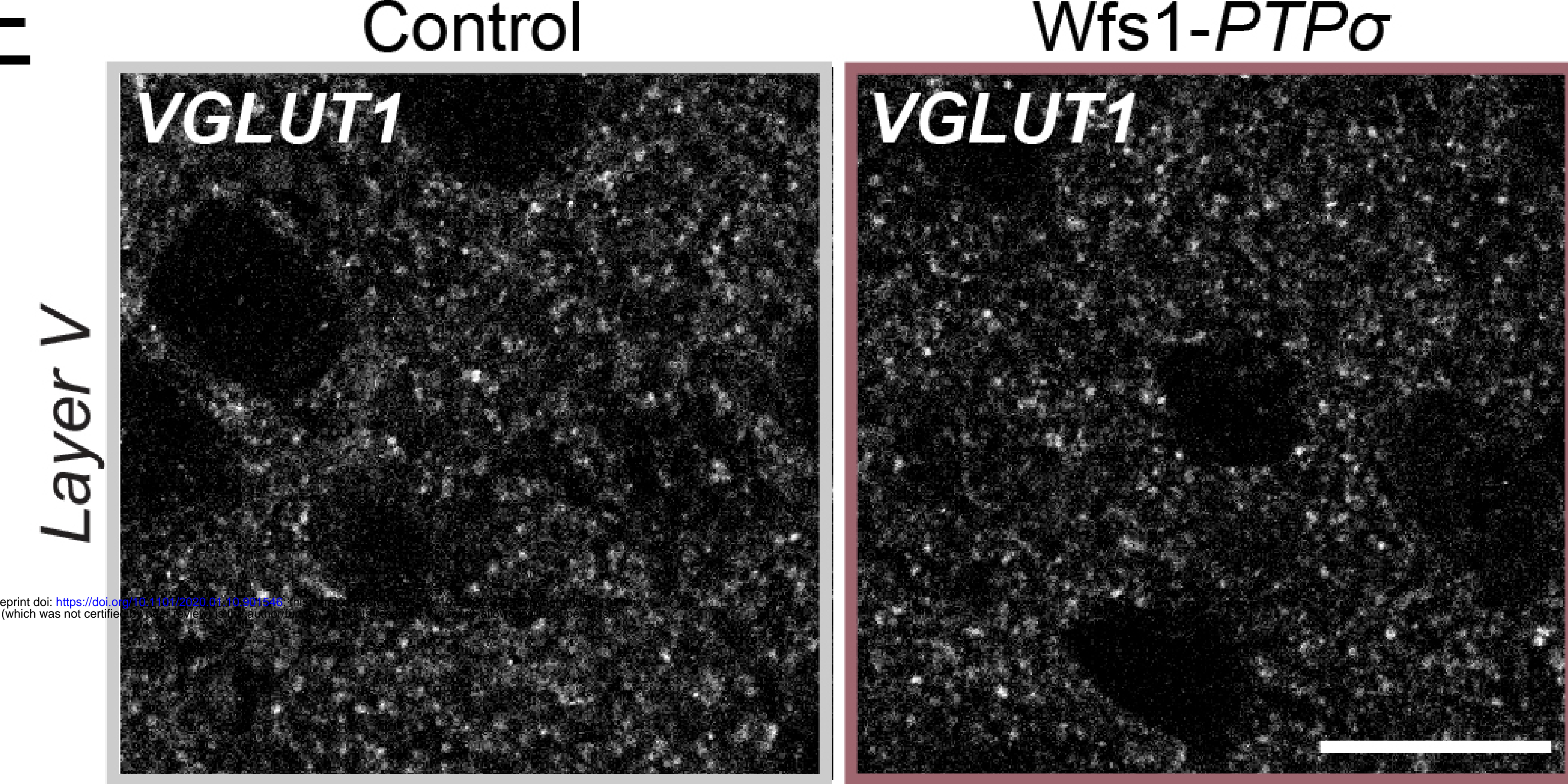

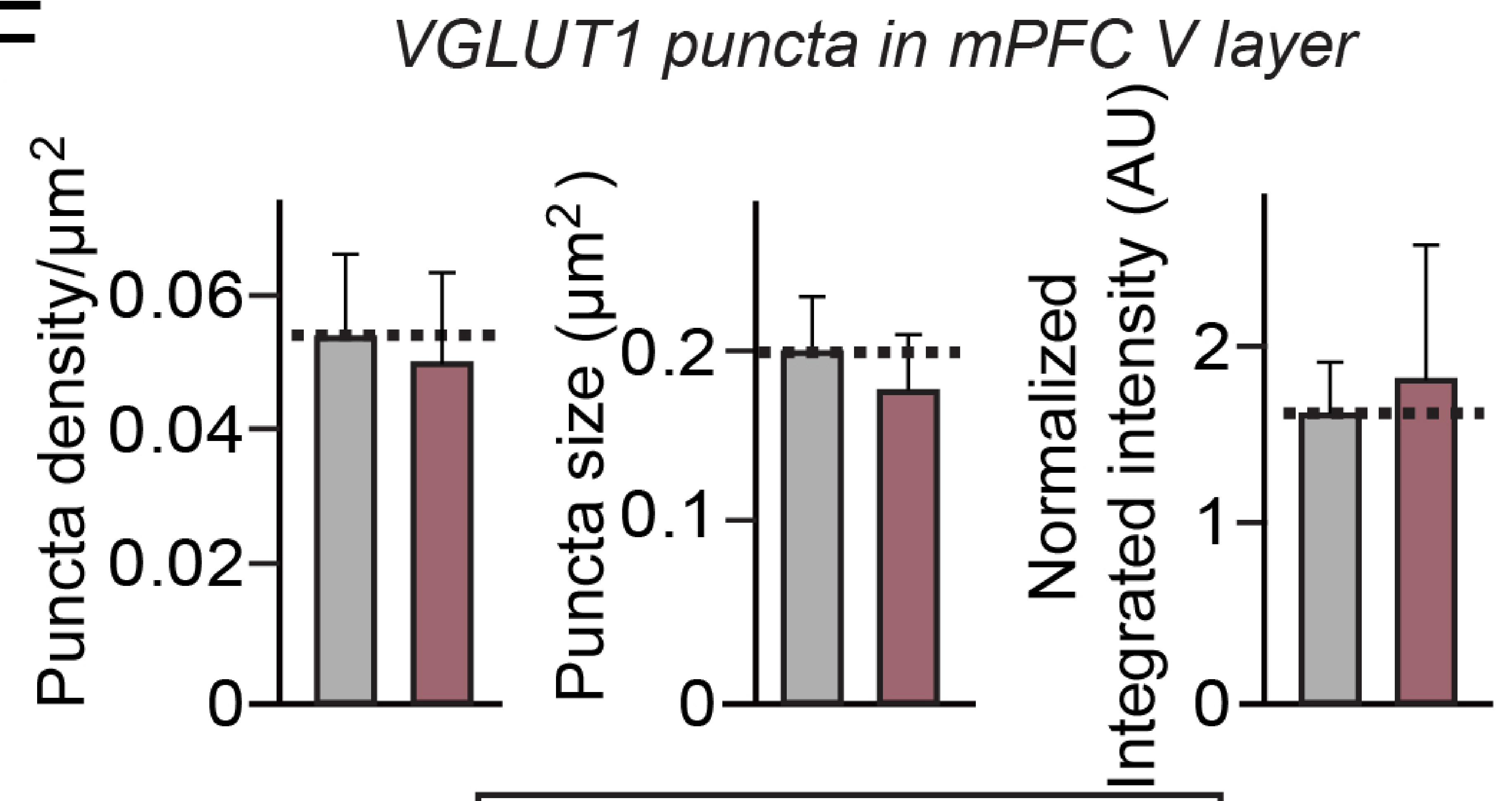

$\square$ Control $\square$ Wfs1-PTPo

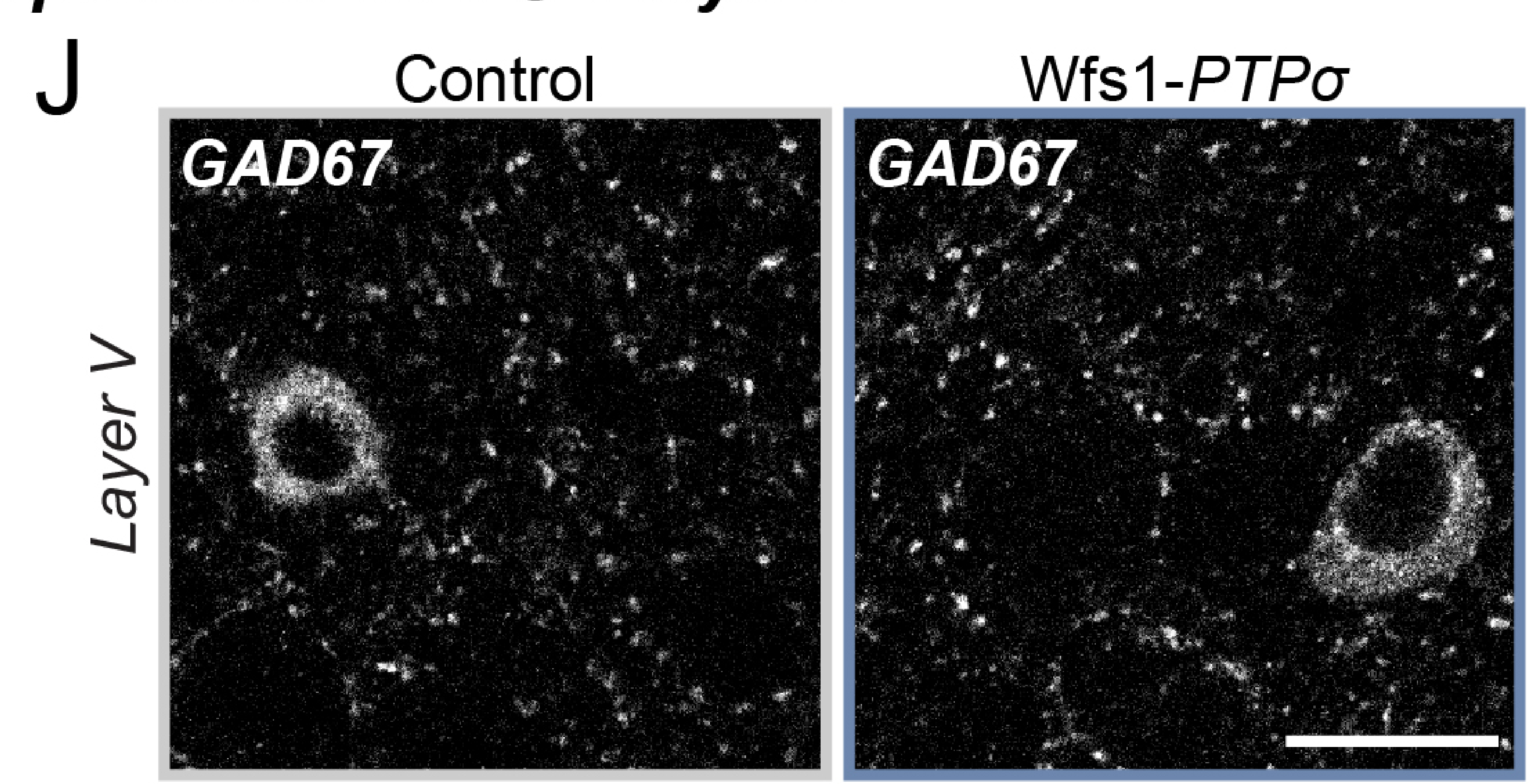

$\mathrm{K}$

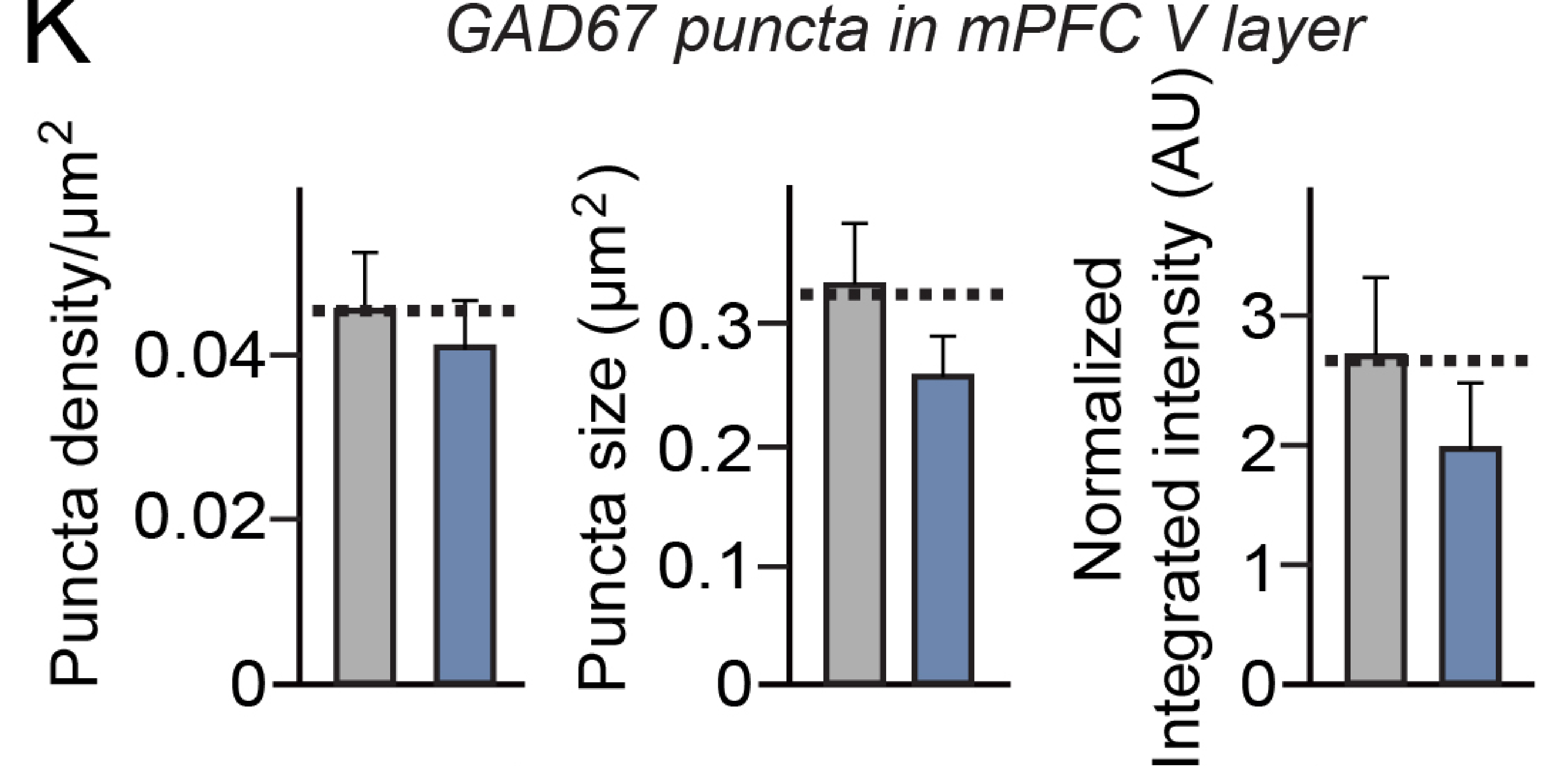

$\square$ Control $\square$ Wfs1-PTPo 

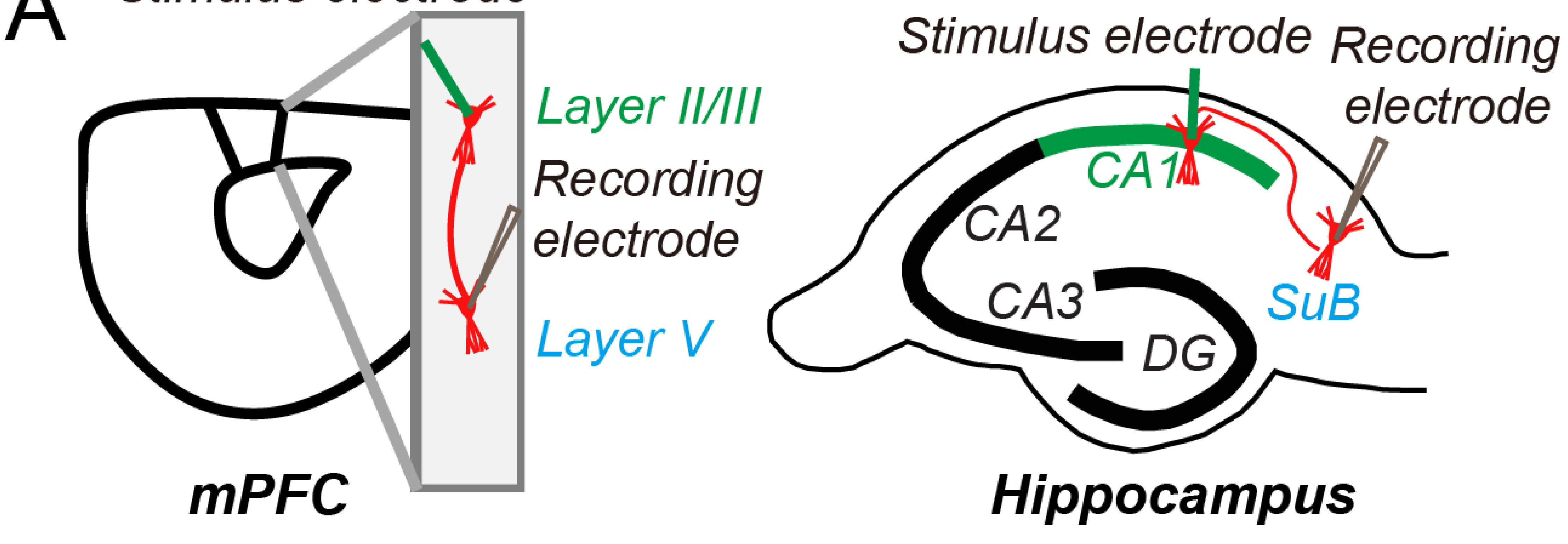

Experimental strategies for electrophysiological recordings

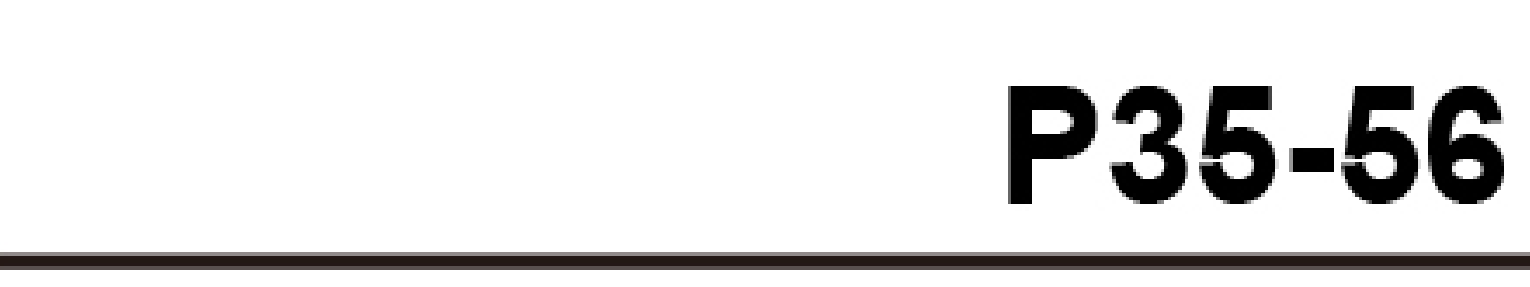

P56-63

Breeding of Wfs1-PTPo mice

Physiological analysis of presynaptic PTP deletion (paired-pulse ratios) in mPFC layer $V$ or SuB neurons

B EPSC-PPR (mPFC layer II to V) Control
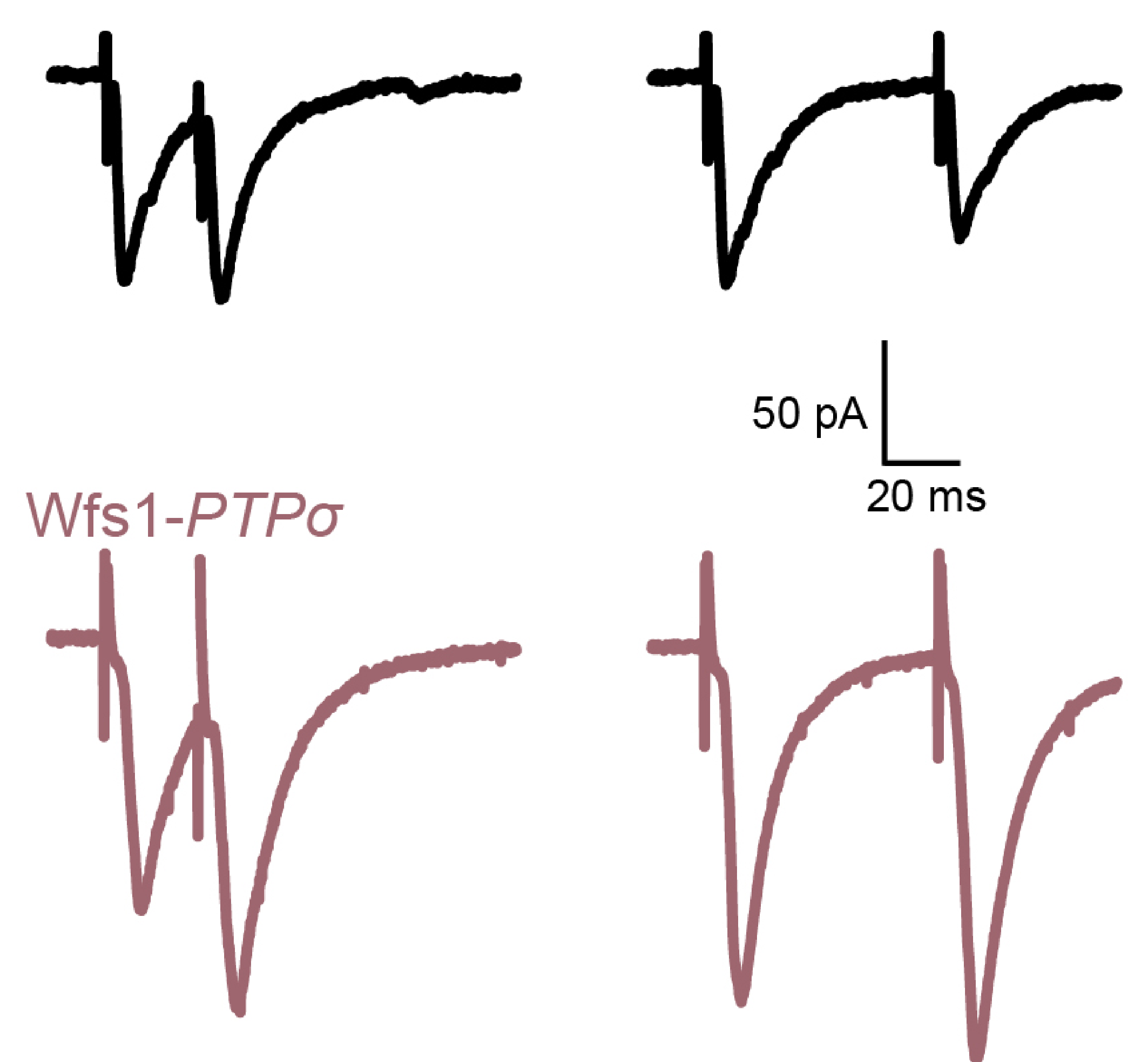

EPSC-PPR (mPFC layer II to V)

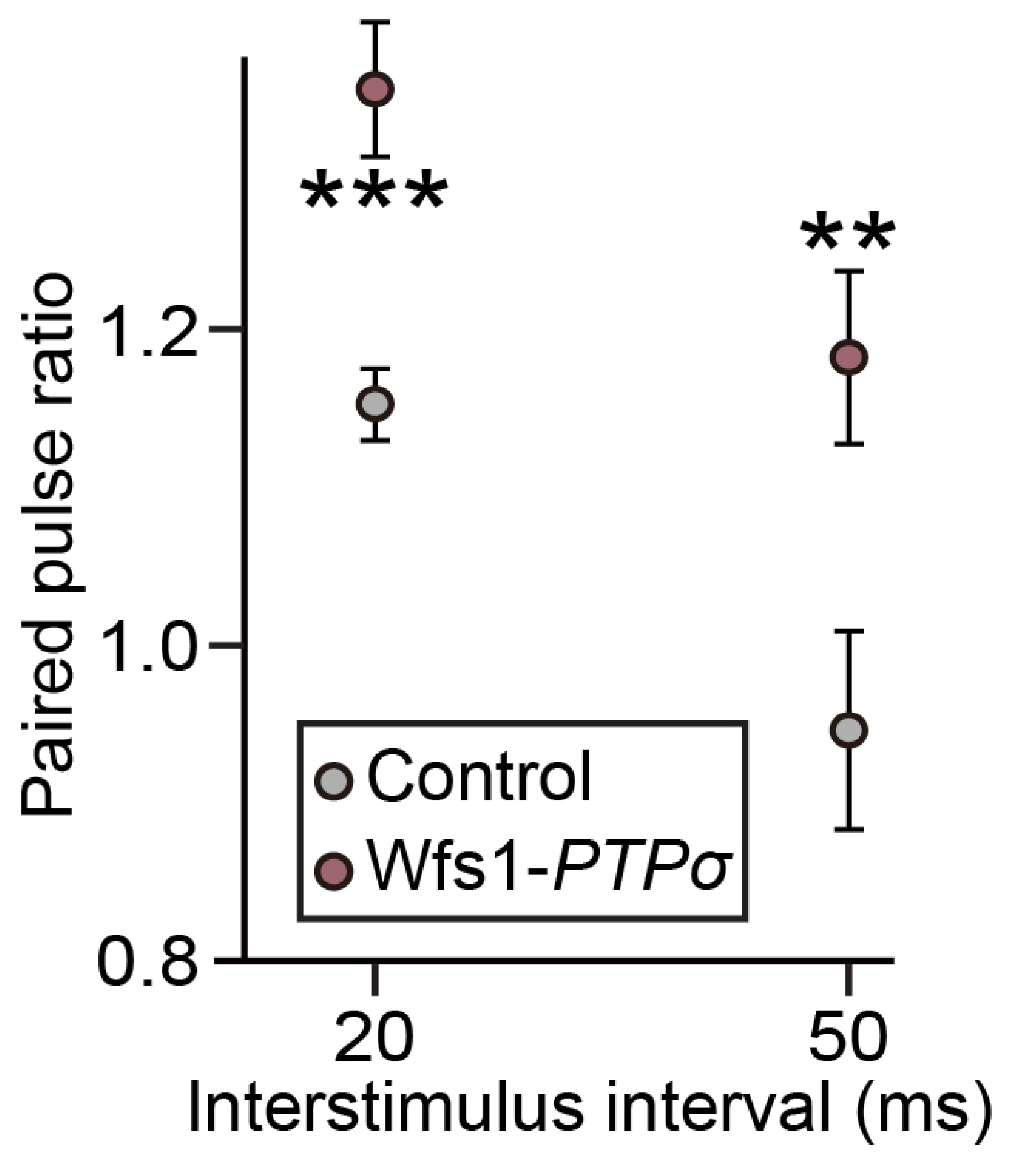

D IPSC-PPR (mPFC layer II to V) Control
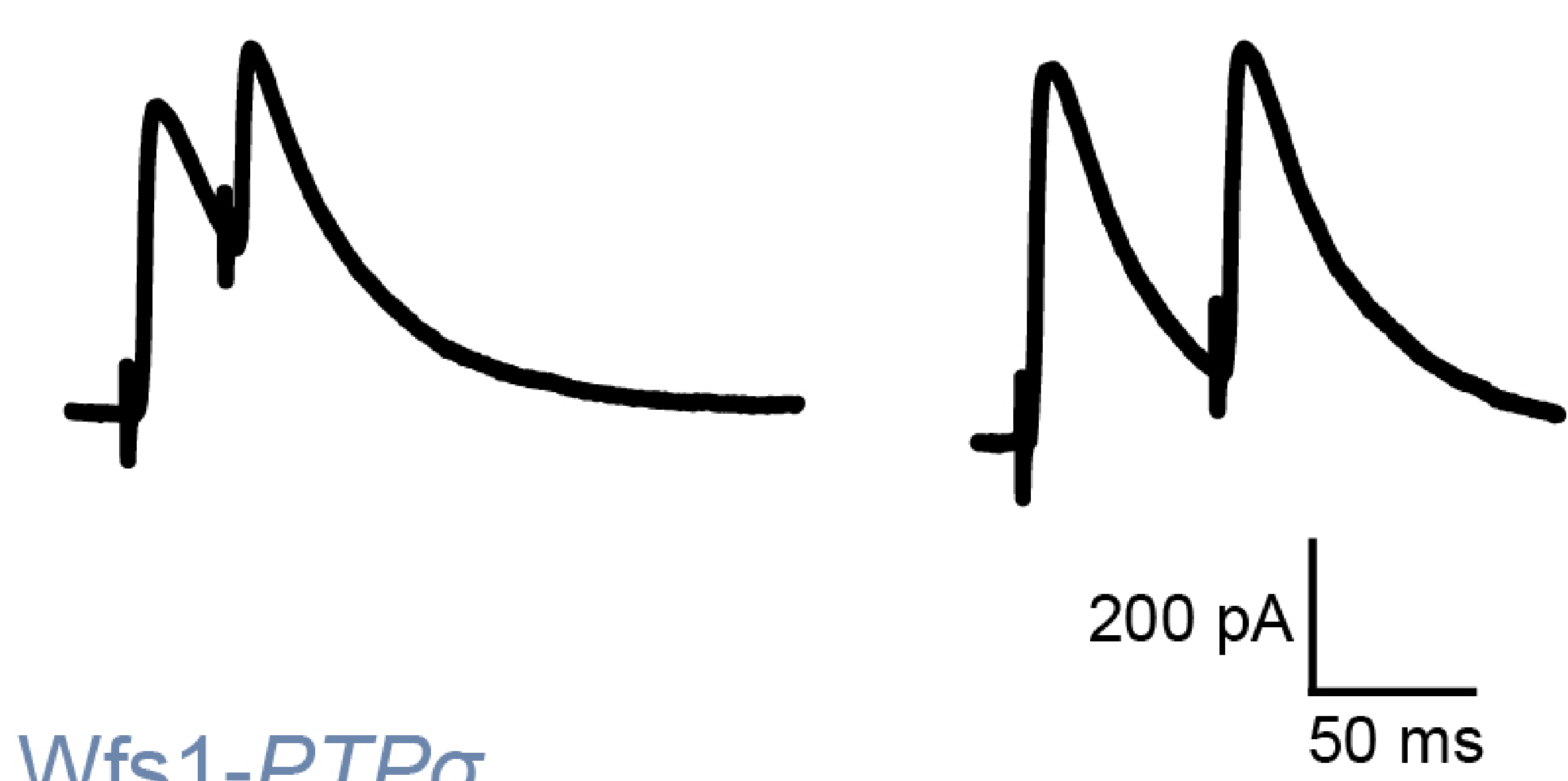

Wfs $1-P T P \sigma$
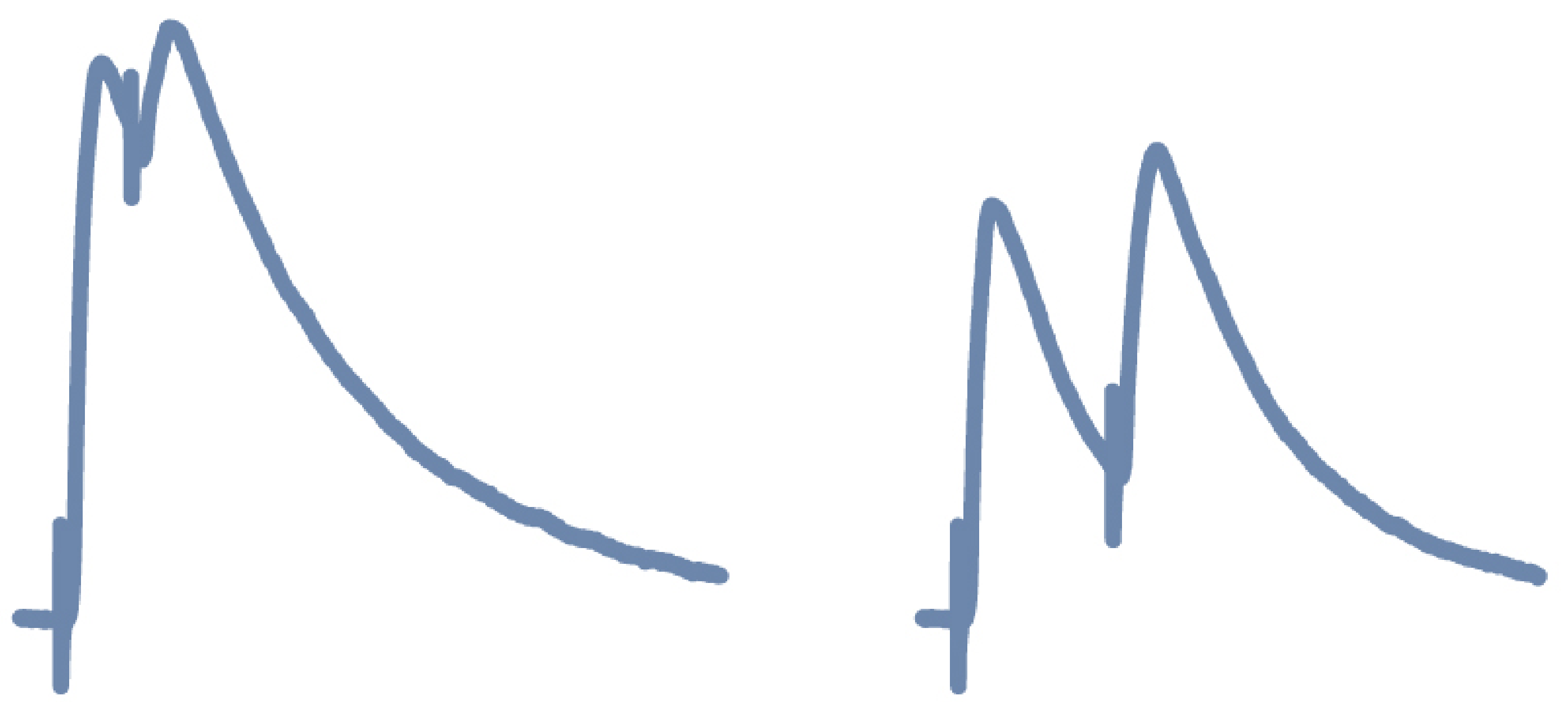

E IPSC-PPR (mPFC layer II to V)

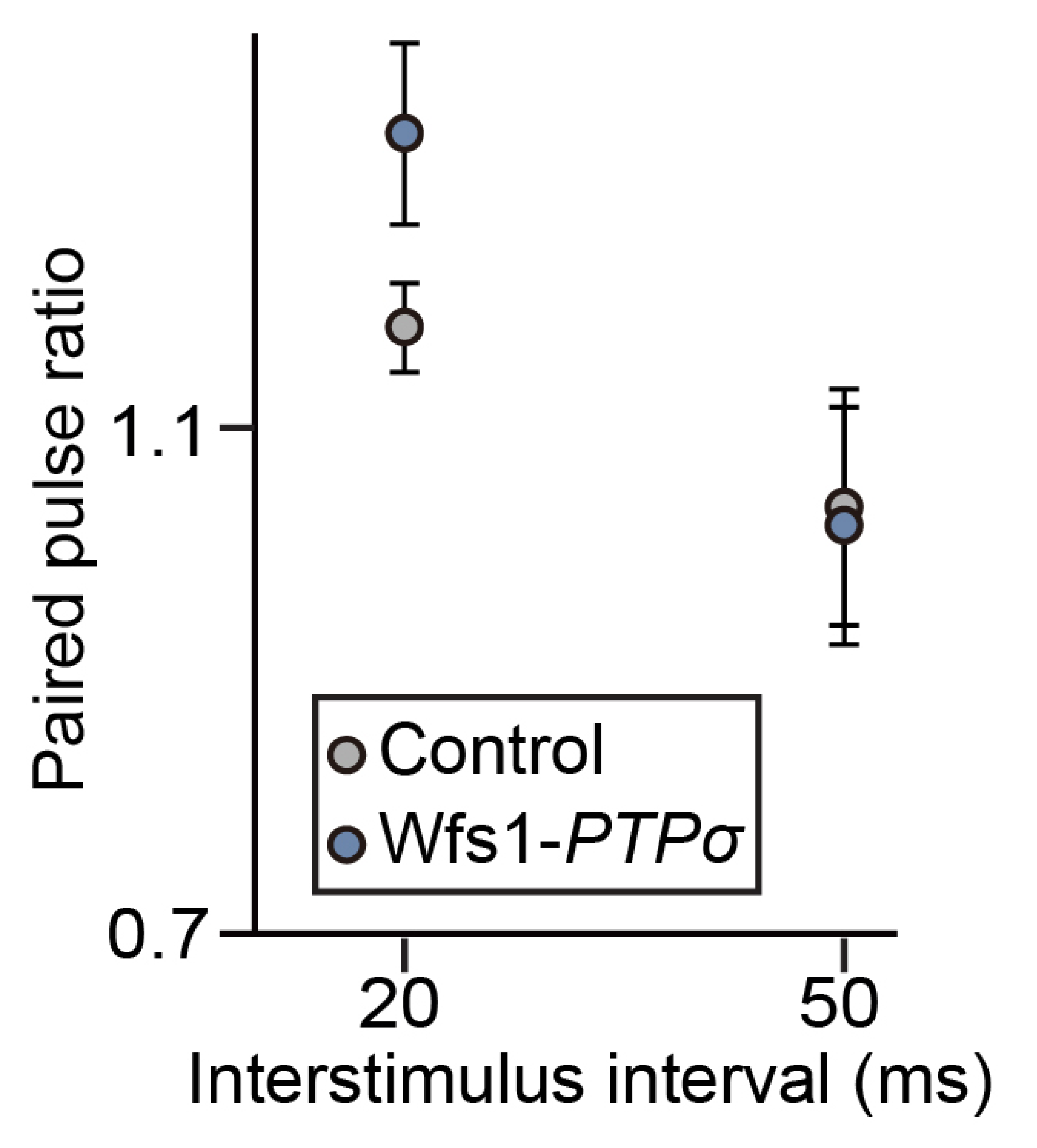

F EPSC-PPR (CA1 to SUB) Control

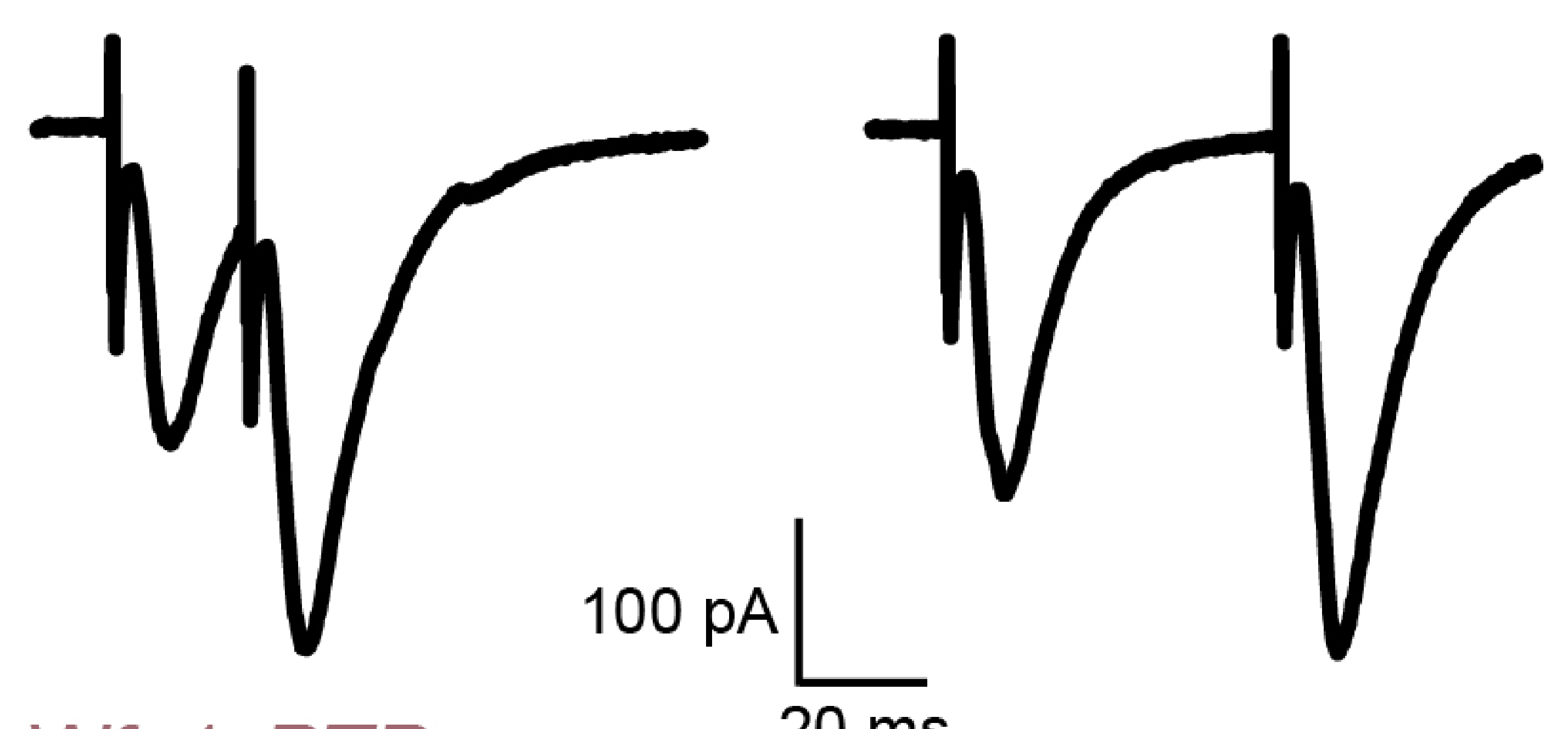

Wfs1-PTPo $20 \mathrm{~ms}$
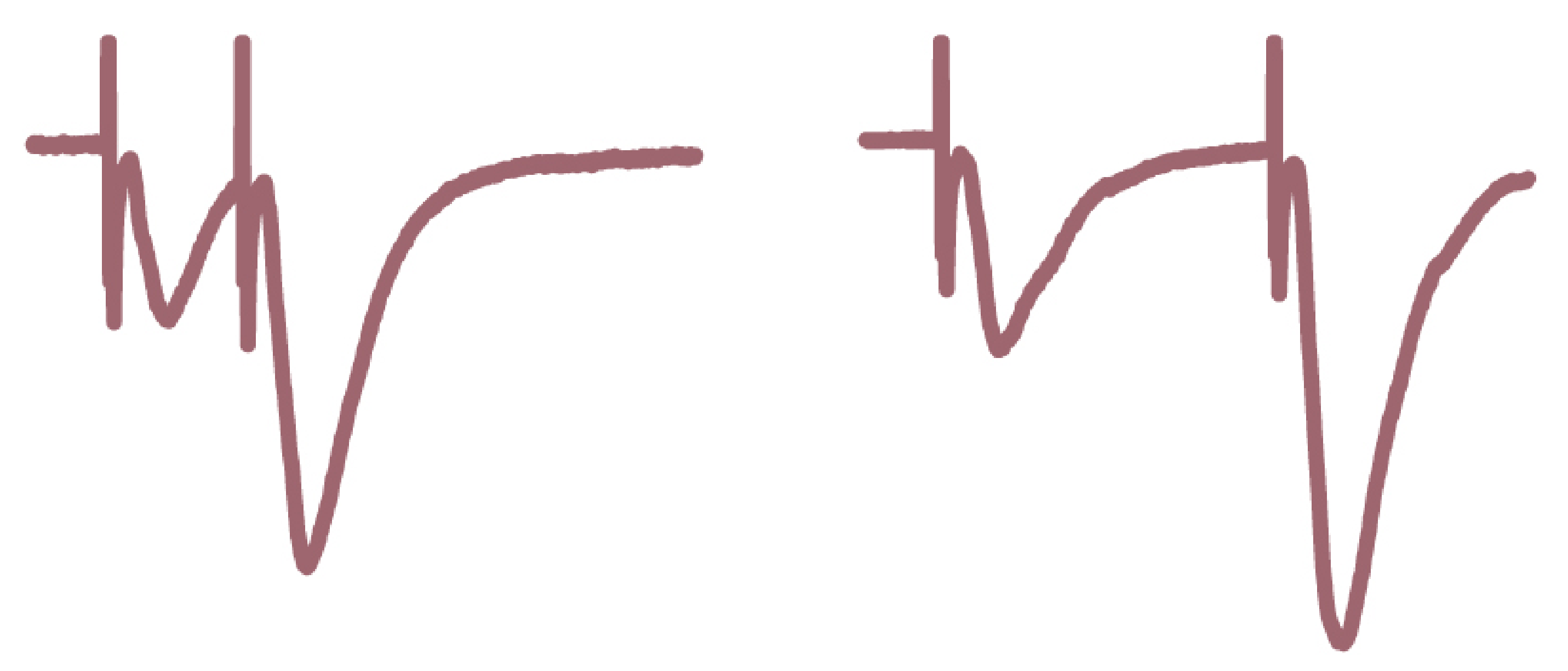

G EPSC-PPR (CA1 to SuB)

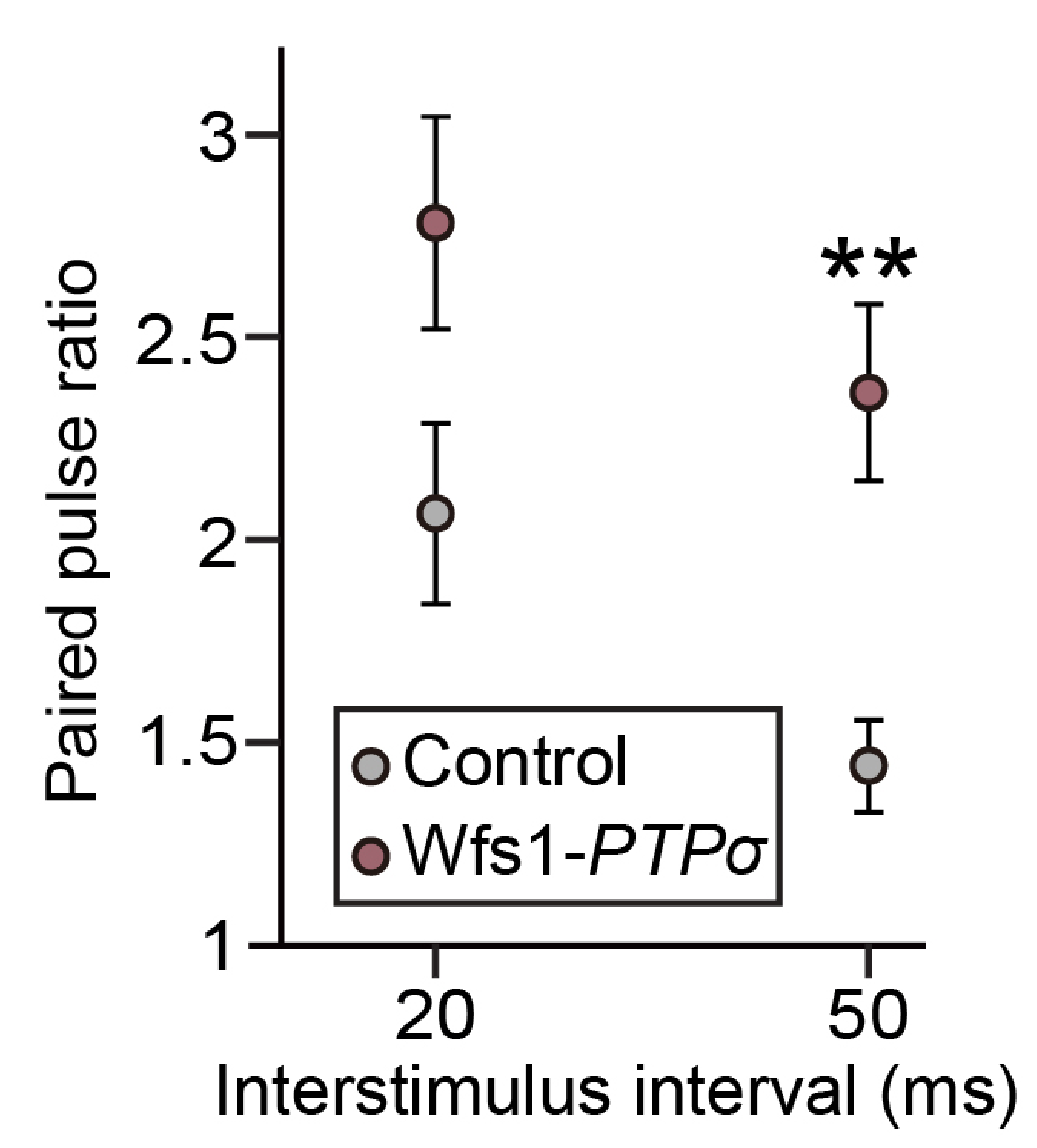


Quantification of synaptic puncta in hippocampal CA1 by postsynaptic PTPo deletion

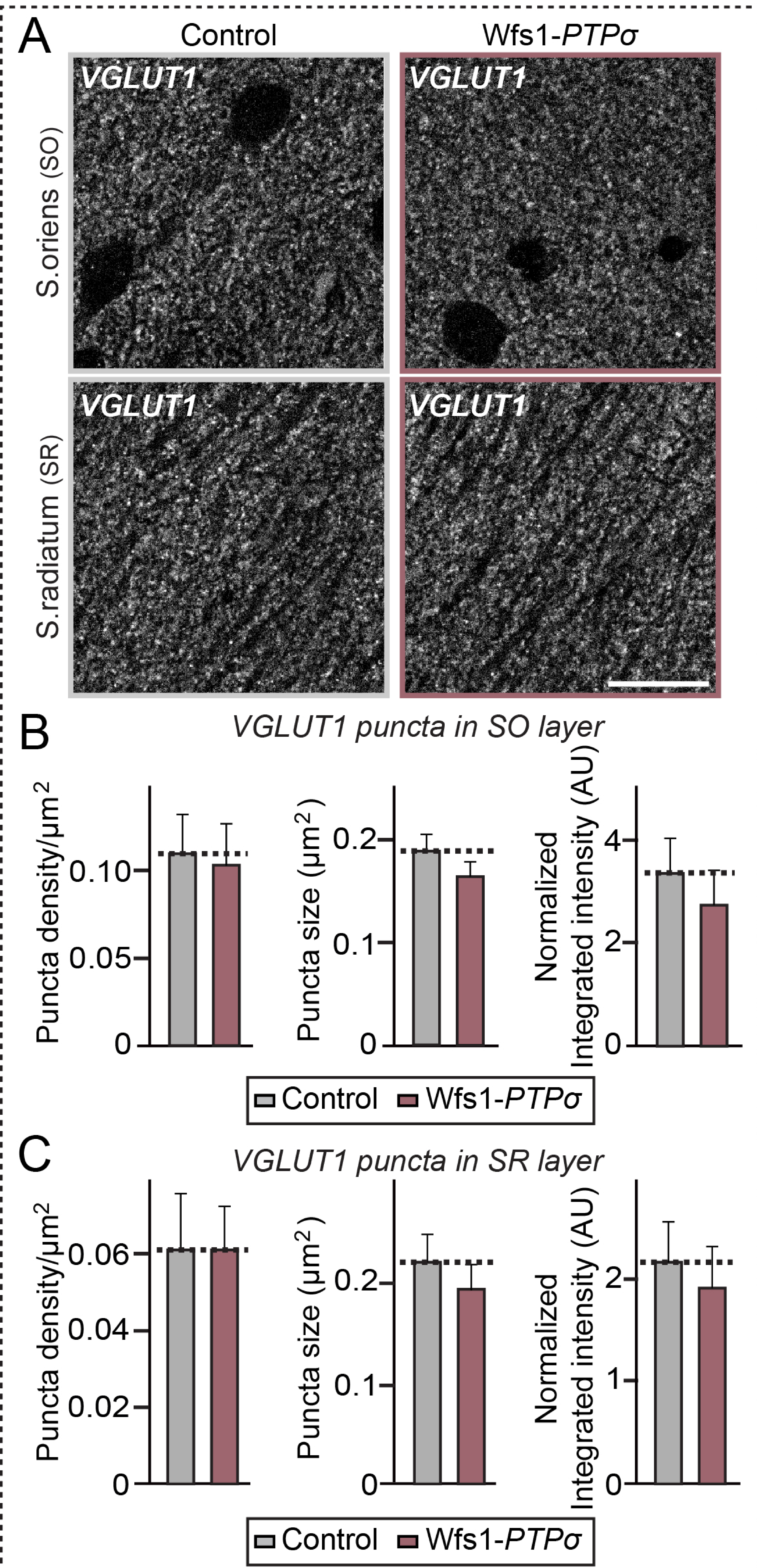

$B$



$\square$ Control $\square$ Wfs1-PTPo

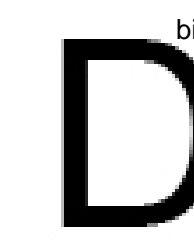

VGLUT1 puncta in SO layer

$\square$ Control $\square$ Wfs1-PTPo

VGLUT1 puncta in SR layer

:<smiles>C1#CCCCCCC#C1</smiles>

a

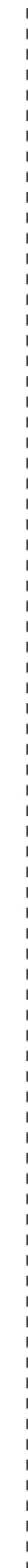

$\square$ Control $\square$ Wfs1-PTPo

$\mathrm{H}$

(5)
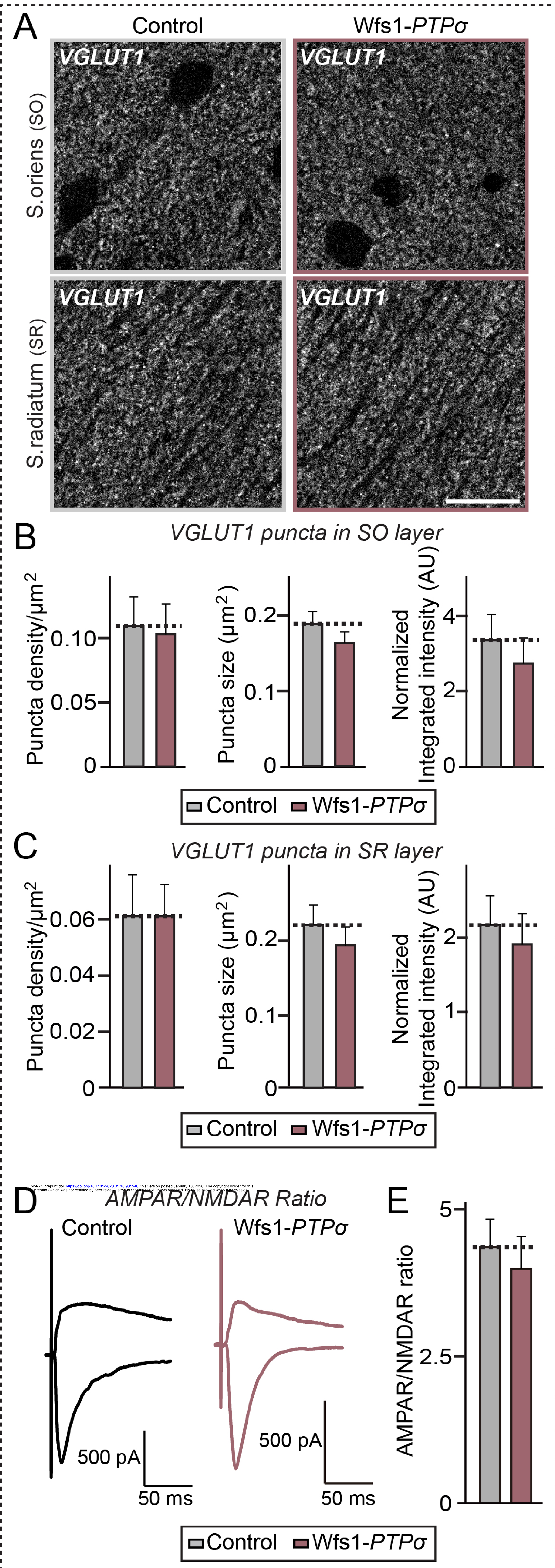

G
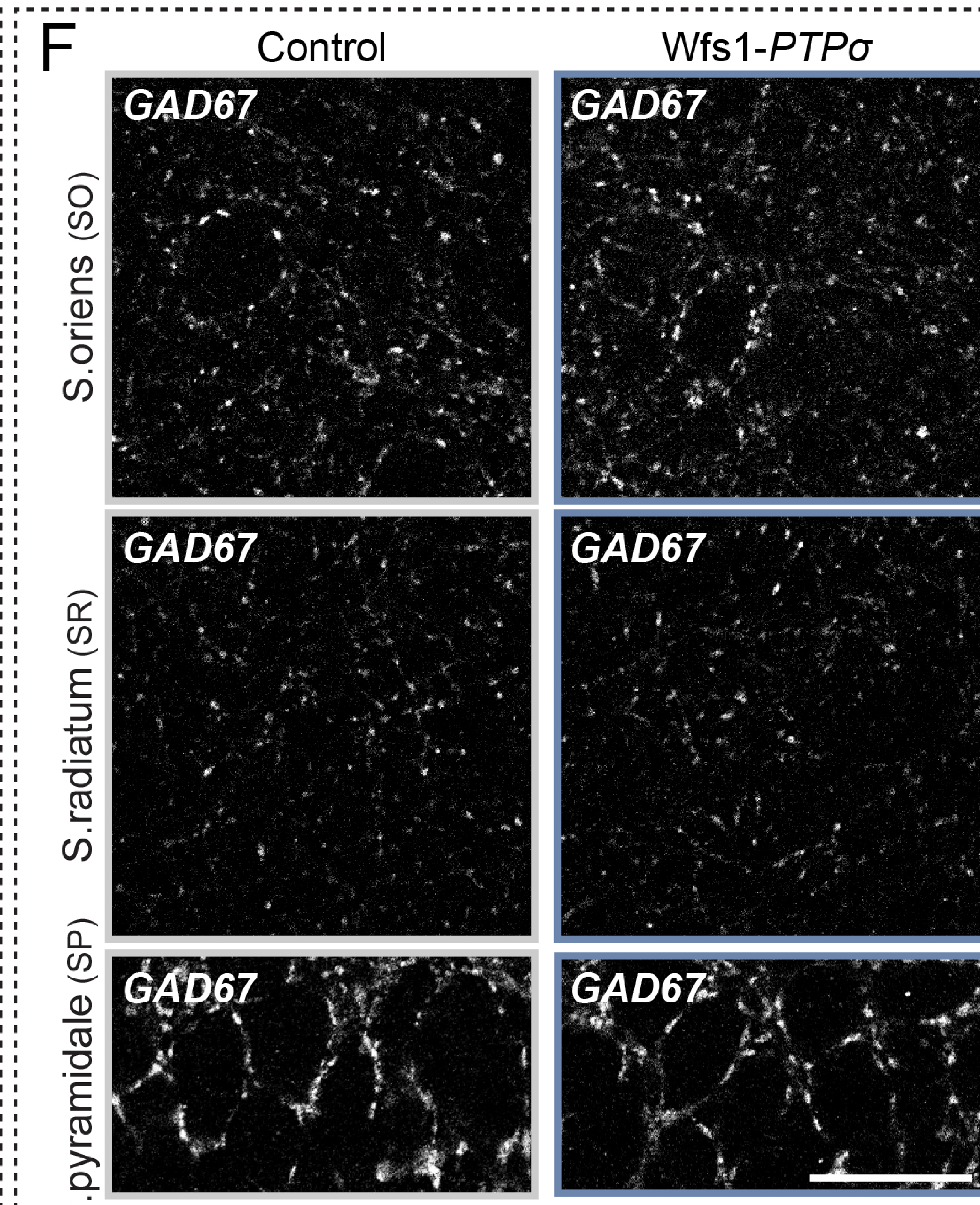

GAD67 puncta in SO layer
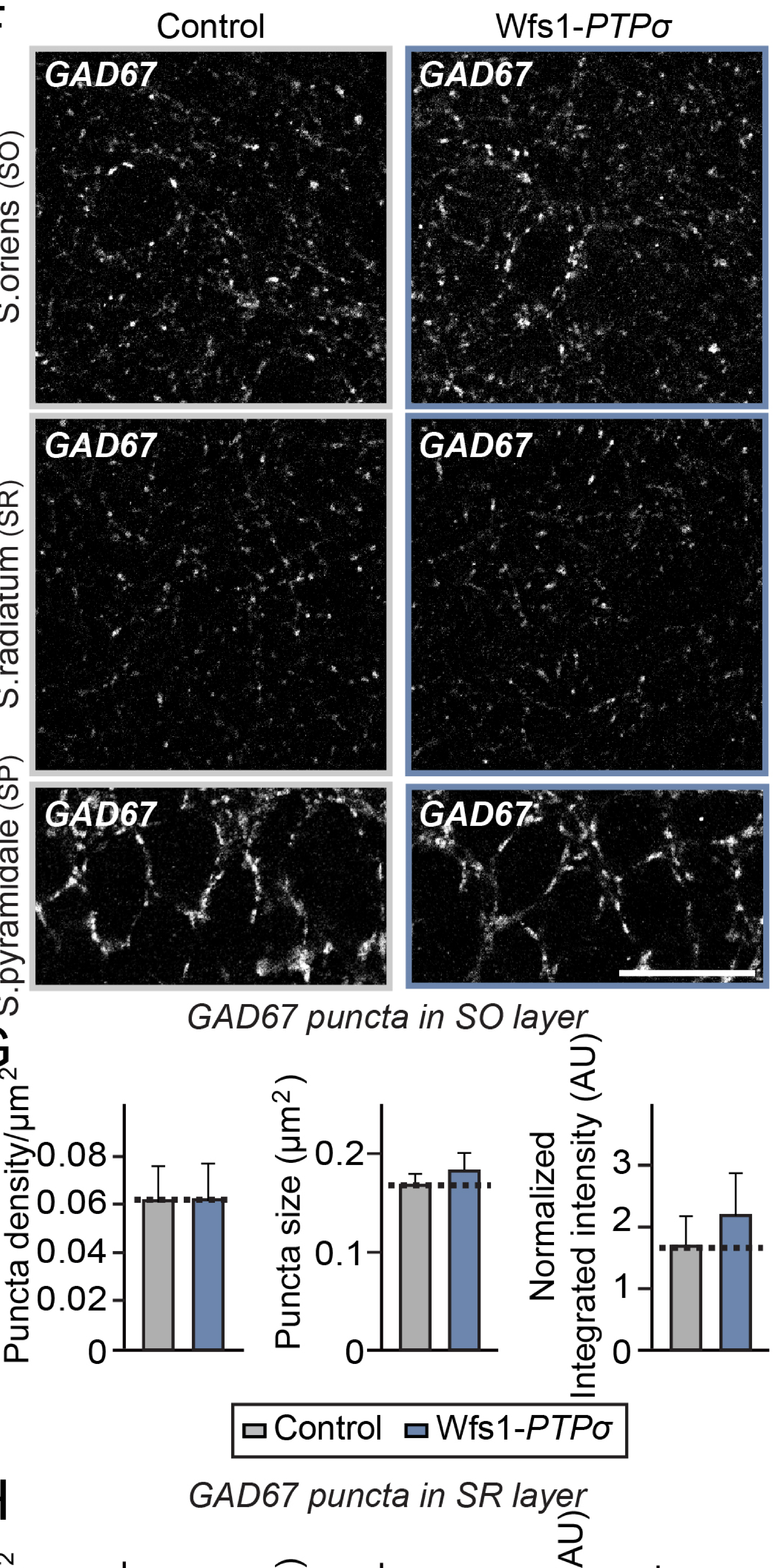

$\square$ Control $\square$ Wfs1-PTPo

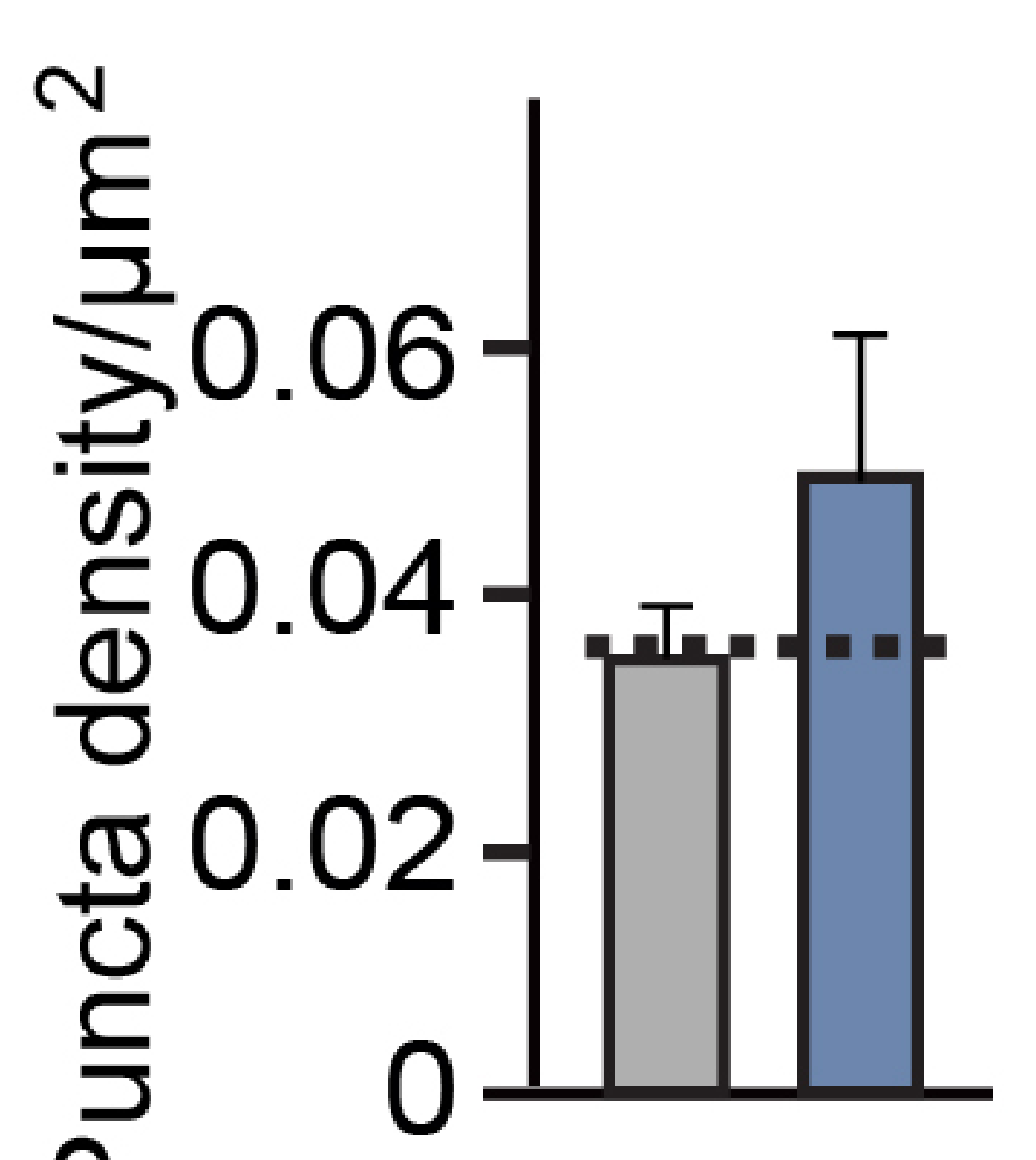

GAD67 puncta in SR layer
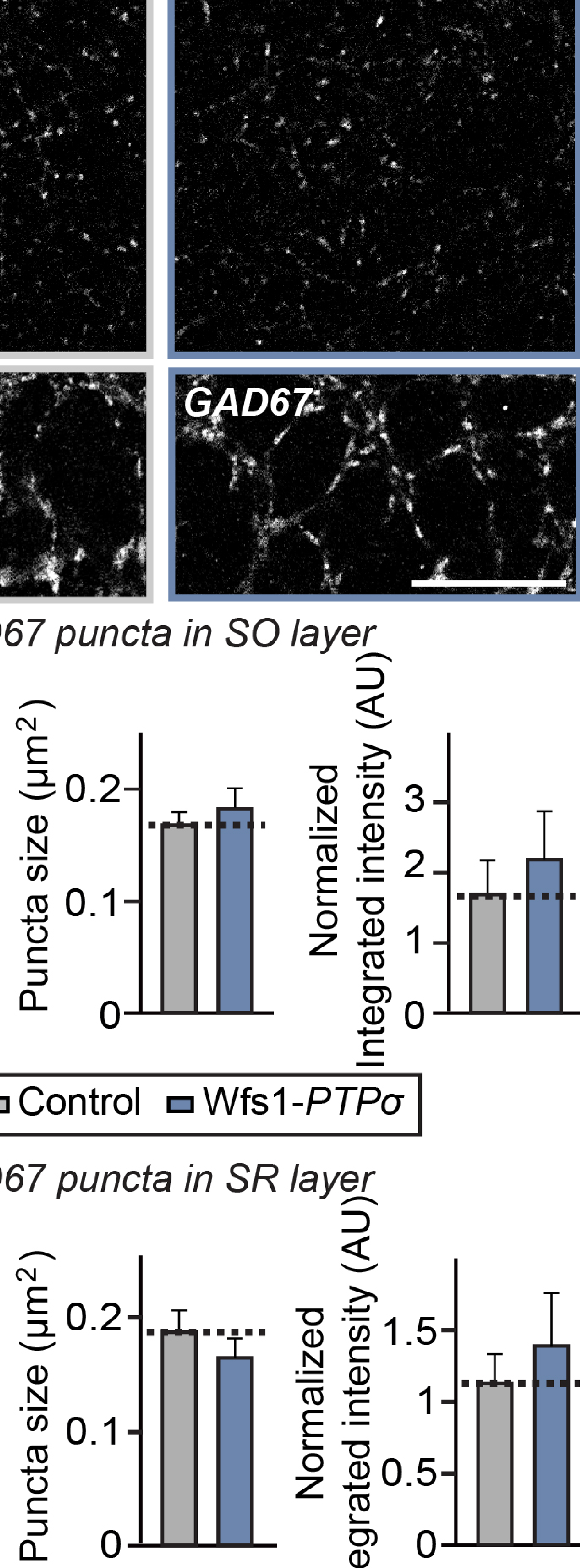
